\title{
UCRL-50962 \\ AN AC TEMPERATURE TECHNIQUE FOR MEASURING THE HIGH TEMPERATURE SPECIFIC HEAT OF METALS
}

Ronald Matti Finnila

This report was prepared as an sesotht of wotk sponsored by the United States Government. Neither the United States not the United States Alomic Energy
Commission, nor any of their employes, nor any of thei contractors, subcontracters, or their employes, omikes any warraty, expres or implied, or nuremes any lesal liability of responsibitity for the sccuracy, com. pieteness or userilnets of any information, opparatus, pieteness or userilness of any information, opparatus, would got infringe printely owned rights. 


\section{Contents}

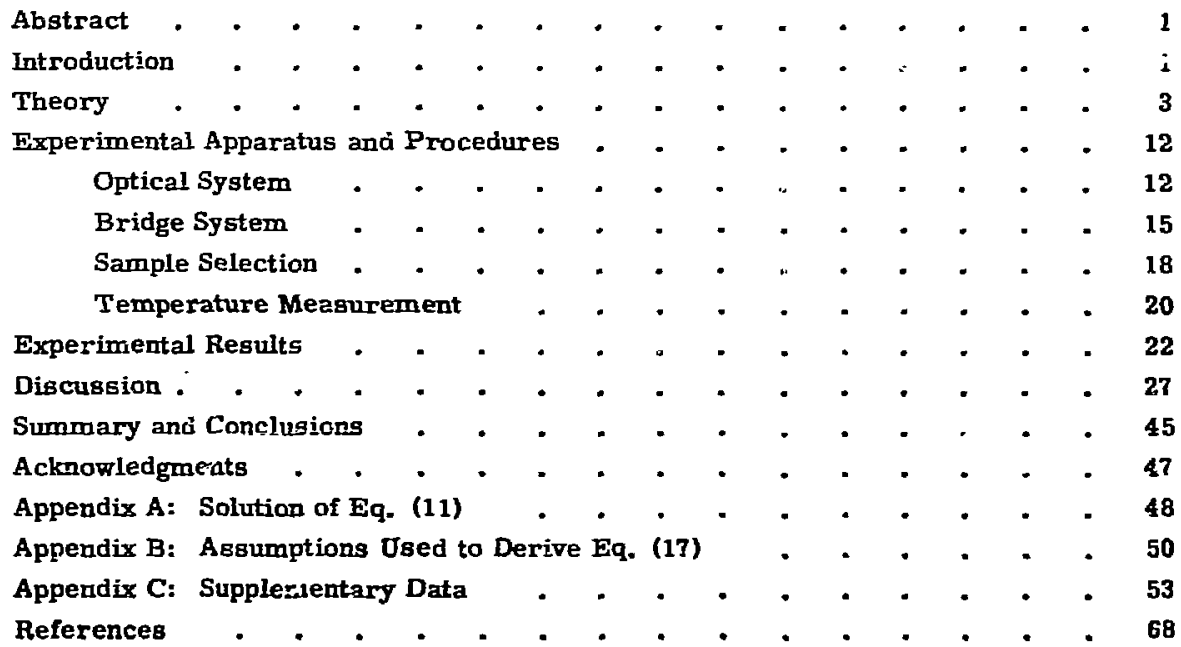




\section{AN AC TEMPERATURE TECHNIQUE FOR MEASURING THE HIGH TEMPERATURE SPECIFIC HEAT OF METALS}

Abstract

An ac temperature technique for measuring the specific heat of electrical conductors has been developed. This technique can be used to measure the specific heat of small wire or foil samples in the temperature range of a few mudred degrees Kelvin to temperatures near tine melting point of the sample. The accuracy of the specific heat data obtained using this technique is limited soleiy by the accuracy of the measurement of the sample's temperature coefficient of registance.

This ac temperature technique has been used to measure the specific heat of turggten in the temperature range $800 \mathrm{~K}^{\circ}$ to $3400^{\circ} \mathrm{K}$. In this range the following equation was found to represent the specific heat with an estimated accuracy of $\pm 1 \%$ at low temperatures to $\pm 3 \%$ at high termpe-atures:

$$
\begin{aligned}
\varepsilon_{p}(T) & =(5.43) \div\left(9.50 \times 10^{-4}\right) \mathrm{T}+\left(1.05 \times 10^{-7}\right) \mathrm{T}^{2} \\
& +\left(2.92 \times 10^{13} / \mathrm{T}^{2}\right) \exp \left(-4.63 \times 10^{4} / \mathrm{T}\right) \mathrm{cal} / \mathrm{mole}-{ }^{-} \mathrm{K}
\end{aligned}
$$

A method of analyzing specific heat data to determine the contribution of lattice mono-vacancies has also been developed. This method has been used to determine the following data for tungsten:

1. The energy of formation of mono-vacancies, $\Delta E_{V}=3.90 \pm 0.30 \mathrm{eV}$.

2. The eutropy of formation of mono-vacancies, $\Delta S_{\mathrm{V}} / \mathrm{k}=8.4 \pm 1.3$.

3. The concentration of mono-vacancies at the melting point, $c_{m p}=2.1 \pm 0.7$ mole percent.

4. The migration erergy for mono-vacancies, $\mathrm{E}_{M}=2.74 \pm 0.56 \mathrm{eV}$.

5. The anharmonic-lattice specific heat $(800 \% \mathrm{~K}<\mathrm{T}<3400 \mathrm{~K})$, $c_{A}=-0.48+\left(0.57 \times 10^{-3}\right) \mathrm{T}+\left(0.015 \times 10^{-6}\right) \mathrm{T}^{2} \mathrm{cal} / \mathrm{mole}-\sigma_{\mathrm{K}}$

\section{Introduction}

The high-temperature heat capacity is a quantity which frequently is of acientific and engineering importance. Its value as a function of temperature yields useful information about the electronic and atomic structure of materials from the point of view of the scientist while at the same time constituting vital information for engineering in the high-temperature regime. Unfortimately, the specific heat of any substance is 


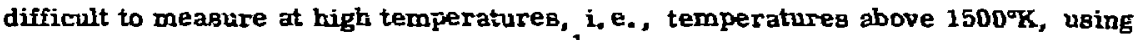
conventional drop calorimeter techniques. ${ }^{1}$ Although accurate data has been obtained in some cases (see particularly the work of V. A. Kirillin et al. ${ }^{2,3}$ ), much of the data obtained using these methods exhibits a significant lack of agreement among different experimenters. Some progress toward reliable data has been made with the development of the pulge-heating technique. ${ }^{4-9}$ However, this method suffers from the fact that accurate measurements of transient voltages and temperaturee are difficult.

Early in this century Corbino 10,11 devised a method for measuring hightemperature specific heats of metals which promised to avoiu most of the difficulties encountered with other techniquas. He noticed that when an electrical conductor is heated by an alternating current, the temperature of the conductor is generally a periodic function of time. That is, $T(t)=\bar{T}+\Delta T(t)$, where $T(t)$ is the temperature of the conductor, $\overline{\mathrm{T}}$ is the average temperature, and $\Delta \mathrm{T}$ is a periodic function of time which will heareforth be called the "ac temperature." In investigating 'che ac temperature, Corbino discovered that its amplitude conld be related to the heat capacity of the electrical conductor.

Shortly after Corbino's work, Worthing, ${ }^{4}$ Smith and Bigler, ${ }^{12}$ Bockstahler, $_{2}{ }^{13}$ and $Z$ wiker $^{14}$ all attempted to use his method to measure the specific heat of tungsten at high temperatures. With the metal in the form of a wire, they attempted to determine the amplitude of the ac temperature from the res"iting oscillations of the thermionic emission current. Their results showed considerable scatter, probably due to the fact that the thermionic emission current is very sensitive to the microscopic state of the metal gurface. ${ }^{15}$

Langmuir and Malter ${ }^{16}$ used Corbino's method to measure the specific heat of tantalum in 1939. They apparently measured botts the ac light output and the ac thermionic emission current. Howiver, they did not give details about their experimental technique.

More recently, Low enthal, ${ }^{17}$ Kraftmacher, ${ }^{18-23}$ and Holland ${ }^{24-26}$ have used Corbino's method combined with modern electronic techniques to measure the specific heats of several metals. Kraftmacine: and Holland, in particular, have developed the technique to a considerable level of sophistication. Filipov and Yurchak $^{27}$ have extended the technique to cover electron-beam heating of the sample.

The modern extensions of Corbinok method are similar to techniques for measuring the low temperature specific heats of metals developed by Sullivan and Seidel ${ }^{28,29}$ and Handler, Mapother, and Rayl. ${ }^{30}$ These experimenters have measured the change in the heat capacity of indium between the normal and superconducting states, the quantum oscillations in the heat capacity of beryllium due to the variation of the density of electronic states at the Fermi level produced by a magnetic field, and the heat capacity of nickel near its critical point.

The first objective of the present work is to investigate the theory and practice of Corbino's method for measuring the high temperature specific heats of metals. The 
first section of the text consists of a detailed discussion of the theory behind this method. The second seation describes an experimental apparatus capable of accurate meagurements of the epecific heats of metals from several hundred degrees Kelvin to the melting point of most metals. The third section contains the results of the measurement of the specific heat of tungsten made with this apparatus. These results illustrate the capabilities of the method and of the equipment.

Near the melting point, a sharp rise in the heat capacity at constant pressure has been observed in many metals (aluminun, ${ }^{3 i, 32}$ copper, ${ }^{33}$ gold, ${ }^{34}$ Iead, ${ }^{3 i}$ molybdenum, ${ }^{2,9,20}$ niobium, 21,35 platinum, ${ }^{23}$ potassium, ${ }^{36}$ rhenium, ${ }^{9}$ sodium, ${ }^{37}$ tantalum, 9,38 thorium, ${ }^{39}$ tungsten, ${ }^{19}$ and zirconimm ${ }^{22}$ ). This rise in heat capacity has been used by some authors (Kraftmacher and Strelkov, ${ }^{\leq 0}$ Wallace, ${ }^{39}$ Pochapsky, ${ }^{31}$ Carpenter, ${ }^{41}$ and Kirillin et ai. ${ }^{2}$ ) to calculate the energy of formation and concentration of vacancies. However, this approach has been criticized because of the calculational procedures used. Hence, the second objective of this work is to examine the possibility of developing an improved technique for obtaining the energy of formation and concentration of vacancies from high-temperature heat capacity data. The fourth section of the text presents severd calculational techiques which can be used to determine the energy of formation anil concentration of vacancies from specific heat data for some metals. Aluminum and copper data are used to illustrate the accuracy of these techniques, which are then applicd to the tungsten data contained in the third section of this work.

\section{Theory}

Given a thin metal wire (or foil) which is heated by an electric currert, the equation for the conservation of power (neglecting power loss through heat conduction out of the ends of the wire and the radiai temperature gradient) is

$$
1^{2} R=(d T / d t) C_{p}+L
$$

where

$t$ is the time (units: seconds),

$T=T(t)$ is the temperature (degrees Kelvin),

$I=I(t)$ is the electric current (amps),

$R=\mathbf{R}(T)$ is the resiatance (ohms?.

$C_{p}=C_{p}(T)$ is the heat capacity at constant pressure (joules per degree Kelvin), and

$L=L(T)$ is the rate of energy loss from the metal surface (watis). 
The electric current is composed of a direct current plus an alternating current of circular frequency $\omega$.

$$
I=i_{0}+i(\sin t)
$$

where $i_{0}$ is the direct current $s_{3}$ and $(\sqrt{2} / 2) i=i_{\text {ress }}$ is the root-mean-square value of the alternating current.

Now asoume the following:

and

$$
\begin{aligned}
& \mathrm{T}=\overline{\mathrm{T}}+\Delta \mathrm{T} \text { with } \Delta \mathrm{T}<\overline{\mathrm{T}}, \\
& \mathrm{L}=\overline{\mathrm{L}}+(\mathrm{dL} / \mathrm{dT})_{\overline{\mathrm{T}}} \Delta \mathrm{T}, \\
& \mathrm{R}=\overline{\mathrm{R}}+(\mathrm{dR} / \mathrm{dT})_{\overline{\mathrm{T}}} \Delta \mathrm{T},
\end{aligned}
$$

$$
\mathrm{C}_{\mathrm{p}} \approx \overline{\mathrm{C}}_{\mathrm{p}}
$$

where a bar over a quantity indicates the time average of the quantity. $\Delta T$ is a small alternating component of the temperature which is produced by the alternating electric current. The derivativer in sqs. (4) and (5) are 3 valuated at the average temperature, $\vec{T}$. The variation of $C_{p}$ with $T$ is neglected in Eq. (6). This resitis in the loss of a term proportional to the amplitude of $\Delta \mathrm{T}$ sepuared from $E q$. (1). If we use these assumptions, Eq. (1) becomes

$\left[i_{0}+i(s i \pi w t)\right]^{2} \cdot\left[\bar{R}+\langle d R / d T\rangle_{-} \Delta T\right]=(d \Delta T / d t) \bar{C}_{p}+\bar{T}+(d L / d T\rangle_{\bar{T}} \Delta T$.

Now the average power must be conserved, therefore

$$
\widetilde{\mathbf{R}}\left(i_{0}^{2}+i^{2} / 2\right)=\bar{L}
$$

where a term proportional to the amplitude of the ac temperature timen $(\mathrm{dR} / \mathrm{dT})_{\mathrm{T}}$ has been neglected. With this approximation Eq. (7) reduces to

$$
\begin{aligned}
2 i_{0} i \bar{R}(\text { oiswt }) & +\left(i_{0}^{2}+i^{2} / 2\right)(d R / d T)_{T} \Delta T-\vec{R}\left(i^{2} / 2\right)(\cos 2 \omega t) \\
& +2 i_{0} i(d R / d T)_{\bar{T}} \Delta T(\sin \omega t)-(d R / d T)_{\bar{T}}\left(i^{2} / 2\right) \Delta T(\cos 2 \omega t) \\
& =(d \Delta T / d t) \bar{C}_{p}+(d L / d T)_{T} \Delta T
\end{aligned}
$$

The terms proportional to (dR/dT) $)_{T} \Delta T$ are small compared to the terms proportional to $\overline{\mathbf{R}}$. Therefore, in order to simplify the solution of Eq. (9), the last two terms on the left-hand side of Eq. (9) will be neglected. That is, 


$$
\frac{d \Delta T}{d t}+\left(\frac{M}{\bar{C}_{f}}\right) \Delta T=\left(\frac{2 i_{0} i \bar{R}}{\bar{C}_{p}}\right)(s i n t)-\left(\frac{\overline{R i}^{2}}{2 \bar{C}_{p}}\right)(\cos 2 \omega t)
$$

where

$$
M \equiv(\mathrm{dL} / \mathrm{dT})_{\bar{T}}-\left(i_{0}^{2}+i^{2} / 2\right)(\mathrm{dR} / \mathrm{dT})_{\bar{T}} .
$$

The solution of this equation is shown in Appendix $A$ to be given by

$$
\Delta T=\Delta T_{1} \sin (\omega t-\phi)-\Delta T_{2} \sin (2 \omega t+\theta)
$$

where

and

$$
\begin{aligned}
& \Delta T_{1}=\left[\left(2 i_{p} i \bar{R}\right) /\left(\omega \bar{C}_{p}\right)\right] \sin \phi, \\
& \tan \phi=\left(\omega \bar{C}_{p}\right) / M \\
& \Delta T_{2}=\left[\left(i^{2} \bar{R}\right) /\left(4 \omega \bar{C}_{p}\right)\right] \cos \theta,
\end{aligned}
$$

Therefore, the heat capacity of the specimen is given by

$$
\bar{C}_{p}=\left(2 i_{0} i \bar{R}\right) /\left(\Delta T_{1} \omega\right)_{\sin \phi \sigma r} \bar{C}_{p}=\left(i^{2} \bar{R}\right) /\left(\Delta T_{2} 4 \omega\right) \cos \theta .
$$

If $\Delta T_{1}$ or $\Delta T_{2}$ can be measured experimentally with $w$ sufficiently large so that $\phi=90^{\circ}$ or $\theta=0^{\circ}$, then idq. (17) can be used to calculate the heat capacity of the metal wire (or foil) specimen. Alternately, if $\Delta T_{1}$ or $\Delta T_{2}$ can be measured at two or more frequencies, Eq. (17) is replaced by a system of equations which can be solved to give the heat capacity of the specimen without a priori knowledge of $\phi$ or $\theta$.

In Appendix $B$ the assumptions used in the derivation of Eq. (17) are examined. It is shown that these assumptions do not place any serious restrictions upon the use of this equation for the design and analysis of practical experiments.

An idea of the size of the ac temperature can be obtained from Figs. 1, 2 and 3 where $\Delta T_{1}$ is plotted as a fumction of the frequency (these plots and the ones which follow are based on ones drawn by a Calcomp plotter using a program developed by J. R. Terrall ${ }^{42}$ ). In the figures $P 1=2 i_{0} i \bar{R}, P 2=\bar{C}_{P^{\prime}}$ and $P 3=M, 80$ that

$$
\Delta T_{1}=\frac{P 1}{P 2}-\frac{1}{\omega} \sin \phi \text { with } \tan \phi=\frac{P 2}{P 3} \cdot \omega .
$$




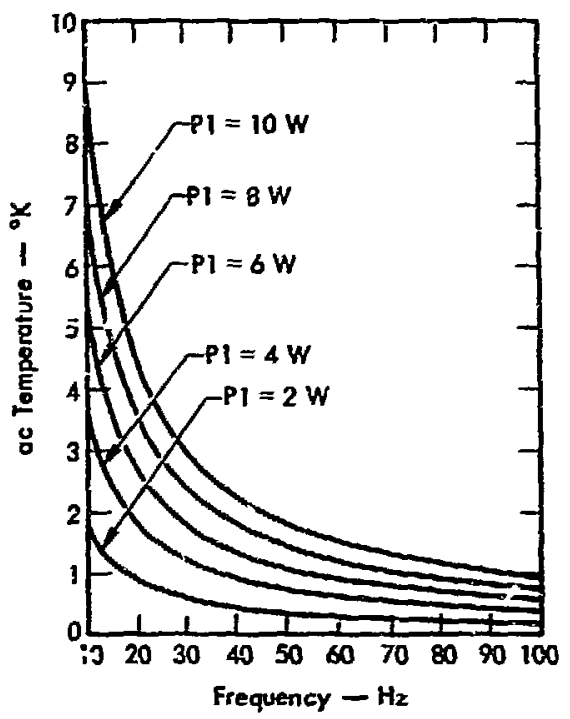

Fig. 1. Plot of Eq. 18. $P 2=0.05 \mathrm{~J} /{ }^{\circ}$, $\mathbf{P 3}=0.5 \mathrm{~W} / \mathrm{mK}$.

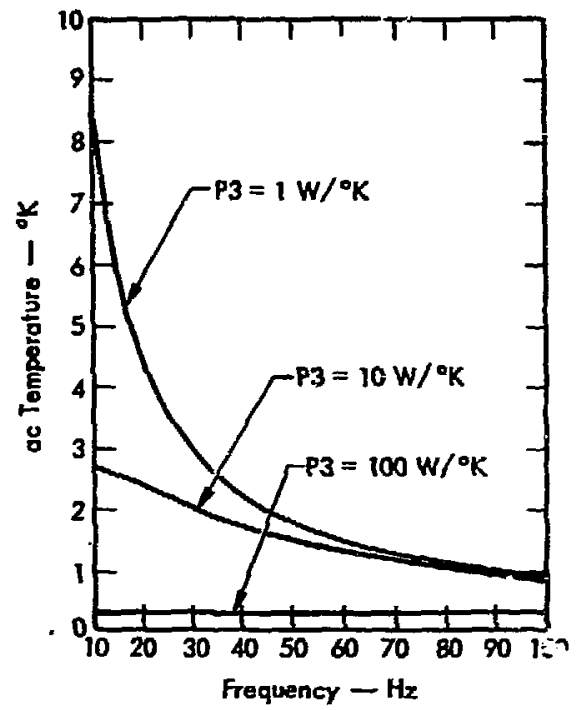

Fig. 3. Plot of Eq. 18. $P 1=10 \mathrm{w}$, $P 2=0.05 \mathrm{~J} / \mathrm{K}$.

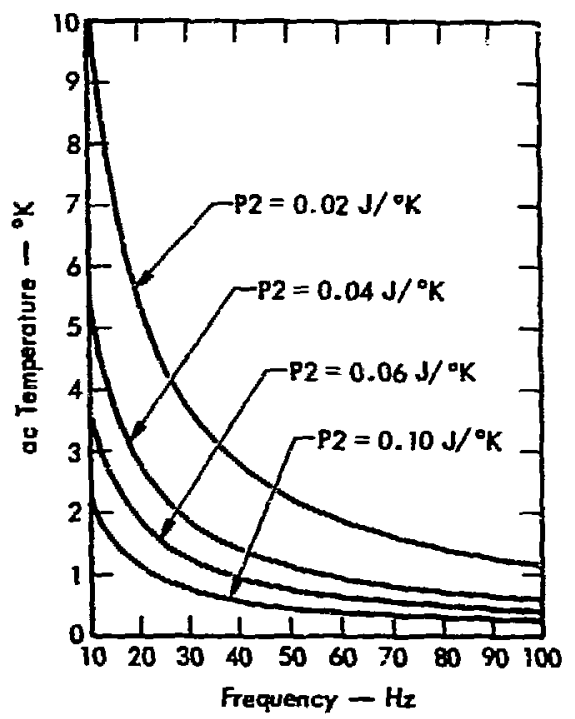

Fig. 2. Plot of Eq. 18. $P 1=5 W$, $\mathrm{P3}=0.5 \mathrm{~W} /{ }^{\circ} \mathrm{K}$.

It is possible to measure $\Delta T_{1}$ and $\Delta T_{2}$ by pureig electrical means. Toward this end, consider the potential drop. $V$, in the specimen corresposding to a current, I. The impedance of the specimen is equal to its resistance gince the parallel capacitance anc. peries intuctance of the wire are assumed to be negligible. Therefore,

$$
\mathbf{Z}=\mathbf{R}=\overline{\mathbf{R}}+\Delta \mathrm{T}(\mathrm{dR} / \mathrm{dT})_{\mathbf{T}^{\prime}}
$$

and the potential drop is given by

$\mathbf{v}=\mathbf{I Z}=\left[\mathbf{i}_{0}+\mathbf{i}_{1}(\mathbf{w} \boldsymbol{w} \mathrm{t} t)\right]$

$\left[\overline{\mathbf{R}}+\Delta \mathbf{T}\left(\mathrm{dR} / \mathrm{dT} \mathbf{r}_{\overline{\mathbf{T}}}\right]\right.$ 
The fnllowing identities are needed:

$$
\begin{aligned}
& \sin (\omega t-\phi)=(\sin \omega t)(\cos \phi)-(\cos \omega t)(\sin \phi), \\
& \sin (2 \omega t+\theta)=(\sin 2 \omega t)(\cos \theta)+(\cos 2 \omega t)(\sin \theta), \\
& (\sin \omega t)(\sin 2 \omega t)=1 / 2(\cos \omega t)-\cos 3 \omega t),
\end{aligned}
$$

and

$$
(\sin \omega t)(\cos 2 \omega t)=1 / 2(\sin \omega t-\sin \omega t) .
$$

Now using Eq. (i2) and the above identities in Eq. (20), we can write

$$
v=v_{0}+v(w)+v(2 w)+v(3 w)
$$

with

$$
\begin{aligned}
V_{0}= & i_{0} \bar{R}+(i / 2)\left(\Delta T_{1}\right)(d R / d T)_{T}(\cos \phi), \\
V(\omega)= & {\left[\left(i_{0} \Delta T_{1}\right)(d R / d T)_{T}(\cos \phi)\right](\sin \omega t)+(i \bar{R})(\sin \omega t) } \\
& -\left[(i / 2)\left(\Delta T_{2}\right)(d R / d T)_{T}(\cos \theta)\right](\cos \omega t) \\
& -\left[\left(i_{0} \Delta T_{1}\right)(d R / d T)_{T}(\sin \phi)\right](\cos \omega t) \\
+ & {\left[(i / 2)\left(\Delta T_{2}\right)(d R / d T)_{T}(\sin \theta)\right](\sin \omega t), } \\
V(2 \omega)= & -\left[\left(i_{0} \Delta T_{2}\right)(d R / d T)_{\bar{T}}\right][(\cos \theta)(\sin 2 \omega t) \\
& +(\sin \theta)(\cos 2 \omega t)], \\
V(\widehat{3} \omega)= & +\left[(i / 2)\left(\Delta T_{2}\right)\left(d R / d T^{\prime}\right)-\bar{T}\right][(\cos \theta)(\cos 3 t) \\
& -(\sin \theta)(\sin 3 \omega t)] .
\end{aligned}
$$

It is convenient to rewrite $\mathrm{V}(\omega)$ in complex form (a bar under a symbol will be used to indicate a complex number:,

$$
\underline{\underline{Y}}(\omega)=v_{1}(\omega)+j \nabla_{2}(\omega)
$$

where

$$
\begin{aligned}
j^{2} & =-1, \\
v_{1}(\omega) & \left.=i \bar{R}+\left[(d R / d T)_{T}\right]\left[i_{0} \Delta T_{1}\right) \cos \phi+(i / 2)\left(\Delta T_{2}\right] \sin \theta\right]
\end{aligned}
$$


and

$$
v_{2}(\omega)=-\left[(d R / d T)_{\bar{T}}\right]\left[\left(i_{0} \Delta T_{1}\right) \sin \phi+(i / 2)\left(\Delta T_{2}\right) \cos \theta\right]
$$

The alternating component of the current in complex form is

$$
\underline{I}_{\mathrm{ac}}=\mathrm{i}+\mathrm{j0}=\mathrm{i} \text {. }
$$

Now the equivalent impedance of tize specimen at frequency $\omega$ for the alternating component of the current in complex form is

$$
\underline{z}=\left[\underline{V}(\omega) / \underline{I}_{a c}\right]=v_{1}(\omega) / i+j\left[v_{2}(\omega) / i\right]
$$

Therefore,

$$
\operatorname{Re}(\underline{Z})=\overline{\mathrm{R}}+\left[(\mathrm{dR} / \mathrm{dT})_{\bar{T}}\right]\left[\left(\mathrm{i}_{0} / \mathrm{i}\right)\left(\Delta \mathrm{T}_{1}\right) \cos \phi+(\mathrm{i} / 2)\left(\Delta \mathrm{T}_{2}\right) \sin \theta\right]
$$

and

$$
\left.\operatorname{lm}(\underline{Z})=-\left[(\mathrm{dR} / \mathrm{dT})_{\bar{T}}\right]\left[\dot{i}_{0} / \mathrm{i}\right)\left(\Delta \mathrm{T}_{1}\right) \sin \phi+(1 / \bar{z})\left(\Delta \mathrm{T}_{2}\right) \cos \theta\right]
$$

The impedance, $\underline{Z}_{A}$, of a resistance, $R_{A}$ shunter by a small capacitance, $C_{A^{*}}$. has a form which is similar to Eq. (25), that is

$$
\underline{z}_{A}=\left[1 /\left(1+\omega^{2} C_{A}^{2} R_{A}^{2}\right)\right]\left[R_{A}-j\left(\omega C_{A} R_{A}^{2}\right)\right]
$$

or

$$
\underline{Z}_{A}=R_{A}-j\left(\omega C_{A} R_{A}^{2}\right) \text { when }\left(\omega C_{A} R_{A}\right)^{2} \ll 1
$$

This suggests that $\underline{Z}$ might be measured with an impedance bridge of the type shown in Fig. 4. When this bridge is balanced,

$$
\underline{Z}=\left(\underline{z}_{A} / \underline{z}_{B}\right) \underline{Z}_{C}
$$

now let

$$
\underline{z}_{I}=R_{I}+j X_{I}(I=A, B, C)
$$

so that using Eq. (30), the balance condition, we have 


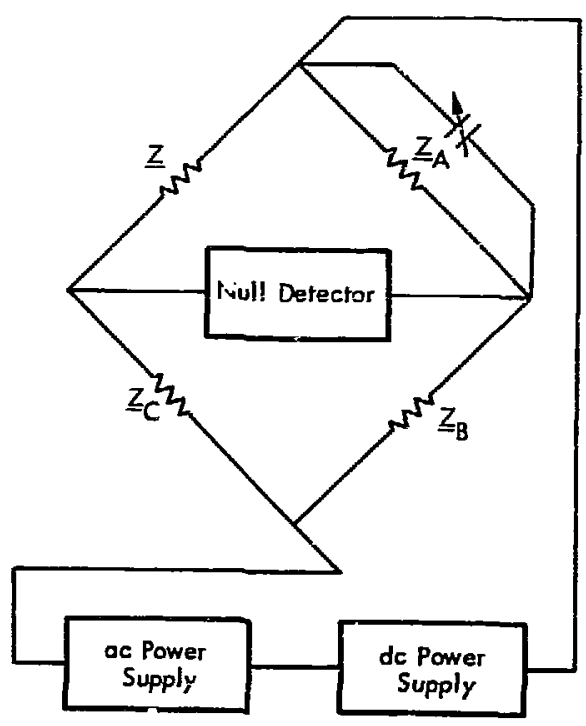

Fig. 4. In oedance bridge for specific heat measurement.

$$
\begin{aligned}
{[\operatorname{Im}(\underline{Z}) / \operatorname{Re}(\underline{Z})] } & =\left[\left(\mathrm{X}_{A} R_{C}\right)-\left(\operatorname{Re}(\underline{Z}) X_{B}\right)\right. \\
& \left.+\left(R_{A} X_{C}\right)\right] /\left[R_{A} R_{C}\right. \\
& \left.+\operatorname{Im}(\underline{Z}) \underline{X}_{B}-X_{A} X_{C}\right]
\end{aligned}
$$

In general, the bridge impedances $\underline{z}_{I}$ will have the form

$$
\begin{aligned}
\underline{Z}_{I}=\left\{R_{I}\right. & \left.+j\left[L_{I}\left(1-\omega^{2} C_{I} L_{I}\right)-C_{I} R_{I}^{2}\right]\right\} /[(1 \\
& \left.\left.-\omega^{2} C_{I} L_{I}\right)^{2}+\omega^{2} C_{I}^{2} R_{I}^{2}\right]
\end{aligned}
$$

which is the impedance of a reeistance, $R_{1}$, and a series inductance, $L_{I}$, shunted by a capacitance, $C_{I^{*}}$ We will assume that $\omega^{2} C_{A} L_{A} \ll 1$; then

$$
\begin{array}{r}
\underline{z}_{A}=\left[R_{A}+j\left(L_{A}-C_{A} R_{A}^{2}\right)\right] /[1 \\
\left.+\omega^{2} C_{A}^{2} R_{A}^{2}\right]
\end{array}
$$

Therefore

$$
x_{A}=x_{A}^{\prime}+x_{A}^{\prime \prime}
$$

with

$$
x_{A}^{\prime}=-\left(\omega C_{A} R_{A}^{2}\right) /\left(1+\omega^{2} C_{A}^{2} R_{A}^{2}\right)
$$

and

$$
X_{A}^{\prime \prime}=\left(\omega L_{A}\right) /\left(1+\omega^{2} C_{A}^{2} R_{A}^{2}\right)
$$

Jising Eqs. (36) in Eq. (32), we find

$$
\operatorname{Im}(\underline{z}) / \operatorname{Re}(\underline{z})=\left(R_{C} X_{A}^{\prime}+R_{X}\right) /\left(R_{A} R_{C}+X_{X}\right)
$$


where

$$
R_{X}=R_{C} X_{A}^{\prime \prime}-\operatorname{Re}(\underline{Z}) X_{B}+R_{A} X_{C}
$$

and

$$
x_{X}=\operatorname{Im}(\underline{Z}) \mathbf{x}_{\mathbf{B}}-\mathbf{x}_{\mathbf{A}} \underline{x}_{C}
$$

Now we assume that the bridge is constructed so that $\mathbf{X}_{X}<<R_{A} \mathbf{R}_{C}$, so Eq. (37) becomes

$$
\operatorname{Im}(\underline{Z}) / \operatorname{Re}(\underline{Z})=X_{A}^{\prime} / R_{A}+\left(R_{X} / R_{A} R_{C}\right)
$$

Using Eq. (26) with

$$
\bar{R} \gg\left[(\mathrm{dR} / \mathrm{d} T)_{\mathrm{T}}\right]\left[\left(\mathrm{i}_{0} / \mathrm{i}\right)\left(\Delta \mathrm{T}_{1}\right) \cos \phi+(1 / 2)\left(\Delta \mathrm{T}_{2}\right) \sin \theta\right],
$$

we find

$$
\operatorname{Re}(\mathbf{Z})=\overline{\mathbf{R}} \text {. }
$$

Therefore with Eqg. (27) and (39) we have

$$
\operatorname{Im}(\underline{Z}) / \operatorname{Re}(\underline{Z})=-\left[(1 / \bar{R})(\mathrm{dR} / \mathrm{dT})_{T}\right]\left[\left(i_{D} / \mathrm{i}\right)\left(\Delta T_{1}\right) \sin \phi+(1 / 2)\left(\Delta T_{2}\right) \cos \theta\right] .
$$

Recalling Egs. (13) to (16) and some trigonometry, we find:

$$
\Delta T_{1} \sin \phi=\left[\left(2 i_{0} i \bar{R}\right) /\left(\omega \bar{C}_{p}\right)\right]\left[\left(\omega \bar{C}_{p}\right)^{2} /\left(M^{2}+\omega^{2} \bar{C}_{p}^{2}\right)\right.
$$

and

$$
\Delta T_{2} \cos \theta=\left[\left(i^{2} \overline{\mathrm{F}}\right) /\left(4 \omega \bar{C}_{p}\right)\right]\left[\left(\omega \omega \bar{C}_{p}\right)^{2} /\left(M^{2}+4 \omega^{2} \bar{C}_{p}^{2}\right)\right]
$$

Therefore Eq. (40) becomes

$\operatorname{Im}(\underline{Z}) / \operatorname{Re}(\underline{Z})=-\left[\left(\omega \bar{C}_{p}\right)(d R / d T)-\bar{T}\right]\left[\left(2 i_{0}^{2}\right) /\left(M^{2}+\omega^{2} \bar{C}_{p}^{2}\right)+\left(i_{r m s}^{2}\right) /\left(M^{2}+4 \omega \omega_{p}^{2} \bar{C}_{p}^{2}\right)\right]$.

Now Eqs. (36), (38), and (43) can be combined to give

$$
\begin{gathered}
{\left[\left(R_{A} C_{A}\right) /\left(1+\omega^{2} C_{A}^{2} R_{A}^{2}\right)\right]=\left[(d R / d T)-F_{T}\right]\left[\left(2 i_{0}^{2} \bar{C}_{p}\right) /\left(M^{2}+\omega^{2} \bar{C}_{p}^{2}\right)+\left(i_{i m s}^{2} \bar{C}_{p}\right) /\left(M^{2}+4 \omega^{2} \bar{C}_{p}^{2}\right)\right]} \\
+(1 / \omega)\left(R_{X} / R_{A} R_{C}\right)
\end{gathered}
$$


Now let

$$
P 1^{\prime}=(d R / d T)_{T^{\prime}}, P 2=\bar{C}_{P^{*}}, P 3=M, P 4=i_{0^{\prime}}, P 5=i_{r m 9^{\prime}}, P 6=\frac{R_{X}}{R_{A^{\prime}} R_{C}}
$$

tinen

$$
\begin{aligned}
& {\left[\left(R_{A} C_{A}\right) /\left(1+\omega^{2} C_{A}^{2} R_{A}^{2}\right]=\left[P 1^{\prime}\right]\left[\left(2 P_{4}^{2} \cdot P 2\right) /\left(P^{2}+\omega^{2} P^{2}\right)\right.\right.} \\
& \left.+\left(\mathrm{Ps}^{2} \cdot \mathrm{P} 2\right) /\left(\mathrm{P3}^{2}+4 \omega^{2} \mathrm{P2}^{2}\right)\right]+\mathrm{P} 6 / \omega
\end{aligned}
$$

This equation is plotted in Figs. 5 and 6 for the indicated values of P1' through P6.

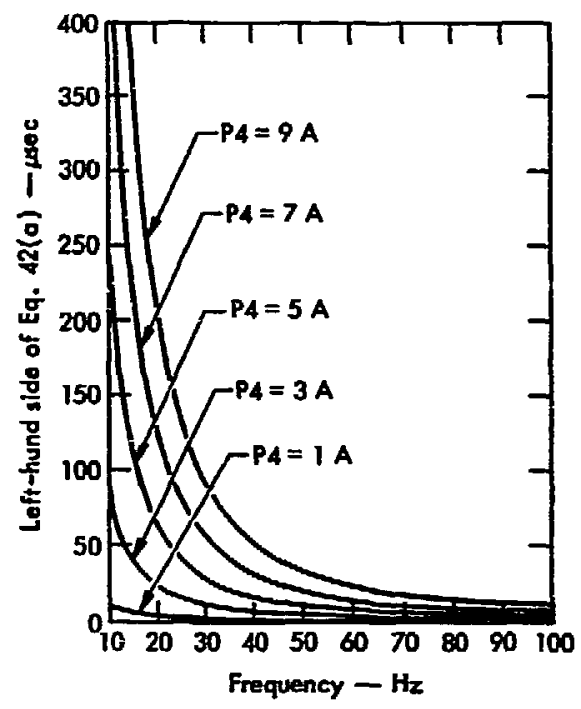

Fig. 5. Plot of Eq. 45. $P 1^{1}=0.001 \Omega / \% \mathrm{~K}$, $P 2=0.05 \mathrm{~J} /{ }^{\circ \mathrm{K}}, \quad \mathrm{P3}=0.5 \mathrm{~W} / \mathrm{\sigma}^{\mathrm{K}}$, P5 $=(\mathbf{P 4} / 10) \mathrm{A}, \mathbf{P 6}=2.0$ usec.

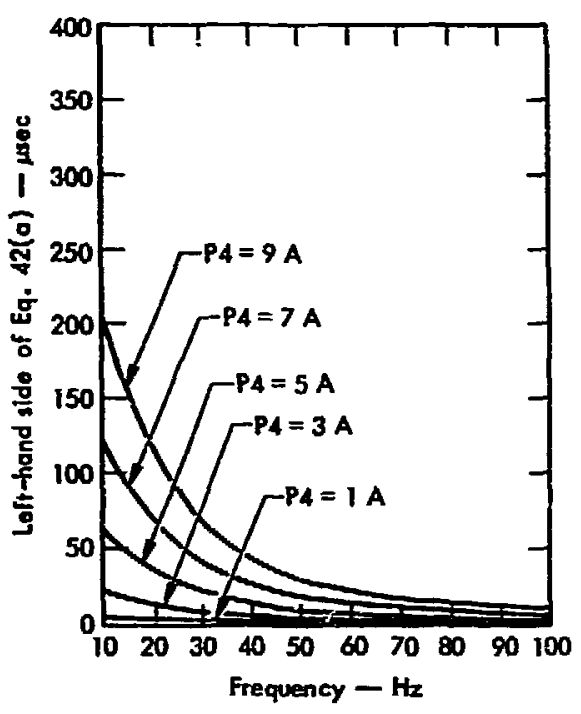

Fig. 6. Plot of Eq. 45. $P 1^{\prime}=0.001 \Omega /{ }^{\circ} \mathrm{K}$, $\mathbf{P 2}=0.05 \mathrm{~J} /{ }^{\circ} \mathrm{K}, \mathbf{P 3}=5.5 \mathrm{~W} /{ }^{\circ} \mathrm{K}$, $\mathbf{P} 5=\left(\mathbf{P}_{4} / 10\right) \mathrm{A}, \mathbf{P S}=2.0 \mu \mathrm{sec}$.

Equation (44) can be written in a more convenient form if we let

$$
\begin{aligned}
& P_{1}=\vec{C}_{p} / M, \\
& P_{2}=(2 / M)(d R / d T)_{T}
\end{aligned}
$$

and

$$
P_{3}=(1 / \omega)\left(R_{X} / R_{A} F_{C}\right)
$$


Then

$$
\begin{aligned}
{\left[\left(R_{A} C_{A}\right) /\left(1+\omega^{2} C_{A}^{2} R_{A}^{2}\right)\right]=\left[P_{2}\right]\left[\left(i_{0}^{2} P_{1}\right) /(1\right.} & \left.+\omega^{2} P_{1}^{2}\right) \\
& \left.+\left(i_{\operatorname{rmB}}^{2} \cdot P_{1} / 2\right) /\left(1+4 \omega^{2} P_{1}^{2}\right)\right]+P_{3}
\end{aligned}
$$

with

$$
\bar{C}_{p}=2\left(P_{1} / P_{2}\right) \cdot(d R / d T)_{T^{*}}
$$

Equation (46) is an equation in three unknowns, $\mathbf{P}_{1}, \mathbf{P}_{2}$, and $\mathbf{P}_{3}$, which are independent of frequency $\left(P_{3}\right.$ is independent of frequency since $R_{X}$ is approximately proportianal to the frequency, $\left.R_{X} \propto \omega\right)$. Therefore, if the bridge is balanced at three or more different frequencies, the system of equations of type (46) can be solved for $P_{1}, P_{2}$, and $P_{3}$. Then Eq. (47) may be used to solve for the heat capacity of the specimen.

\section{Experimental Apparatus and Procedures}

Two different experimental techniques were tested. The first system, similar to Lowenthal's system, ${ }^{17}$ was designed to measure the ac temperature of a metal foil sample using optical techniques. The second system, similar to Kraftmacher's system, ${ }^{13}$ was an ac bridge designed to measure the impedance of a metal wire or foil sample.

\section{OPTICAL SYSTEM}

It was shown above in Eg. (17) that the heat capacity of a metal specimen is given by

$$
\bar{C}_{p}=\left(2 i_{0} i \bar{R}\right) /\left(\Delta T_{1} \omega\right)_{\sin \phi} \text { or } \bar{C}_{p}=\left(i^{2} \bar{R}\right) /\left(\Delta T_{2} 4 \omega\right) \cos \theta
$$

If an optical system is used to measure the ac iemperature, then

$$
\Delta T_{i}=(\sqrt{2} / 2)(d T / d \bar{V}) \Delta \nabla_{i} \text { for } i=1,2
$$

where $\Delta \nabla_{i}$ is the rms ac voltage out of the detector (e.g., photomultiplier tube, photo resigtor or photo dicde), $\bar{v}$ is the dc voltage out of the detector, and $(d T / d \bar{v})$ is the slope of temperature-versus-dc-voltage curve for the detector. 
Therefore, in order to measure the heat capacity, it is necessary to measure the ac and de currents supplied to the sample, the average resistance of the samiple, the frequency of the ac current, the ac and dc voltages out of the detector, the response of the detector (i, e., dV $/ d T$ ), and the temperature of the sample. A schematic diagram of an optical system designed to make these measurements is shown in Fig. 7.

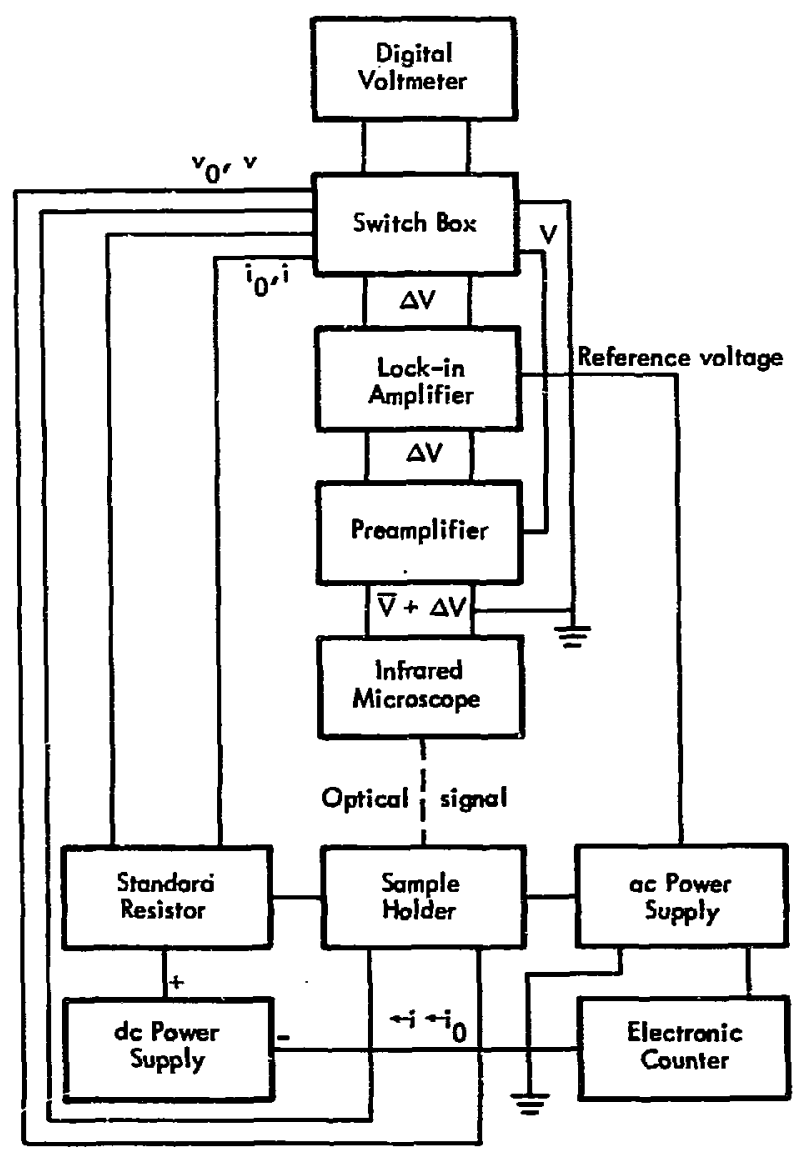

Fig. 7. Optical system for specific heat measurement.

The ac current was provided by an ac power supply (General Radio Type 1308-A) with a transformer-coupled output which would pass up to five amps direct current while providing up to five amps ac current. The oscillator in the power supply was used to provide the reference channel voltage to the lock-in amplifier. 
The frequency of the ac current was measured with an electronic counter (Hewlett Packard). The dc current was supplied by a regulated dc power supply (Tygon Electronice Model M60-10A).

A resistor (Nat: onal Bureau of Standards, calibrated, one-tenth ohm) was placed in geries with the sample. The voltage acrogs the resistor was measured and the current computed by Ohm's law.

The various voltages in the system were measured with a digital voltmeter (Dana Model 5603) which could be awitched into the circuit at the desired point by using a selection switch.

The average resistance of the sample was found by measuring the voltage drop across the sample with potential leads. The reaistance was obtained by dividing the voltage across the sample by the current through the sample.

An infrared microscope (Barnes Engineering Company, Infrared Radiometric Microscope Model RM-2A) was used to measure $\bar{V}$ and $\Delta V_{i^{*}}$ The microscope contained an indium antimonide detector (InSb) operating at $77^{\circ} \mathrm{K}$, with a spectral range of 1.8 to 5.5 microns. The optics gave a resolution of $0.00356 \mathrm{~cm}$.

It was found that the electronics provided with the microscope were not suited to measuring $\Delta V_{i}$. Therefore, the microscope was modified by taking the voltage directly from the indium antimonide detector to an external preamplifier thus bypassing all the original electronics.

A linear preamplifier (de to 50kc) with a gain of one hundred was used as the external preamplifier. It had two outputs: one for $\Delta V_{i}(\bar{V}$ was excluded by capacitive coupling), and a eccond for $\vec{V}\left(\Delta V_{i}\right.$ was fultered out with a RC filter).

The $V_{i}$ roltage waş supplied to the input channel of the lock-in amplifier (Princeton Applied Research Corporation Lock-in Amplifier Model HR-8). The meter on the lock-in amplifier was sometimes used to read the voltage $\Delta \mathbf{V}_{i}$, but usually the output was taken from the lock-in amplifier and measured with the digital voltmeter.

The samples for this system were made by cutting thin strips fiom a piece of platinum foil (0.5-1.0 mills by $1 / 8$ in. by 3 in.). They. vere clamped at the ends with copper clamps, the top part of the clowap being connected to the curreni leads and the bottom part to the potential leads. The sample, supported only at its ends by the clamps, was placed in a chamber which could be evacuated or filled with argon, the chamber was fitted with a $\mathrm{CaF}_{2}$ window through which the sample could be observed with the microscope.

Two major difficulties were. enconntered with this system. It was found that $\Delta \mathbf{V}_{2}$ could not be measured with sufficient accuracj, and that $\mathrm{d} \overrightarrow{\mathrm{V}} / \mathrm{dT}$ was difficult to measure.

The aample was subject to mechanical vibration, a problem noted also by other authors. 13,17 The sample vibrated in response to an interaction between the ac current and the stray magnetic fields in the neighborhood of the gample. This could be 
demonstrated by placing a small permanent magnet near the sample chamber and observing the resulting change in $\Delta \mathbf{V}_{2^{*}}$. A magnetic shield was constructed out of alternate layers of $\mathrm{Mu}$ metal and copper (three layers of $\mathrm{Mu}$ metal with two interBpersed layers of copper). Since it was impossible to completely enclose the sample by the shield, the vibration was reduced, but not eliminated.

Although the vibration of the filament could not be directly observed, it wag believed to be a rocking motion of the foil driven at the same frequency as the ac current. This gave rise to an ac light flur at the detector, since the detector was observing a varying amount of foil surface. The amount of area viewed by the detector passed through a maximum twice for each period of the mechanical vibration. Therefore, the frequency of the mechanically induced light flux was twice the period of the ac current, $i$. e., the same frequency as $\Delta \mathbf{v}_{\mathbf{2}}$.

Since $\Delta \mathbf{V}_{2}$ could not be measured accurately, and since we thought that the mechanical vibration should not contribute a light-nux oscillation at the frequency of the ac current, it was decided that $\Delta \nabla_{1}$ should be the quantity measured. It was found that this could be done without any effect due to the mechanical vibration of the sample being observed. It is the author's opinion that this is the preferred mode of operation for the optical method, although it does not appear to have been used before.

The response of the detector, $\mathrm{d} \overline{\mathrm{V}} / \mathrm{d} T$, was measured by recording $\overline{\mathrm{V}}$ as a function of temperature and determining the slope graphically. The temperature was measured with a calibrated pyrometer, and the true temperature calculated using an emmisitivy

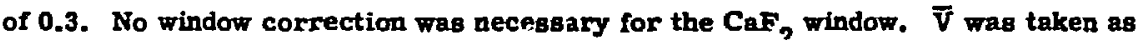
the difference between the output $\left(\nabla_{T}\right)$ of the detector when viewing the sample at temperature $T$, and the output of the detector $\left(\bar{V}_{0}\right)$ when viewing a room-temperature piece of cardboard. That is, $\bar{V}=\bar{V}_{T}-\bar{V}_{0}$. This tended to minimize the effect of drift in the detector. Even so, there was considerable scatter in the data, and it was found that an accuracy of only five percent was possible for $d \bar{v} / d T$.

Becaupe of the inaccuracy of the $d \bar{V} / d T$ measurements, the overall accuracy of the specific beat measurements was limited to plus or minus five percent with the optical system. For this reason work on the optical system was terminated, and a bridge system was constructed.

\section{BRIDGE SYSTEM}

A schematic diagram of the bridge system is shown in Fig. 8. This system measures the ac and dc currents supplied to the sample, the ac and de voltage acrose the sample, the frequency of the ac current, the voltage across $\underline{Z}_{C}$, and the impedance $\underline{Z}_{A}$ necessary to balance the bridge. With these quantities measured, Eq. (44) can be used to determine the heat capacity of the gample.

The ac and dc current were suppligd by the same equipment that was used in the optical system. Again, the ground point is lucated between the ac and de power 


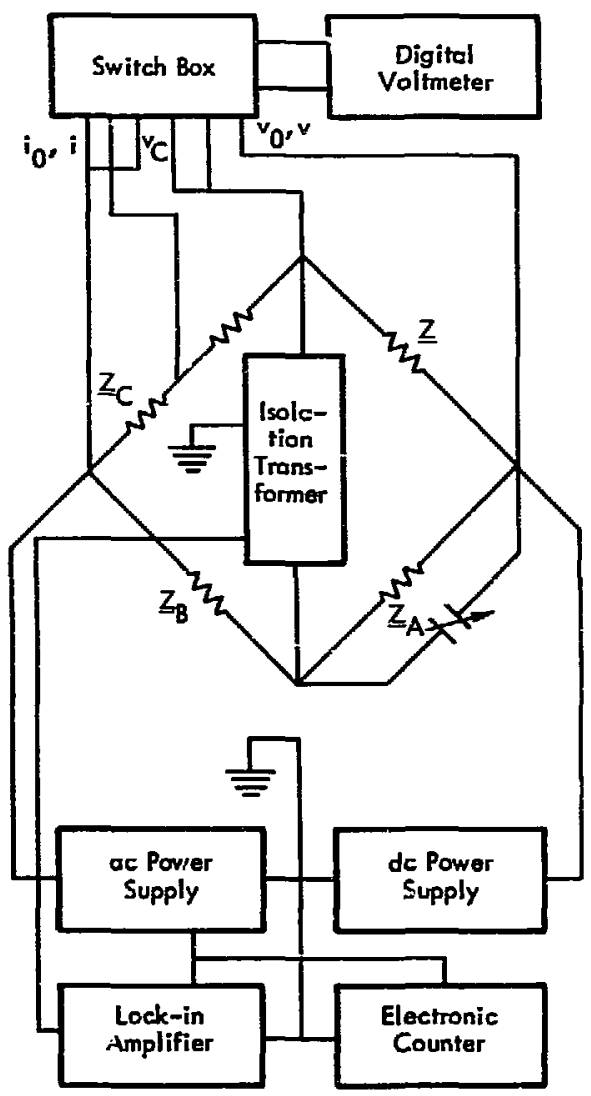

Fig. 8. Impedance bridge for specific heat measurement.

eupplies. If the ground point is located inside the bridge, an ac ground loop can result because there is some capacitance to ground through the output transistors of the dic pcrwer supply. To make matters worse, this capacitance depends on the supply voltage. These problems are avoided by positioning the ground point as indicated.

The bridge components are made up of the sample, $\underline{Z}$, the other high-current arm, $\underline{Z}_{C}$, and the ratio arms, $\underline{Z}_{A}$ and $\underline{Z}_{B}$. The sample in this case may be a wire or a foil connected as a four-terminal resistor with both current and potential leads.

The $\underline{Z}_{C}$ arm is made up of the 0.1 -ohm standard resistor used in the optical system in series with a 1.0-ohm low-inductance resistor. This arm is capable of carrying ten amps. Initially $\underline{Z}_{C}$ was nsed with only the 0.1 -ohm resistor. However, 
it was determined that this gave rise to a rather large $P_{3}$, leading to errors in the high frequency operation of the bridge. A one-ohm resistor which would carry ten amps without changes in its resistance was difficult to obtain, 80 the voltage across $\underline{Z}_{C}$ was measured at each current setting and the resistance was calculated by dividing the voltage by the current.

Two ac resigtance boxes (J. G. Biddle AC-DC Decade Resistors) were used for the ratio arns. These boxes had fire decades each (100-ohm, 10-ohm, 1-ohm, 0.1-ohm, and 0.01-ohm), and were normally operated so that each box had a resistance of at least one hundred olms. The $\underline{Z}_{A}$ arm has a decade capacitor (General Radio Company Polystyrene Decade Capacitor Type 1419-B or 1412-BC) in parallel with the decade resistor. Two different capacitors were used; both had a maximum capacitance of 1 microfarad, but one was a five-decade box while the other had four decades. The two boxes were found to give identical results.

The lock-in amplifier was used in this case as an ac null detector. As before, the reference-channel voltage was taken from the oscillator of the ac power supply. An isolation transformer (Triad Geoformer G-10) was used to isolate the lock-in amplifier from the bridge. The lock-in amplifier could have been operated with a differential input, but it was found that there was less noise picksp with the transformer.

$A B$ in the optical case, the digital voltmeter was used to measure the various voltages. It was discovered that the best null could be obtained if the digital voltmeter was discomected from the bridge during the balancing procedure.

It was found that great care had to be exercised in shielding and wiring the bridge to minimize the ground loops and noise pickup. The shields were constructed according to the principles discussed by Hague. 43 The bridge components were arranged an as to minimize the lesd length between components while keeping the values of inductive and capacitive coupling small.

The bridge was balanced by an iterative process. First, a rough balance was achieved by adjusting $\mathbf{R}_{A}$ until the de voltage was ten microvolts or less, then the sample resistance and $C_{A}$ were adjusted to minimize the ac voltage across the bridge. The phase adjustment on the lock-in amplifier was adjusted so that the amplifier was locked in to the component of the bridge voltage which was in phase with the current, then the dc current was adjusted to give a minimum ac voltage. Next, the phase control was shifted by ninety degrees, and $C_{A}$ was adjusted to give a minimum ac voltage across the bridge. This process was repeated with increasing sensitivity until the noise limit was reached. The noise which was encountered at low voltage levels seemed to be due to thermal fluctuations in the bridge resistance, particularly in the sample.

The bridge sensitivity was very high; changes in resistance of one part in $10^{6}$ could be readily detected and changes in $\mathbf{C}_{\mathbf{A}}$ of ten picofarads rere normally detectable. In general, the sensitivity of the balance exceeded the absolute accuracy of the components ( $0.1 \%$ for the resistors and $0.5 \%$ for the capacitor). 
$f_{18}$ in the optical gystem, the dc and ac currents through the sample were computed by Ohm's law from the dc and ac voltages across the one-tenth-ohm calibrated resistor. The voltages were measured with high accuracy (better than $0.1 \%$ ) by the digital voltmeter.

The resistance of the sample was measured in two ways: from the bridge balance with $\bar{R}=R_{C}\left(R_{A} / R_{B}\right)$ and from the voltage across the sample, $v_{0}$, and the current through the sample, $i_{0}$. with $\bar{R}=v_{0} / i_{0^{*}}$. In all cases these measurements agreed to better than $0.5 \%$, and they usually agreed to better than $0.1 \%$. However, the measuremants were not independent since the resistance $R_{C}$ was obtained by measuring the voltage across the resistor, $v_{C}$, and the current through $i \bar{i}, i_{0}$. with $R_{C}=\nabla_{C} / i_{0}$. However, the digital voltmeter was calibrated before and after the experiment and found to be accurate to better than $0.1 \%$ in all the ranges used in the data acquisition.

As in the optical case, an electronic counter was used to measure the frequency. By measuring the period rather than the frequency, an accuracy of $0.01 \%$ could be achieved.

The zero-degree resistance of each sample was meagured in an ice bath with a precision Kelvin bridge.

\section{SAMPLE SELECTION}

Tungsten was chosen ss the metallic element for study for the following reasons:

(1) Samples suitable for use in the bridge system were easily obtainable.

(2) The high-temperature performance of the bridge could be demongtrated with tungsten.

(3) The literature values for the specific heat of tungsten, which are in good agreement below $1200 \mathrm{~K}$, differ by more than $50 \%$ in some cases at temperatureg above $3000 \mathrm{~K}$.

(4) The vacancy contribution to the specific heat has been reported ${ }^{19}$ to be large.

The samples were made from a commercially available tungaten light bulb, General Electric Model 6.6A/T4Q/1CL-200-W quariz-icdine lamp. Therefore, the samples consisted of a tungsten filament in series with some lead wires of tungsten and molybdenum.

$A s$ in the optical system, the sample was fastened at the ends with the top part of the clamp being comected to the current leads and the bottom part connected to the potential leads of the bridge. In this way the lamp was supported by its leads. The leads were molybdenum wires which were spot-welded to molybdenmm foil feedthroughs that passed through the quartz envelope of the lamp. Inside the quartz envelope, the molybdenum foil feedthroughs were spot-welded to tungsten leads which connected to and supported the filament. 
During the normal operation of a conventionel incandescent lamp. tungsten is transferred from the filament to the wall of the lamp by evaporation from the filament to the wall of the lamp by evaporation and diffusion, or in some cases through the operation of the water cycle. ${ }^{44}$ This effect limited the operation of Lowenthal's 17 equipment to temperatures below $2400^{\circ} \mathrm{K}$. In the quartz-iodine lanp, these problems are aroided by the use of the iodine cycle. ${ }^{45}$ When the iodine cycle is operating, iodine atoms produced by the pyrolysie of molecular iodine in the vicinity of the flament diffuse to the wall of the lamp and under the proper conditions react with the adsorbed tungsten, forming a volatile tungsten di-iodide which diffuses to the filament. The tungsten di-iodide is decomposed on the filament, resulting in the deposition of tungsten on the filament and the production of iodine atoms which then diffuse to the wall to repeat the cycle. Pure iodine gas is not used in these lamps, but rather argon is mixed with it to decrease the rate of evaporation of tungsten. In fact, the lamp is eupplied with a mixture of argon and iodine which minimizes the rate of transfer of tungeten (approximately $600 \mathrm{~mm}$ of argon and $4.5 \mathrm{~mm}$ iodine pressure at room temperature).

Argon alone can significantly reduce the rate of evaporation of the tungsten filament. Kraftmacher and Strelkov ${ }^{19}$ were able to obtain specific heat data up to $3600 \%$ using a pure argon atmosphere.

Since it was thought that the action of the iodine cycle might contribute to the measured specific heat, the quartz envelope of one of the lamps was opened, evacuates, and back-filled with xenon (approximately $1 / 2$ atmosphere pressure at room temperature). A aecond bulb was opened and evacuated to a pressure of less than $10^{-6}$ Torr and then resealed. Specific heat data was taken on the same samples before and after the gas environment had been changed so that any effect due to the iodine gas could be discovered.

The zero-degree resistance of the lamps was measured before and after the gas environment had been changed. It was discovered that the resietance of the lamp increased slightly after the quartz entelope had been opened by the glass blower. This was attributed to a slig": $:$ oxidation of the filament.

The masses of all the filaments were measured at the end of the experiment on a precision balance. Care was taken in removing the filament from the leads so that the mass of the entire filament corid be measured. In those cases where the gas atmosphere had been changed, the original mass of the filament was calculated from the mass of the filament at the end of the experiment and the gers-degree resistance before and after the gas had been changed. That is, $m=\left(R_{0}^{\prime} / R_{0}\right) m^{\prime}$, where $m$ is the mass of the filament before the envelope was opened to change the gas, $\mathrm{m}$ ' is the mass of the filament at the end of the experiment, $R_{0}$ is the resintance of the filament at zero degrees centigirade before the envelope was opened, and $R_{0}^{\prime}$ is the resistance of the filament at the end of the experiment. The zero degree resistance of the lamps was also measured before and after the lamps were run at high temperature to see if 
the possible loss of tungsten through evaporation could be detected. No loss of tungsten was observed in any of the gas-filled lamps.

In order to find the zero-degree resistance of the lamp filaments, it was necessary to measure the zero-degree resistance of the leads to the filament. This was done by attaching leads to the filament after it had been removed from the quartz envelope (at the end of the experiment) and measuring the zero-degree-centigrade resistance of the filarnent alone. The lead resistance was then calculated by subtracting the filament resistance from the resistance of the lamp (i.e., the filament-plus-lead resistance) which was measured at zero degrees centigrade just before the quartz envelope was broken.

\section{TEMPERATURE MEASUREMENT}

Two different methods of tempercture measurement vere used. The first method was the standard optical pyrometry technique. When this technique was found to be unsatisfactory, a resistance technique was employed.

A recently-calibrated optical pyrometer was used to measure the monochromatic brightness temperature of the filament at a wavelength of 0.65 microns. The true temperature was then calculated using emissivity data in the review by Thom and Winslow. 46 Accurate resulis could not be obtained using this method because the brightness temperature of the filament was very nonuniform. The nonuniform brightness temperature probably was caused by the radiation conditions associated with the filament being wound in the form of a double helix. An attempt was made to measure the brightness temperature on selected portions of the filament, but this proved to be impractical.

The resistance technique used was the same one that Kraftmacher and Streikov 19 used in their measurement of the specific heat of tungsten. As discussed previously, the resistance of the sample was measured during the experiment. Therefore, it was possible to calculate the relative resistance of the tungsten fulament, $R_{T} / R_{273}$ where $R_{T}$ is the resistance of the filament at the temperature $T^{\circ} \mathrm{K}$ and $R_{273}$ is the resistance of the filament at $273^{\circ} \mathrm{K}$. The procecture which was used to measure $R_{273}$ has been discussed above. The resistance of the filament at elevated temperature, $R_{T}$, was found by subtracting the lead resistance from the total sample resistance. The lead resistance was taken to be the lead resistance as measured at $273^{\circ} \mathrm{K}$ as previously described. This procedure neglected the change in lead resistance with temperature, but the error introduced was one percent or less.

Literature values ${ }^{47}$ of the relative resistance of tungsten versus temperature were fit by the method of least squares to the piecewise quadratic function

$$
\left(R_{T} / R_{273}\right)_{i}=a_{i}+b_{i} T+c_{i} T^{2} \text { with } i=1,2,3
$$


where $i=1$ was used in the region $273^{\circ} \mathrm{K}$ to $1500^{\circ} \mathrm{K}, i=2$ was used in the region $1300^{\circ} \mathrm{K}$ to $2500^{\circ} \mathrm{K}$, and $\mathrm{i}=3$ was used in the region $2300^{\circ} \mathrm{K}$ to $3600^{\circ} \mathrm{K}$. The three equations were then solved to give the temperature as a function of the relative resistance. Using these equations and the measured values of the relative resistance, the temperature of the filament was calculated.

The functions $\left(R_{T} / R_{273}\right)_{i}$ were also used to calculate $(d R / d T)_{T}$. That is,

$$
(\mathrm{dR} / \mathrm{dT})_{\mathrm{T}}=\mathrm{R}_{273}\left(\mathrm{~b}_{\mathrm{i}}+2 \mathrm{c}_{\mathrm{i}} \mathrm{T}\right) \text { with } \mathrm{i}=1,2,3
$$

where $i$ indicates the same set of ranges as above. These data are given in Table 1.

Table 1. The functions $\left(\mathrm{R}_{\mathrm{T}} / \mathrm{R}_{273}\right)_{\mathrm{i}}$ and $(\mathrm{dR} / \mathrm{dT})_{\mathrm{T}}$.

$$
\begin{aligned}
& 273^{\circ} \mathrm{K} \leq \mathrm{T} \leq 1500^{\circ} \mathrm{K} \\
&\left(\mathrm{R}_{\mathrm{T}} / \mathrm{R}_{273}\right)_{1}=(-0.253)+\left(4.335 \times 10^{-3}\right) \mathrm{T}+\left(0.687 \times 10^{-6}\right) \mathrm{T}^{2} \\
&(\mathrm{dR} / \mathrm{dT})_{\mathrm{T}}=\left(\mathrm{R}_{273}\right)\left[\left(4.335 \times 10^{-3}\right)+\left(1.375 \times 10^{-6}\right) \mathrm{T}\right]
\end{aligned}
$$

$1300^{\circ} \mathrm{K} \leq \mathrm{T} \leq 2500^{\circ} \mathrm{K}$

$$
\begin{aligned}
& \left(R_{T} / R_{273}\right)_{2}=(-0.796)+\left(5.190 \times 10^{-3}\right) T+\left(0.353 \times 10^{-6} / T^{2}\right. \\
& (d R / d T)_{T}=\left(R_{273}\right)\left[\left(5.190 \times 10^{-3}\right)+\left(0.705 \times 10^{-6}\right) T\right]
\end{aligned}
$$

$2300^{\circ} \mathrm{K} \leq \mathrm{T} \leq 3600^{\circ} \mathrm{K}$

$$
\begin{aligned}
& \left(R_{T} / R_{273}\right)_{3}=(-1.278)+\left(5.613 \times 10^{-3}\right) T+\left(0.260 \times 10^{-6}\right) T^{2} \\
& (d R / d T)_{T}=\left(R_{273}\right)\left[\left(5.613 \times 10^{-3}\right)+\left(0.521 \times 10^{-6}\right) T\right]
\end{aligned}
$$

Langmuir ${ }^{48}$ has criticized the use of the relative resistance technique. He claims that

$$
\begin{aligned}
& \text { "the method proves to be one of the least accurate methods of } \\
& \text { estimating temperatures for the following reasons: (1) The } \\
& \text { resistance increases relatively slowly with the temperature } \\
& \text { as compared with most other properties used for temperature } \\
& \text { estimation. (2) The resistance and its temperature coefficient } \\
& \text { are very sensitive to traces of impurities (carbon). (3) At } \\
& \text { room temperature the resistance of the filament is often so } \\
& \text { low that uncertainties in the lead and contact resistance are } \\
& \text { apt to play a large part." }
\end{aligned}
$$

With the greater accuracy of modern experimental apparatus and the use of digital computers to aid in fitting data to empirical relations, Langmuir's first point is not as important as it was when he wrote it. This can also be said of the third point since the effects due to lead and contact resistance can be adequately accounted for. The second point is still a valid objection. The literature values of the relative resistance 
cited above may or may not be for pure tungsten; no aralysis oi the tungsten used is given by the authors. However, Kraftmacher and Strelkov ${ }^{19}$ checked the data at selected temperatures and found reasonable agreement between their data and the literature values cited above.

\section{Experimental Results}

The resistances at zero degrees centigraie, the masses and the gas environments of the tungsten filaments used in the experiment are listed in Table 2.

Table 2. Tungsten filaments and gas environments in the experiments.

\begin{tabular}{cccc}
\hline Sample No. & Resistance @ $0^{\circ} \mathrm{C}$ & Mass & Gas \\
\hline la & $0.2461 \Omega$ & $0.1662 \mathrm{~g}^{\mathrm{a}}$ & $\mathrm{Ar}+\mathrm{I}_{2}$ \\
1b & $0.2474 \Omega$ & $0.1653 \mathrm{~g}$ & Vacuum \\
2a & $0.2502 \Omega$ & $0.1714 \mathrm{~g}^{\mathrm{a}}$ & $\mathrm{Ar}+\mathrm{I}_{2}$ \\
$\mathrm{2b}$ & $0.2515 \Omega$ & $0.1705 \mathrm{~g}$ & Xenon \\
3 & $0.2507 \Omega$ & $0.1746 \mathrm{~g}$ & $\mathrm{Ar}+\mathrm{I}_{2}$ \\
4 & $0.2408 \Omega$ & $0.1643 \mathrm{~g}$ & $\mathrm{Ar}+\mathrm{I}_{2}$ \\
\hline
\end{tabular}

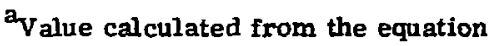

$$
m_{a}=\left(m_{b} \times R_{0_{b}}\right) /\left(R_{0_{a}}\right)
$$

where $m_{a}$ is the mass of sample number $1 \mathrm{a}$ or $2 \mathrm{a}, \mathrm{m}_{\mathrm{b}}$ is the mass of sample mumber $1 \mathrm{~b}$ or $2 \mathrm{~b}, \mathrm{ROb}_{\mathrm{b}}$ is the resistance at $0^{\circ} \mathrm{C}$ of sample number $1 \mathrm{~b}$ or $2 \mathrm{~b}$, and $\mathrm{RO}_{\mathrm{a}}$ is the resistance at $0^{\circ} \mathrm{C}$ of sample number 12 or $2 a$.

Measurements of $R_{A}, C_{A}, i_{0}$, and $i_{\text {rms }}$ were generaliy made at $20 \mathrm{Ez}, 25 \mathrm{~Hz}$, $35 \mathrm{~Hz}, 45 \mathrm{~Hz}, 55 \mathrm{~Hz}, 65 \mathrm{~Hz}, 75 \mathrm{~Hz}, 85 \mathrm{~Hz}$, and $95 \mathrm{~Hz}$ for each value of the temperature, $\overline{\mathrm{T}}$. However, some of the data were taken at $20 \mathrm{~Hz}, 25 \mathrm{~Hz}, 35 \mathrm{~Hz}, 55 \mathrm{~Hz}, 75 \mathrm{~Hz}$, and $95 \mathrm{Ez}$. These data are tabulated in Appendix C. The system of equations of the form

$$
\frac{\left(R_{A k} C_{A k}\right)}{\left(1+\omega_{k}^{2} C_{A k}^{2} R_{A k}^{2}\right)}=\left[P_{2}\right] \times\left[\frac{\left(i_{0 k}^{2} P_{1}\right)}{\left(1+\omega_{k}^{2} P_{1}^{2}\right)}+\frac{\left(i_{r m s, k}^{2} P_{1}\right)}{2\left(1+4 \omega_{k}^{2} P_{1}^{2}\right)}\right]+P_{3}
$$


(where there is one equation for each value of $k$, with $\omega_{1}=20 \mathrm{~Hz}, \varepsilon_{2}=25 \mathrm{Bz}$, etc., and $R_{A k}, C_{A k^{\prime}} i_{O k}$ and $i_{\text {rms,k }}$ are the measured values of $R_{A^{\prime}}, C_{A^{\prime}} i_{0^{\prime}}$ and $i_{\mathrm{rms}}$ at frequency $\omega_{k}$ ) was solved for $P_{1}, P_{2}$, and $P_{3}$. Then Eq. (47), along with the value of $(\mathrm{dR} / \mathrm{dT})_{\mathrm{T}}$ (calculated from the computer fit of the literature values of the relative resistance versus temperature) was used to calculate the heat capacity of the filament. Finally, the specific heat was calculated by dividing the heat capacity of the filament by its mass, that is,

$$
\bar{c}_{\mathrm{p}}=\bar{C}_{\mathrm{p}} / \mathrm{m}=(2 / \mathrm{m})\left(\mathrm{P}_{1} / \mathrm{P}_{2}\right) \times(\mathrm{dR} / \mathrm{dT})_{\bar{T}}
$$

These results are listed in Table 3.

The system of equations (49) with either six or nine equations is an overdetermined system which is nonlinear in $P_{1}$, but linear in $P_{2}$ and $P_{3}$. The solution of this system for $P_{1}, P_{2}$, and $P_{3}$ was based upon a modified least-squares procedure which was programmed to rm on a Control Data Corporation 6600 digital computer.

An initial value of $P_{1}$ was chosen (i, e., $P_{1}=P_{11}$ ) and then values of $P_{2}$ and $P_{3}$ were calculated to give initial values of $P_{2}=P_{21}$ and $P_{3}=P_{31}$. This calculation was done using a program called $M L R$, developed by $R$. $E$. von Foldt. ${ }^{49}$ In this case the program determined the values $P_{2}=P_{21}$ and $P_{3}=P_{31}$ such that the sum of the squares of the residuals wos minimized, that is,

$s q_{1} \equiv \sum_{k}\left(R_{1_{k}}\right)^{2}=\sum_{k}\left[Y_{k}-Y C_{k}\left(P_{1}, P_{2}, P_{3}\right)\right]$ is minimized for $P_{1}=P_{11}$

when

$$
\mathbf{P}_{2}=\mathbf{P}_{21} \text { and } \mathbf{P}_{3}=\mathbf{P}_{31}
$$

where $s q_{1}$ is the sum of the squares of the residuals, $\mathbf{R}_{\mathbf{1}_{\mathbf{k}}}$,

$$
Y_{k} \equiv\left(R_{A k} C_{A k}\right) /\left(1+\omega_{k}^{2} C_{A k}^{2} R_{A k}^{2}\right)
$$

and

$$
\mathbf{Y C}_{k}\left(\mathbf{P}_{1}, \mathbf{P}_{2}, \mathbf{P}_{3}\right) \equiv\left[\mathbf{P}_{2}\right] \times\left[\frac{\left(i_{0 k}^{2} P_{1}\right)}{\left(1+\omega_{k}^{2} P_{1}^{2}\right)}+\frac{\left(i_{r m s_{k}}^{2}\right)}{2\left(1+4 \omega_{k}^{2} P_{1}^{2}\right)}\right]+P_{3}
$$


Table 3. Measured and calculated experimental parameters.

\begin{tabular}{|c|c|c|c|c|c|c|c|c|}
\hline$\underset{\left({ }^{\circ} K\right)}{T}$ & $\underset{(\Omega / \Omega)}{\mathbf{R}_{\boldsymbol{T}}} ; \mathbf{R}_{0}$ & $\begin{array}{c}(\mathrm{dR} / \mathrm{dT})_{\bar{T}} \\
\left(\Omega /{ }^{\circ} \mathrm{T}\right)\end{array}$ & $\begin{array}{c}P_{1} \\
\text { (sec) }\end{array}$ & $\begin{array}{c}P_{2} \\
\left(A^{-2}\right)\end{array}$ & $\begin{array}{c}P_{3} \\
\text { (sec) }\end{array}$ & $\underset{\left(\sec ^{2}\right)}{s q}$ & $\begin{array}{l}\text { No.data } \\
\text { points }\end{array}$ & $\underset{\text { (cai/mole }}{\bar{c}_{p}}$ \\
\hline & \multicolumn{8}{|c|}{ Sample No. 1a $\left(A r+I_{2}\right)$} \\
\hline 726 & 3.258 & 0.001324 & 2.0937 & 3449.5 & c.06206 & 0.000154 & 9 & \\
\hline 934 & 4.398 & 0.001393 & 2.0883 & 7528.8 & 0.13244 & 0.008843 & 9 & \\
\hline 935 & 4.399 & 0.001393 & 2.0887 & 5059.5 & 0.08847 & 0.000290 & 9 & \\
\hline 1134 & 5.545 & 0.001447 & 2.0952 & 4555.2 & 0.07887 & 0.001529 & 9 & \\
\hline 1325 & 6.702 & 0.001496 & 2.0781 & 5355.8 & 0.09315 & 0.000391 & 9 & \\
\hline 1513 & 7.866 & 0.001540 & 2.0487 & 4826.0 & 0.08444 & 0.000953 & 9 & \\
\hline 1699 & 9.041 & 0.001572 & 1.9823 & 4161.8 & 0.07317 & 0.015496 & 9 & \\
\hline 1885 & 10.241 & 0.001605 & 1.9796 & 5060.1 & 0.09045 & 0.004160 & 9 & \\
\hline 2068 & 11.449 & 0.001637 & 1.9896 & 7531.3 & 0.13711 & 0.002941 & 9 & \\
\hline 2251 & 12.675 & 0.001668 & 1.9364 & 5499.4 & 0.10114 & 0.000758 & 9 & \\
\hline 2419 & 13.827 & 0.001692 & 1.9237 & 5437.6 & 0.10160 & $0.0011 \mathrm{~d} 7$ & 9 & \\
\hline 2562 & 14.816 & 0.001711 & 1.8901 & 5012.3 & 0.09532 & 0.001020 & 9 & \\
\hline 2705 & 15.814 & 0.001728 & 1.8658 & 4751.6 & 0.09267 & 0.001018 & 9 & \\
\hline 2847 & 16.818 & 0.001746 & 1.8389 & 4431.3 & 0.08939 & 0.001907 & 9 & \\
\hline 2990 & 17.838 & 0.001764 & 1.8083 & 4200.3 & 0.08872 & 0.000844 & 9 & \\
\hline 3134 & 18.870 & 0.001783 & 1.7633 & 4283.5 & 0.09631 & 0.003918 & $\mathbf{9}$ & \\
\hline 3206 & 19.399 & 0.001792 & 1.4691 & 5440.8 & 0.12737 & 0.007869 & 9 & \\
\hline 3279 & 19.927 & 0.001801 & 1.3972 & 4540.1 & 0.11100 & 0.060390 & 9 & \\
\hline
\end{tabular}

Sample No. lb (Vacuum)

$\begin{array}{rrrrrrrrr}831 & 3.824 & 0.001368 & 2.1338 & 3524.9 & 0.06074 & 0.000068 & 9 & 6.26 \\ 1032 & 4.956 & 0.001425 & 2.1163 & 4789.4 & 0.08194 & 0.000228 & 9 & 6.48 \\ 1226 & 6.095 & 0.001477 & 2.1157 & 6805.1 & 0.11675 & 0.000088 & 9 & 6.73 \\ 1413 & 7.242 & 0.001526 & 2.0975 & 8275.6 & 0.14298 & 0.000099 & 9 & 7.01 \\ 1597 & 8.397 & 0.001563 & 2.0728 & 6150.1 & 0.10724 & 0.000148 & 9 & 7.24 \\ 1779 & 9.559 & 0.001594 & 2.0409 & 6966.9 & 0.12304 & 0.000318 & 9 & 7.48\end{array}$

Sample No. $2 \mathrm{a}\left(\mathrm{Ar}+\mathrm{I}_{\mathbf{2}}\right)$

$\begin{array}{lllllllll}922 & 4.331 & 0.001412 & 2.0881 & 3750.2 & 0.06677 & 0.000070 & 9 & 6.44\end{array}$ $\begin{array}{llllllllll}3166 & 19.108 & 0.001817 & 1.5029 & 4653.6 & 0.10870 & 0.005504 & 9 & 10.86\end{array}$

Sample No. 2b (Xenon)

$\begin{array}{rrrrrrrrr}815 & 3.735 & 0.001386 & 2.1272 & 2668.8 & 0.04697 & 0.000914 & 9 & 6.29 \\ 917 & 4.299 & 0.001419 & 2.1131 & 4235.2 & 0.07414 & 0.000215 & 9 & 6.40 \\ 1016 & 4.860 & 0.001449 & 2.1197 & 6118.8 & 0.10655 & 0.000288 & 9 & 6.50 \\ 1112 & 5.419 & 0.001472 & 2.1226 & 7281.5 & 0.12684 & 0.000207 & 9 & 6.61 \\ 1207 & 5.981 & 0.001499 & 2.1196 & 8092.3 & 0.14086 & 0.000342 & 9 & 6.72\end{array}$


Table 3. (Continued)

\begin{tabular}{|c|c|c|c|c|c|c|c|c|}
\hline $\begin{array}{c}\mathrm{T} \\
\left({ }^{\circ} \mathrm{K}\right)\end{array}$ & $\begin{array}{c}\overline{\mathbf{R}}_{\overline{\mathrm{T}}} / \mathbf{R}_{0} \\
(\Omega / \Omega)\end{array}$ & $\begin{array}{c}(\mathrm{dR} / \mathrm{dT})_{\overline{\mathrm{T}}} \\
\left(\Omega /{ }^{\circ} \mathrm{K}\right)\end{array}$ & $\begin{array}{c}P_{1} \\
\text { (sec) }\end{array}$ & $\begin{array}{c}P_{2} \\
(A-2)\end{array}$ & $\begin{array}{c}P_{3} \\
(s e c)\end{array}$ & $\stackrel{s q}{\left(\sec ^{2}\right)}$ & $\begin{array}{l}\text { No. data } \\
\text { points }\end{array}$ & $\underset{\left(c a l / m o l e-{ }^{\circ} K\right)}{\left.\bar{c}_{p}\right)}$ \\
\hline \multicolumn{9}{|c|}{ Sample No. $2 b$ (Xenon)(Continued) } \\
\hline 1299 & 6.541 & 0.001524 & 2.1045 & 5777.8 & 0.10161 & 0.000432 & 9 & 6.84 \\
\hline 1390 & 7.107 & 0.001544 & 2.1018 & 6541.2 & 0.11417 & 0.000017 & 6 & 6.95 \\
\hline 1482 & 7.676 & 0.001568 & 2.0920 & 6328.8 & 0.11106 & 0.000089 & 6 & 7.09 \\
\hline 1574 & 8.249 & 0.001584 & 2.0777 & 7043.3 & 0.12430 & 0.000127 & 6 & 7.21 \\
\hline 1664 & 8.820 & 0.001600 & 2.0507 & 6148.1 & 0.10918 & 0.000019 & 6 & 7.32 \\
\hline 1754 & 9.393 & 0.001616 & 2,0319 & 5177.8 & 0.09225 & 0.000463 & 6 & 7.42 \\
\hline 1843 & 9.973 & 0.001632 & 2.0191 & 5666.8 & 0.10168 & 0.000609 & 6 & 7.55 \\
\hline 1933 & 10.555 & 0.001648 & 2.0090 & 5881.5 & 0.10624 & 0.000087 & 6 & 7.67 \\
\hline 2022 & 11.142 & 0.001664 & 1.9849 & 5429.2 & 0.09843 & 0.000414 & 6 & 7.77 \\
\hline 2111 & 11.732 & 0.001680 & 1.9842 & 6639.9 & 0.12134 & 0.002769 & 6 & 7.91 \\
\hline 2199 & 12.324 & 0.001695 & 1.9936 & 7422.9 & 0.13667 & 0.004392 & 6 & 8.04 \\
\hline 2287 & 12.922 & 0.001711 & 1.9831 & 7926.3 & 0.14703 & 0.003998 & 6 & 8.18 \\
\hline 2375 & 13.520 & 0.001726 & 1.9633 & 7916.2 & 0.14805 & 0.005138 & 6 & 8.32 \\
\hline 2462 & 14.125 & 0.001738 & 1.9256 & 5639.3 & 0.10629 & 0.001247 & 6 & 8.44 \\
\hline 2550 & 14.730 & 0.001746 & 1.9176 & 5810.0 & 0.11078 & 0.001720 & 6 & 8.58 \\
\hline 2638 & 15.342 & 0.001757 & 1.9052 & 5896.0 & 0.11409 & 0.002669 & 6 & 8.76 \\
\hline 2654 & 15.458 & 0.001759 & 1.8790 & 5170.4 & 0.10019 & 0.001543 & 9 & 8.78 \\
\hline 2725 & 15.953 & 0.001768 & 1.8547 & 4677.9 & 0.09178 & 0.000150 & 6 & 8.95 \\
\hline 2813 & 16.571 & 0.001780 & 1.8560 & 4021.3 & 0.09227 & 0.000572 & 6 & 9.20 \\
\hline 2900 & 17.191 & 0.001791 & 1.8346 & 4403.5 & 0.09054 & 0.000276 & 6 & 9.49 \\
\hline 2987 & 17.816 & 0.001803 & 1.7908 & 7398.5 & 0.08030 & 0.005420 & 6 & 9.82 \\
\hline 3076 & 18.452 & 0.001814 & 1.5425 & 5401.0 & 0.11879 & 0.011427 & 9 & 10.28 \\
\hline 3146 & 18.962 & 0.001824 & 1.5527 & 8873.0 & 0.20205 & 0.003388 & 9 & 10.70 \\
\hline \multicolumn{9}{|c|}{ Sample No. $3\left(\mathrm{Ar}+\mathrm{I}_{2}\right)$} \\
\hline 1117 & 5.446 & 0.001470 & 2.1077 & 5020.1 & 0.08973 & 0.000878 & 9 & 6.61 \\
\hline 1490 & $i .725$ & 0.001565 & 2.0488 & 3581.4 & 0.06393 & 0.004062 & 9 & 7.02 \\
\hline 1854 & 10.039 & 0.001630 & 2.0309 & 6306.6 & 0.11625 & 0.004159 & 8 & 7.56 \\
\hline \multicolumn{9}{|c|}{ Sample No. $4\left(A r+I_{2}\right)$} \\
\hline 953 & 4.504 & 0.001368 & 2.1174 & 5372.9 & 0.09443 & 0.000379 & 9 & 6.42 \\
\hline 953 & 4.504 & 0.001368 & 2.1356 & 6230.9 & 0.11024 & 0.000524 & 9 & 6.46 \\
\hline 3200 & 19.353 & 0.001753 & 1.5582 & 5439.6 & 0.12847 & 0.004549 & 9 & 11.07 \\
\hline 3202 & 19.364 & 0.001754 & 1.5536 & 5542.1 & 0.13080 & 0.004459 & 9 & 11.06 \\
\hline 3346 & 20.425 & 0.001771 & 1.5000 & 7453.9 & 0.19462 & 0.002896 & 6 & 12.36 \\
\hline 3383 & 20.691 & 0.001776 & 1.4987 & 6024.4 & 0.16219 & 0.004354 & 6 & 12.78 \\
\hline 3418 & 20.954 & 0.001780 & 1.4927 & 9443.3 & 0.26324 & 0.006638 & 6 & 13.27 \\
\hline
\end{tabular}

${ }^{\mathrm{a}}$ Data taken after the highest temperature data. 
The next step was to choose a new value of $P_{1}$ ouch that $B q_{2}<B q_{1}$, then $P_{1}=P_{12}, P_{2}=P_{22}$, and $P_{3}=P_{32}$. This process was repeaied until $8 q_{k+1}=8 q_{k}$ (normally sixty iterations). The computer time for the total process was usually about 0.1 minute.

The above procedure gave values of $P_{1}, P_{2}$, and $P_{3}$ which gave a value of $8 q$ which was very close to the actual miniminn. These values along with the final value of sq are given in Table 3 .

Errors in $P_{1}, P_{2}$, and $P_{3}$ could have been introduced in the measurement of $\mathbf{R}_{A}$, $C_{A}, i_{0}, i_{r m s}$, and $w$, and in the use of Eq. (46) which is not an exact expression. The errors introciuced in the measurement process were a few tentis of a percent at most because the bridge could be balanced with great precision formally better than $0.1 \%$ ) and the absolute accuracy of the bridge resistors and capacitors and the absolute accuracy of the current measurements were all better than half a percent. The random errors in the measurements had a minimal effect on the calculated values of $P_{1}, P_{2}$, and $\mathbf{P}_{3}$ due to the least-aquares procedure used in the calculation. The approximations involved in deriving Eq. (46) were checked and found to introduce negligible errors. This is also verified by the fact that the sum of the squares of the residuals for the calculated values of $P_{1}, P_{2}$, and $P_{3}$ is very small, indicating that the form of Eq. (46) is correct.

The above considerations indicate that the errors in $\mathbf{P}_{1}, \mathbf{P}_{\mathbf{2}}$, and $\mathbf{P}_{\mathbf{3}}$ are certainly less than one percent. However, the error in the temperature is unknown since the temperature measurement depends upon the values of the relative resiatance versus temperature, which are of unknown accuracy. The temperature measurement is certainly no better than one percent and an error of five percent would not be surprising in the high temperature region. The errors introduced in the temperature measurement are reflected in the specific heat as calculated by using Eq. (50) through the (dR/dT) term. Therefore, there is an unkmown error in the value of the specific heat and in the temperature at which it was measured. As an overall estimate, the specific heat data probably is accurate to plus or minus one percent at the low temperatures with decreasing accuracy as the temperature is increased, until near the melting point as accuracy of plus or minus three percent might be expected.

The data discussed above were taken with the dc current, $i_{0}$, much larger than

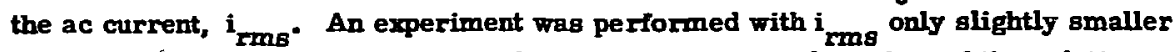
than $i_{0}$ to determine if the calculated specific heat was independent of the relative size of $i_{\text {rms. }}$. Changing the size of $i_{\mathrm{rms}}$ with respect to $i_{3}$ changes the amplitudes of the ac temperatures, $\Delta T_{1}$ and $\Delta T_{2}$, while keeping the frequency and the average temperature the same. The results of this experiment are shown in Table 4. Only a small effect was observed, less than one percent change in the specific heat resulted from doubling the size of the ac current. This experiment suggests that by changing the ratio of ac current to dc current when the frequency is changed, the amplitude of 
Table 4. Data from $i_{\text {rms }} \leq i_{0}$ experiment.

\begin{tabular}{|c|c|c|c|c|c|c|c|c|c|c|}
\hline$\underset{\left({ }^{2} \mathrm{~K}\right)}{T}$ & $\begin{array}{c}\overline{\mathbf{F}}_{\mathrm{T}} / \mathbf{R}_{0} \\
(\Omega / \mathrm{m}\end{array}$ & $\begin{array}{l}\text { (dR/dTh } h_{T} \\
\left(\Omega /{ }^{\circ} \mathbf{K}\right)\end{array}$ & $\begin{array}{c}P_{1} \\
\text { (sec) }\end{array}$ & $\begin{array}{c}P_{2} \\
\left(A^{-2}\right)\end{array}$ & $\begin{array}{c}P_{3} \\
\text { (sec) }\end{array}$ & $\begin{array}{l}\text { sq } \\
\left(\sec ^{2}\right)\end{array}$ & $\begin{array}{l}\text { No. data } \\
\text { points }\end{array}$ & $\begin{array}{r}\text { io } \\
\text { (A) }\end{array}$ & ifms & $\begin{array}{c}\bar{c}_{p} \\
\text { (cs:/mole-" } K)\end{array}$ \\
\hline 2063 & 11.415 & 0.001635 & $2.00 \div 0$ & 3283.8 & 0.13285 & 0.002520 & 9 & 3.526 & 0.500 & $7.8 \mathrm{a}^{\mathrm{a}}$ \\
\hline 2063 & 11.414 & 0.001635 & 1.9968 & 4621.9 & 0.08476 & 0.000362 & $\mathrm{a}$ & 3.427 & 1.000 & $7.93^{\mathrm{a}}$ \\
\hline 953 & $4.50 \%$ & 0.001368 & 2.1174 & 5372.9 & 0.03443 & 0.000379 & 9 & 1.575 & 0.100 & $6.42^{b}$ \\
\hline 953 & $4.50=$ & 0.001368 & 2.1356 & 6230.9 & 0.11024 & 0.000524 & 9 & 1.552 & 0.300 & $6.46^{b}$ \\
\hline 3200 & 19.353 & 0.001753 & 1.5582 & 5439.6 & 0.12847 & 0.004549 & 9 & 6.668 & 0.500 & $11.07^{b}$ \\
\hline 3202 & 19.364 & 0.001754 & 1.5536 & 5542.1 & 0.13080 & 0.004459 & g & 6.679 & 0.250 & $11.06^{b}$ \\
\hline
\end{tabular}

Data taken on Sample No. 11 Ar $\left.+1_{2}\right)$.

basa taken on Sample No. $+\left(A r+I_{2}\right)$.

the ac temperature could be held fixed. Therefore, frequency dependent phenomena could be investigated at a constant ac temperative amplitude.

Some experimenters ${ }^{50-53}$ bave observed time-dependent specific heats near the melting point in certain metals and semi-metals; an experiment was performed to find out if guch an effect occurred in tungaten. The data at $3279 \mathrm{~K}$ was analyzed in the gtandard way and then divided into two groupa, 10 -frequency date $(20 \mathrm{~Hz}, 25 \mathrm{~Hz}$, $35 \mathrm{~Hz}$, and $45 \mathrm{~Hz}$ ) and high-frequency data $(55 \mathrm{~Hz}, 65 \mathrm{~Hz}, 75 \mathrm{~Hz}, 85 \mathrm{~Hz}$, and $95 \mathrm{~Hz}$ ), which were then analyzed separately. The results are presented in Table 5 . The gpecific heat calculated from the high-trequency data is slightly larger (approximately one percent larger) than the specific heat calculated from the low-frequency data. This effect, which appears to be slightly larger than the experimental errors, is the same kind of effect that Smith ${ }^{52}$ observed in germanium.

Table $5^{a}$. Data from frequency dependence analysis.

\begin{tabular}{|c|c|c|c|c|c|c|c|c|c|}
\hline$\underset{\left({ }^{c} \mathrm{~K}\right)}{\overline{\mathrm{T}}}$ & $\begin{array}{c}\overline{\mathrm{R}}_{\overline{\mathrm{T}}} / \mathrm{R}_{0} \\
(\mathrm{\Omega} / \mathrm{\Omega})\end{array}$ & $\begin{array}{c}(\mathrm{dR} / \mathrm{dT}))_{\mathrm{T}} \\
\left(\Omega /{ }^{\circ} \mathrm{K}\right)\end{array}$ & $\begin{array}{c}P_{1} \\
\text { (sec) }\end{array}$ & $\begin{array}{c}P_{2} \\
\left(A^{-2}\right)\end{array}$ & $\begin{array}{c}P_{3} \\
\text { (sec) }\end{array}$ & $\left(\sec ^{2}\right)$ & $\begin{array}{l}\text { No. data } \\
\text { points }\end{array}$ & $\begin{array}{l}\text { Frequencies } \\
\text { used }(\mathrm{Hz})\end{array}$ & $\begin{array}{c}\bar{c}_{p} \\
\text { (cal/mole-"K) }\end{array}$ \\
\hline 3279 & 19.927 & 0.001801 & 1.3972 & 4540.1 & 0.11100 & 0.050390 & 3 & 20 to 95 & 11.64 \\
\hline 3279 & 19.927 & 0.001801 & 1.1736 & 3645.0 & 0.08879 & 0.036250 & 4 & 20 to 50 & 11.60 \\
\hline 3279 & 19.927 & 0.001801 & 1.5378 & 239976 & 5.91000 & 0.001218 & 5 & 55 to 95 & 11.73 \\
\hline
\end{tabular}

${ }^{2}$ Data taken on Sample No. $1\left(A r+I_{2}\right)$.

\section{Discussion}

The specific heat data from Table 2 is plotted in Fig. 9. A large increase (or excess) in the specific heat of tungsten at constant pressure can be observed at temperatures higher than $2750^{\circ} \mathrm{K}$. As was pointed out in the introduction, this is a rather 


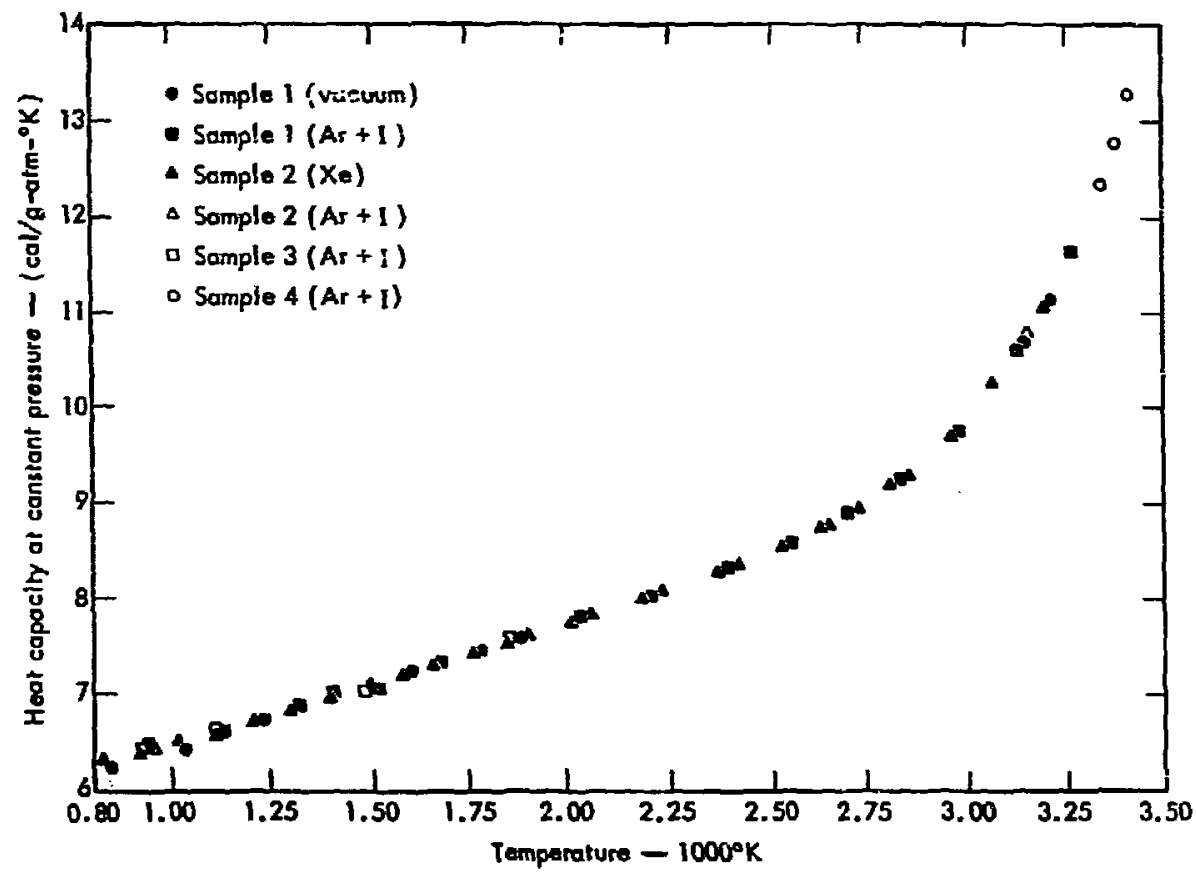

Fig. 9. Heat capacity of tungsten at constant pressure.

common phenomena in metals. It is generally believed that there are three effects which can contribute to the high temperature excesd specific heat in metals: the dilation term (i.e., the difference between the specific heat at constant pressure, $c_{p}$, and the specific beat at constant volume, $c_{v}$, the effects due to anharmonic lattice vibrations, and the contribution of lattice defect 3 to the specific heat.

The dilation term is given by the standard thermodynamic formula,

$$
c_{p}-c_{q}=\left(V \alpha^{2} / x\right) T
$$

where $V$ is the specific volume, $\alpha$ is the coefficient of volume expansion, $k$ is the isothermal compressibility, and $T$ is the absolute temperature. If data were available for $V, \alpha_{\text {, and }} k$ at gufficientiy high temperatures, then it would be fossible to calculate the dilation term and thus convert the specific heat data at constant pressure to its constant-volume value. Unfortunately, reliable data are only avaulable for a few metals. Therefore, approximations for the dilation term are normally used. 
'Two approximations for the dilation term are in common use: the Grueneisen relation,

$$
\left(\mathrm{Vo}^{2} / \kappa\right)=\alpha G c_{v}
$$

where G is Grueneisen's constant which is assumed to be independent of temperature, and the Nerst-Lindemann relation,

$$
\left(V \alpha^{2} / \kappa\right) \simeq A^{\prime} c_{p}^{2}
$$

where $A^{\prime}$ is the Nersi-Lindemann constant which is also assumed to be independent of temperature. In general, both of these approximations have been found to be rather poor, but in most cases ${ }^{32,54,55}$ where they have both been compared with an experimental determination of the dilation term based upon Eq. (51), the Nerst-Lindemann relation proved to be a better approximation than the Grueneisen relation. Another way to approximate the dilation term is to expand it in a pos er series in $T$.

$$
\left(V a^{2} / x\right) T=d_{0}+d_{1} T+d_{2} T^{2}
$$

over the temperature range of interest.

Once a suitable approximation for the dilation term has been chosen, the heat capacity at constant pressure may be reduced to its constant-volume value. Then the specific beat at constant volume can be subdivided into two components, the specific heat of the lattice at constant volume, $c_{L}$, and the specific heat of the electrons at constant volume, $c_{\mathrm{E}}$. The lattice specific heat may be decomposed into three terms: the harmonic specific heat at constant volume, $c_{H^{\prime}}$ the anharmonic specific heat at constant volume, $c_{A^{\prime}}$ and the specific heat due to lattice defects at constant volume, $c_{V}$. Therefore, the specific heat at cor stant pressure becomes

$$
c_{p}=c_{D}+c_{E}+c_{B}+c_{A}+c_{V}
$$

where $c_{D}$ is the dilation term.

The electronic specific heat at constant volume can be appraximated by 56

$$
c_{E}=\gamma T\left[1-\frac{3 \pi^{2}}{10}\left(T / T_{F}\right)^{2}\right]
$$


where $\gamma$ is the electronic specific heat coefficient and $T_{F}$ is the Fermi temperature. In mogt cases, the second term in Eq. (56) is less than one percent of the firgt term and may be neglected. That is,

$$
c_{E}=\gamma \mathrm{T} \text {. }
$$

Most derivations of the lattice specific heat start with an expansion of the potential energy of the lattice in a power series in the displacements of the atoms from their equilibrium positions. If this series is terminated at the quadratic terms, the potential energy appears as a homogeneous quadratic form, the linear terms being zero because of the equilibrim conditions. The specific heat derited from this harmonic approximation of the potential energy is called the harmonic lattice specific heat. The difference between the harmonic lattice specific heat and the total lattice specific heat is called the anharmonic lattice specific heat. It should be noted that the dilation term is an anharmonic specific heat since it is not included in a harmonic lattice approximation. Erowever, it is more wavenient to analyze the lattice specific beat at canstant rolume where the dilation term can be treated separately.

Unfortungtely, an exact expression for the harmonic lattice opecific heat is not available. Therefore an approximation must be used. The Debye theory, in which the specific heat is given by 57

$$
c_{\mathrm{H}}=c_{\text {Debye }}=9 \mathrm{R}(\mathrm{T} / \theta)^{3} \int_{0}^{(\theta / T)} \frac{x^{4} \mathrm{e}^{x}}{\left(\mathrm{e}^{\mathrm{X}}-1\right)^{2}} d x
$$

where $R$ is the gas constant and $\theta$ is the so-called Debye temperature. This is one of the most useful approximations of the harmonic lattice specific heat. Tables of $c_{\text {Debye }}$ versug $(\theta / T)$ are available ${ }^{58}$; however, at high temperature $(T \gg \theta) c_{\text {Debye }}$ can be approximated by the following expresaion:

$$
c_{\text {Debye }}=3 R-\frac{3 R}{20}\left(\frac{\theta}{T}\right)^{2}
$$

A theoretical expression for the anharmonic specific heat is not availatio. Generally, calcuiations $59-03$ have suggested that the aniormonic lattice specific heat is small and perhaps negative in some cases. However, these calculations can only be regarded as crude approximations. An analysis of the experimental specific beat data of aluminum ${ }^{32}$ and copper ${ }^{54}$ indicates that for these metals the anharmonic specific heat is not small and is positive. Until more accurate theoretical work becomes available, it appears that a power series expansion in the temperature is the 
most suitable way of representing the anharmonic lattice specific heat. That is,

$$
c_{A}=a_{0}+a_{1} T+a_{2} T^{2}
$$

over the temperature range of interest.

Lattice defects are usually divided into two groups, line defects and point defects. Line deftets will be considered to include dislocations, substructure (polygonization), and grain boundaries. Although dislocation climb and polygonization do produce thermal effects, the concentration will be small in a well-annealed sample. The presence of line defects will alter the phonon spectrum in an unknown manner, and therefore, the possibility of some detectable effect on the specific heat cannot be ruled out. However, there is no experimental or theoretical evidence presently available to indicate that such effects would be large.

In a well-annealed sample, the concentration of point defects will be in thermal equilibrium. The equilibrium mole fraction of point defects, $x_{V}$, of one type le. $g$. , vacancies, di-vacancies, or interstitials) is given by ${ }^{64}$

$$
X_{v}=A\left[\exp \left(-\Delta E_{\mathbf{v}}^{0} / R T\right)\right]
$$

where $\Delta E_{V}^{0}$ is the standard energy of formation at constant volume of one mole of vacancies, $R$ is the gas constant, and $A$ is usually reforred to as the pre-exponential factor and containg all entropy terms other than the configurational entropy. In particular, $A$ is usually given as ${ }^{64}$

$$
A=\exp \left(\Delta S_{V}^{0} / R\right)
$$

where $\Delta S_{V}^{0}$ is the standard entropy of formation of the defect. Ncw the energy absorption due to the defect formation at a given temperature is given by

$$
\Delta \mathrm{E}_{\mathrm{V}}=\left(\Delta \mathrm{E}_{\mathrm{V}}^{0}\right)\left(\mathrm{X}_{\mathrm{V}}\right)=\mathrm{A}\left(\Delta \mathrm{E}_{\mathrm{V}}^{0}\right)\left[\exp \left(-\Delta \mathrm{E}_{\mathbf{V}}^{0} / R T\right)\right]
$$

Therefore, the excess specific heat due to the point defect is

$$
\Delta \mathrm{c}_{\mathrm{V}}=\left(\mathrm{d} \Delta \mathrm{E}_{\mathbf{V}} / \mathrm{dT}\right)_{\mathbf{v}}=(\mathrm{A} / \mathrm{R})\left(\Delta \mathrm{E}_{\mathbf{V}}^{0} / \mathrm{T}\right)^{2}\left[\exp \left(-\Delta \mathrm{E}_{\mathbf{V}}^{0} / \mathrm{RT}\right)\right]
$$

In most metais, monovacancy point defects can be expected to make the principal contribution to the specific heat. Interstitials, di-vacancies, and other 
point defect clusters may exist in the lattice, but their concentrations under conditions of thermal equilibrium should be small. Borelius ${ }^{65,66}$ has attempted to show that more than one defect must be considered in attempting to interpret high temperature spocific heat data. However, the work of Brooks ${ }^{54}$ and Brooks and Bingham ${ }^{32}$ on copper and aluminum tends to refute Borelius.

From an experimental point of view, it does not appear that specific heat data of gufficient accuracy can be obtained to allow for the separation of specific heat contributions from more than one lattice defect, if anharmonic effects are included. Therefore, it will be assumed that the specific heat due to lattice defects at constant preseure can be approximated by the specific heat due to monovacancies. That is,

$$
c_{T}=\Delta c_{V}
$$

where $\Delta E_{V}^{0}$ is now the energy of formation at constant volume of monovacancies, and $A$ is given by Eq. (62) with $\Delta S_{V}^{0}$ the entropy of formation of monovacancies.

The above approximations can be used to give an equation for the high-temperature specific heat of metals. That is, combining Eq. (55) with Eqs. (54), (57), (56),

(60), (64), and (65), we find

$$
c_{p}-c_{\text {Debye }}=p_{1}+p_{2} T+p_{3} T^{2}+\left(p_{4} / T^{2}\right)\left\{\exp \left(p_{5} / T\right)\right\}
$$

with

$$
\begin{aligned}
& p_{1}=d_{0}+a_{0}, \\
& p_{2}=d_{2}+a_{1}+\gamma_{1} \\
& p_{3}=d_{2}+a_{2},
\end{aligned}
$$

and

$$
P_{4}=\frac{A}{R}\left(\Delta E_{V}^{D}\right)^{2}
$$

and

$$
P_{5}=\left(-\Delta E_{V}^{0} / R\right) .
$$


Alternately, if Eq. (53) is used rather than Eq. (54), we have

$$
c_{p}-c_{\text {Debye }}-A^{\prime} T c_{p}^{2} \simeq p_{1}^{\prime}+p_{2}^{\prime} T+p_{3}^{\prime} T^{2}+\left(p_{4} / T^{2}\right)\left[\exp \left(p_{5} / T\right)\right]
$$

where

$$
p_{1}^{\prime}=a_{0}, p_{2}^{\prime}=a_{1}+\gamma, p_{3}^{\prime}=a_{2} .
$$

Both Eq. (66) and Eq. (69) contain at least five unknown parameters, $p_{1}$ through $p_{5}$. If the Debye temperature, $\theta$, is treated as an unknown, then there are six unknowns which must be determined from the experimental data. This is possible because of the special form of Eqs. (66) and (69) where each term has a temperature dependence which is quite different from the temperature dependence of each of the other terms. It would appear that $A^{2}$ in Eiq. (69) could be treated as an unknown; however, the temperature depentence of this term is not sufficiently different from the other terms in the equation to allow reliable evaluation of all seven unknowns. Therefore, when Eq. (69) is used, a value of $A^{\prime}$ from other experiments must be used.

A computer program was written to fit expeximental specific heat data with Eq. (66) or (69). In form it was very similar to the program which was used to calculate the specific heat from the bridge data; that is, a modified least-squares procedure was used. An initial value of $p_{5}$ and $\theta$ were chosen, then values of $p_{1}, p_{2}, p_{3}$, and $p_{4}$ (or $p_{1}^{\prime}$, etc.) were calculated using the MLR program. A new value of $p_{5}$ was then found, holding $\theta$ fixed, which would give a smaller value of the sum of the squares of the residuals when the new values of $p_{1}, p_{2}, p_{3}$, and $p_{4}$ (or $p_{1}^{\prime}$, etc.) were calculated. This process was repeated enough times so that an accurate approximation to the true minimum value of the sum of the squares of the residuals could be achieved. If the initial value of $\theta$ was chosen as a literature value of the Debye temperature, then the above process would give the best fit to the data in the least-square sense for that value. If the Debye temperature were treated as an unknown, then upon completion of the above process $\theta$ was varied while holding $p_{5}$ fixed to further rechuce the sum of the squares of the residuals. The last step was to again hold the Debye temperature, $\theta$, fixed (at its new value) and vary $p_{5}$ to reduce the sum of the squares of the residuals still further. In this way an accurate approximation of the best fit to the expeximental data (in the least-square sense) by Eq. (66) or (69) could be found.

A second computer program was written which determined the best fit to experimental specific heat data (in the least-\&quare sense) with the Debye temperature chosen so that $p_{1}$ would be approximately equal to zero. This program was almost identical to the one described above. However, in this program $\theta$ was varied while holding $P_{5}$ fixed so that the absolute value of $p_{1}$ was reduced to a value near zero. 
If specific heat data were to be fit over the entire temperature range of a solid (zero degrees Kelvin to the melting temperature), then $d_{0}$ in Eq. (54) and $a_{0}$ in Eq. (60) must be zero since the dilation term and the anharmonic lattice specific heat must be zero at zero degrees Kelvin. That is, $p_{1}$ and $p_{1}^{\prime}$ would have to be zero if specific heat data were fit at low temperatures. Similarly, if high temperature specific heat data was to be extrapolated to very low temperatures, $p_{1}$ and $p_{1}^{\prime}$ should be zero. In this case, the second program should be used.

In general, the two programs will give difierent values for the Debye temperature, 6. The first program will give a Debye temperature which is an average of the Debye temperature over the range of the experimental data. The second program will give a Debye temperature which should be comparable to the Debye temperature determined by low-temperature specific heat data. Of course, neither of the Debye temperatures will have any meaning if the approximations imrolved in deriving Eq. (66) or (69) are not valid. Furthermose, the second program should not be expected to give a good approximation to the low temperature Debye temperature for high-melting-point solidg where the high-temperature specific heat data is obtained at temperatures very much higher than the Debye temperature.

In order to compare the accuracy of the various methods used to fit the specific heat data, the average root-mean-gquare (RMS) error, $\bar{\epsilon}_{\text {RMS, }}$ of each fit can be calculated. This is just the square root of the sum of the squares of the residuals. Unfortunately, the average RMS error is not very useful when comparing fits with different numbers of unknowns. Clearly, the larger the number of unkmowns calculated in the least-Bquares fitting procedure, the smaller will be the valie of the average RMS error.

If it is postulated that the only reason that the root-mean-square error is not zero is that there are independent random errors in the experimental data points, then it is possible to obtain additionai information about the accuracy of the least-squares fit. This point is thoroughly discussed by Hildebrand. ${ }^{67}$ In particular, an estimate for the RMS deviation between the observed function and its calculated approximation over the $N+1$ data points may be calculated. That is,

$$
E_{R M S}=[(N+1) /(N-n)]^{1 / 2} \times E_{R M S}
$$

where $\mathbf{N}+1$ is the number of unknown parameters in the fitting function. This equation is meaningless when $N=n$, since all the data are then needed to determine the unknown parameters, and no data remain for the estimation of the error.

Unfortunately, it is not possible to assume that the only reason that the average RMS error is not zero is that there are independent random errors in the experimental data points, when fitting specific heat data. Since the fitting functions are known to be approximations rather than exact expressions, the experimental data cannot be expected 
to cleviate from these functions in a random pray. Under these circumetances, a calculated value of $E_{\text {pMSS }}$ from Eq. $(71)$ is meaningless.

The above programs were used to analyze the data of Brooks and Bingham ${ }^{32}$ on aluminum, and Brooks et al. ${ }^{33}$ on copper. These authors estirnate that their data has an absolute error of $\mathbf{0 . 7}$ percent. The data were used in three different fitting procedures. The first fit used the Debye temperatures given in the papers of Brooks and Bingham ${ }^{32}$ and Brooks. ${ }^{54}$ The second fit was done with the Debye temperature treated as an unknown and a value determined which minimized the sum of the squares of the residuals. The third fit again treated the Debye temperatare as an unknown, but in this case, the second program was used to find a valne of $\theta$ which minimized the absolute value of $p_{1}$ - The three values of the Debye temperature will be denoted by $\theta_{L}, \theta_{M}$ and $\theta_{0}$, respectively.

The results are shown in Table 6 and in Figu es 10 and 11 . The curves in the figures were made using the results of the second fit. Table 6 includes data on tine

Table 6. Three fits of data on aluminum ${ }^{32}$ and copper. ${ }^{33}$

\begin{tabular}{|c|c|c|c|c|c|c|c|c|c|c|}
\hline Metal & $\theta\left({ }^{\circ} \mathrm{K}\right)$ & $\mathbf{p}_{1}$ & $\mathbf{p}_{2}$ & $\mathbf{p}_{3}$ & $\mathbf{P}_{4}$ & $-P_{5}$ & $\bar{\epsilon}_{\text {RMS }}$ & $\Delta E_{\mathrm{V}}^{0}(\mathrm{sV})$ & $\Delta \mathbf{s}_{\mathbf{v}^{0} / \mathrm{R}}$ & $c_{m p}(\xi)$ \\
\hline Aluminum & $\theta_{L}=405$ & 0.1373 & 0.03234 & 2.106 & 3851 & 85.21 & 0.00761 & 0.735 & 3.28 & 0.20 \\
\hline Aluminum & $0_{M}=453$ & 0.4764 & -0.969 & 2.936 & 10410 & 06.78 & 0.00705 & 0.834 & 4.02 & 0.18 \\
\hline Aluminum & $\theta_{0}=380$ & -0.0352 & 0.5551 & 1.660 & 273B & 80.90 & 0.00765 & 0.698 & 3.05 & 0.37 \\
\hline Copper & $\theta_{\mathrm{L}}=314$ & -0.157 & 1.149 & -0.00985 & 5638 & 11.00 & 0.00372 & 0.950 & 3.15 & 0.70 \\
\hline Copper & ${ }^{\theta}{ }_{M}=287$ & -0.21 & 1.437 & $-0,210$ & 4205 & 10.54 & 0.00330 & 0.909 & 2.97 & 0.83 \\
\hline Copper & $\theta_{0}=353$ & 0.01881 & 0.7149 & . 0.2829 & 9240 & 11.82 & 0.00491 & 1.019 & 3.50 & 0.55 \\
\hline
\end{tabular}

Note: The valies give for $\mathrm{pl}_{1}$ through $\mathrm{p}_{5}$ have units corresponding to the specific heat in units of callimoic-oK and the temperature in units of kilo-degrees Kelvin. In this set of units $\Delta \mathrm{E}_{\mathrm{O}}=-\mathrm{R} \times \mathrm{P}_{\mathbf{5}}$ is given in kilo-cal/mole, which can then be converted to electron volis by multiplying by 0.434 (i.e., $\Delta \mathrm{E}_{\mathrm{V}}^{\mathrm{O}}=-0.434 \times \mathrm{R} \times \mathrm{P}_{5} \mathrm{eV}$ with $\mathrm{R}=1.99 \mathrm{cal} / \mathrm{moxe}^{-0} \mathrm{~K}$ ).

energy of formation of vacancies, $\triangle E_{V}^{0}$, the entropy of formation of vacancies, $\Delta S_{V}^{0} / R$, and the mole percent of vacancies at the melting temperature of the metal, cmp. $\Delta \mathrm{E}_{\mathrm{V}}^{0}$ was calculated using Eq. (68),

$$
\Delta \mathbf{E}_{\mathbf{V}}^{0}=-\mathbf{R} \times \mathbf{p}_{\mathbf{5}}
$$

A was calculated using Eq. (68), ṇote also,

$$
A=\left(p_{4}\right) /\left(R \times p_{5}^{2}\right)
$$


so that $\Delta S_{V}^{0} / R$ could be calculated using Eq. (62).

$$
\Delta S_{\mathbf{V}}^{0} / R=\ln (A)
$$

$c_{\text {mp }}$ was calculated using Eq. (61),

$$
c_{m p}=100 \times A\left[\exp \left(-\Delta E_{\mathbf{p}} / \mathbf{R T}_{\mathrm{mp}}\right)\right]
$$

where $T_{m p}$ is the temperature at the melting point of the metal.

in Table 7, the two values for the Debye temperature, $\theta_{M}$, and $\theta_{0}$, obtained using the second and third fitting procectures are compared with various values of the

Table 7. Various calculations of the Debye temperature.

\begin{tabular}{ccccccccccc}
\hline Metal & $\theta_{M}$ & $\theta_{0}$ & $\theta_{0}^{S}$ & $\theta_{298}^{S}$ & $\theta^{M}$ & $\theta_{0}^{E}$ & $\theta_{298}^{E}$ & $\theta_{m}^{R}$ & $\theta_{m}^{D}$ & $\theta_{298}^{I}$ \\
\hline Aluminum & 453 & 380 & 423 & 390 & 378 & 428 & 403 & 422 & 390 & 383 \\
Copper & 287 & 353 & 342 & 310 & 333 & 345 & 332 & 336 & 320 & 308 \\
\hline
\end{tabular}

Note: All temperatures are given in degrees Kelvin.

Debye temperature taken from Gschneider's compilation. ${ }^{68}$ The Debye temperature as determined from specific heat measurements is designated an $\theta^{S}$, and any oubscript which may be given indicates the particular temperature (absolute) at which $\theta^{S}$ was evaluated. $\theta^{M}$ refers to the Debye temperature calculated from the Lindemann equation,

$$
\theta^{M}=K\left(T_{m p} / M\right)^{1 / 2} \times(1 / V)^{1 / 3}
$$

where $K=138.5, M$ is the atomic mass, and $V$ is the atomic volume. $\theta^{E}$ refers to the Debye temperature as determined trom elastic constants; again, the subscript indicates the particular temperature (absolute) at which $\theta^{\mathbf{E}}$ was evaluated. $\theta_{\mathrm{m}}^{\mathrm{R}}$ is the Debye temperature determined from the electrical resistivity data. These Debye temperatures usually corraspond to an average value for a wide range of temperatures, thro a subscript $\mathrm{m}$ is used. ${ }_{\mathrm{m}}^{\mathrm{D}}$ is the Debye temperature determined from thermal expansion data. $\theta_{298}^{I}$ is the Debye temperature at $298^{\circ} \mathrm{K}$ as determined from x-ray intensity data.

The fitting procechure was not very sensitive to the Debye temperature since the average error, $\epsilon_{\text {RMS }}$ shown in Table 5 does not change very rapidly with $\theta$. Bven 80, the Debye temperatures, $\theta_{0}$ and $\theta_{M}$ are only slightly outside of the range of the Debye temperatures found from other experiments. Considering the approximations used in the fitting procedures and the fact that most of the data were taken at temperatures above the Debye temperature, the values of $\theta_{0}$ and $\theta_{M}$ are perhaps better than one might expect.

The values of $\Delta \underline{F}_{V}^{0}, \Delta S_{V}^{0} / R$, and $c_{m p}$ given in Table 6 are compared with values obtained by other methods in Table 8. The spread in the data from the different methods of fitting shown in Table 6 may be taken as crude approximation to the accuracy of the data. In particular, the values for $\Delta E_{V^{2}}^{0} \Delta s_{V}^{0} / R$, and $c_{m p}$ given in 


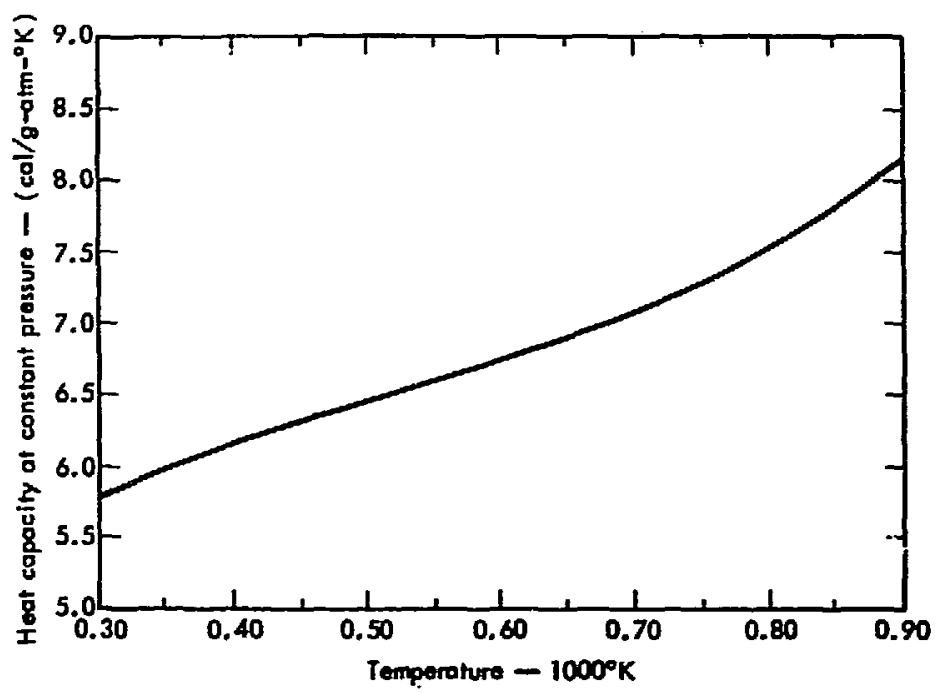

Fig. 10. Heat capacity of aluminum at constant pressure.

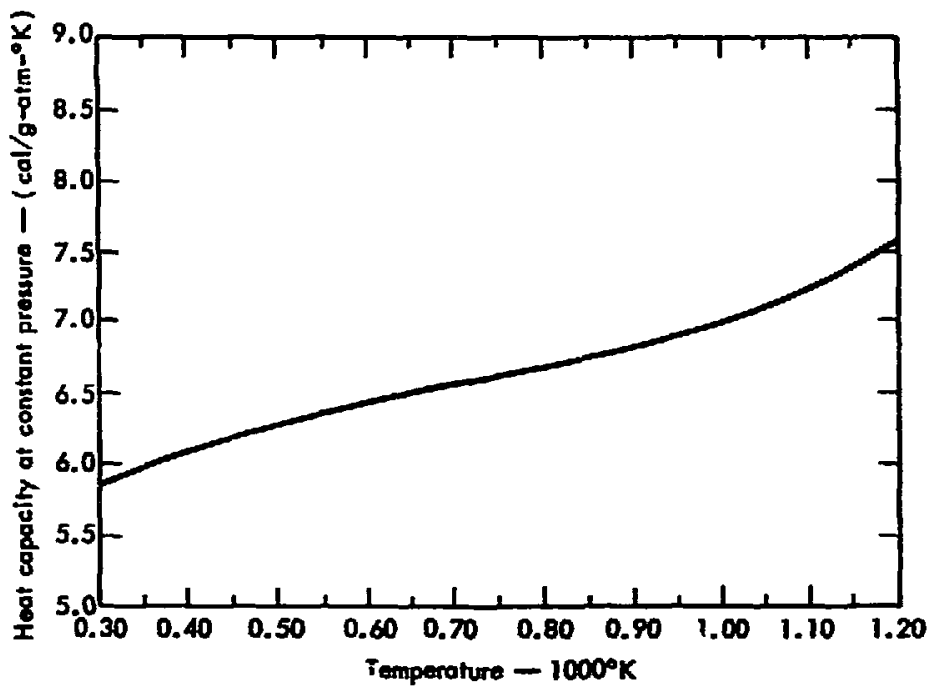

Fig. 11. Heat capacity of copper at constant pressure. 

Table 8. Comparison of values of $\Delta \mathrm{E}_{\mathrm{V}}^{0}, \Delta \mathrm{S}_{\mathrm{V}}^{0} / \mathrm{R}, \mathrm{c}_{\mathrm{mp}}$ found by various
methods.

\begin{tabular}{lccccc}
\hline Metal & Method & $\Delta E_{\mathrm{V}}^{0}(\mathrm{eV})$ & $\Delta \mathrm{S}_{\mathrm{v}}^{0} / \mathrm{R}$ & $\mathrm{c}_{\mathrm{mp}}(\%)$ & Reference \\
\hline Aluminum & $\mathrm{a}$ & $0.76 \pm 0.13$ & $3.5 \pm 1.0$ & $0.3 \pm 0.2$ & Table 5 \\
Aluminum & $\mathrm{b}$ & $0.74-0.86$ & $2.0-3.6$ & $0.1-0.3$ & $(69)$ \\
Aluminum & $\mathrm{b}$ & 0.71 & 1.76 & 0.04 & $(73)$ \\
Alnminum & $\mathrm{b}$ & 0.77 & 1.5 & 0.03 & $(71)$ \\
Alnminum & $\mathrm{b}$ & 0.64 & 1.1 & 0.11 & $(72)$ \\
Aluminum & $\mathrm{a}$ & 1.17 & 8.3 & 0.2 & $(31)$ \\
Copper & $\mathrm{a}$ & $0.96 \pm 0.11$ & $3.2 \pm 0.5$ & $0.7 \pm 0.2$ & Table 5 \\
Copper & $\mathrm{b}$ & $1.17 \pm 0.11$ & $1.5 \pm 0.5$ & 0.02 & $(70)$ \\
Copper & $\mathrm{c}$ & 0.7 & -0.2 & 0.2 & $(74)$ \\
\hline
\end{tabular}

(a) Specific heat at high temperatures.

(b) Thermal expanzion ( $x$-ray diffraction determination of the lattice parameter).

(c) Thermal expansion (extrapolation of low-temperature data).

Table 8 are the average values of the data in Table 6 plus or minus the onread in the data. Of the data given in Table 8 , that of Simmons and Balluffi ${ }^{69,70}$ is generally regarded as more accurate than that of the others. ${ }^{7-74}$ Their data for $\Delta F_{V}^{0}$ are in good agreement with the values obtained from the least-square fitting procedure. However, the values given by Simmons and Balluffi for $\Delta S_{V}^{0} / R$ are not in good agreement. 69,70 This is also reflected in the $c_{m p}$ data. The lack of agreement between Simmons and Balluffi's values for the entropy of formation of vacancies and the values obtained from the least-squares fitting procedure may be due to experimental error, either in their wurk or in the specific heat data or in the fitting procedure. However, theoretical studies ${ }^{75}$ seem to indicate that the values obtained from the least-squares fit are too large. On the other hand, these high values for $\Delta S_{0} / R$ are consistent with the eatimates of Holder and Granato. 76

The application of the least-square fitting programs to the specific heat data of copper and aluminum illustrated the value of the method in obtaining the energy of formation of vacancies. The next step was to apply the same procedures to the analysis of the specific heat data of tungsten.

In addition to the three methods of fit used above, severa' other fitting procedures were used to analyze the tungsten data. Two fits based on Eq. (69) were computed using Gschneidner's ${ }^{68}$ value of the Nernst-Lindemann constant for tungsten $\left(A^{\prime}=0.412 \times 10^{-5} \mathrm{~mole} / \mathrm{cal}\right)$. The first of these fits used a constant value for the Debye temperature, $\theta_{L}^{N}=380^{\circ} \mathrm{K}$. In the second fit, the Debye temperature was considered as an unknown and a value was calculated which minimized the sum of the squares of the residuals. This value will be denoted by $\boldsymbol{\theta}_{\mathbf{M}^{*}}^{\mathbf{N}}$ 
Finally, two fits were calculated using the approximation $c_{\text {Debye }}=3 R$ (R $=1.99 \mathrm{cal} /$ mole- $\mathrm{K}$ ). This approximation when used in Eq. (66) gives

$$
c_{p}=p_{1}^{\prime \prime}+p_{2} T+p_{3} T^{2}+\left(p_{4} / T^{2}\right)\left[\exp \left(p_{5} / T\right)\right]
$$

with

$$
p_{1}^{\prime \prime}=3 R+d_{0}+a_{0}
$$

The first fit used Eq. (76) directly while the second fit was based upon the further assumption that $p_{3}=0$, that is,

$$
c_{p}=p_{1}+p_{2} T+\left(p_{4} / T^{2}\right)\left[\exp \left(p_{5} / T\right)\right]
$$

Equation (78) is equivalent to the linear extrapolation procedure used by Kraftmacher and others ${ }^{18-23}$ to analyze specific heat data. This method is based on more assumptions than any of the other methods described above.

The results of the computer calculations for the various fitting procedures are

\begin{tabular}{|c|c|c|c|c|c|c|c|c|c|c|}
\hline Equation & $\theta\left({ }^{\circ} \mathrm{K}\right)$ & $p_{1}$ & $\mathbf{P}_{2}$ & $P_{3}$ & $\mathbf{P}_{4}$ & $-P_{5}$ & $\bar{\epsilon}_{\text {RMS }}$ & $-E_{v}^{0}(e v)$ & $\Delta \mathbf{S}_{\mathbf{V}^{\prime}}^{\mathbf{R}} \mathbf{R}$ & $c_{m p}(\%)$ \\
\hline (66) & $\theta_{L}=380$ & -0.396 & 0.8385 & 0.1300 & $3.238 \times 10^{7}$ & 46.64 & 0.02313 & 4.03 & 8.92 & 2.34 \\
\hline (66) & ${ }^{B} \mathrm{M}=371$ & -0.402 & 0.8438 & 0.1288 & $3.225 \times 10^{7}$ & 46.63 & 0.02310 & 4.02 & 8.92 & 2.34 \\
\hline (66) & $\theta_{0}=803$ & i) 34310 & 0.4653 & 0.2140 & $4.578 \times 10^{7}$ & 47.96 & 0.02561 & 4.14 & 9.21 & 2.19 \\
\hline (69) & $\theta_{\mathrm{L}}^{N}=380$ & -4.467 & 0.8471 & 0.01854 & $8.003 \times 10^{6}$ & 43.28 & $0.0204: ;$ & 3.74 & 7.67 & 1.68 \\
\hline (69) & $\theta_{M}^{N}=354$ & -0.483 & 0.8612 & 0.01533 & $7.888 \times 10^{6}$ & 43.22 & 0.02041 & 3.73 & 7.66 & 1.68 \\
\hline (76) & --- & 5.434 & 0.9502 & 0.1046 & $2.924 \times 10^{7}$ & 46.25 & 0.02280 & 3.99 & 8.83 & 2.39 \\
\hline (78) & -- & 5.181 & 1.293 & 0.000 & $1.135 \times 10^{7}$ & 42.75 & 0.03077 & 3.69 & 8.05 & 2.81 \\
\hline
\end{tabular}
shown in Table 9. The third fit shown in Table 9 is based upon Eq. (66) with the Debye

Table 9. Results of various fitting procedures applied to the tungsten data.

Note: The values given for $p_{1}$ through $p_{5}$ have units corresponding to the specific heat in urits of cal/mole- ${ }^{-K}$ and the temperature in units of kilo-degrees Kelvin. In this set of units $\Delta E_{V}^{0}=-R \times p_{5}$ is given in kilo-cal/mole, which can then be converted to electron volts by multiplying by 9.434 (i.e., $\Delta E_{V}^{0}=-0.434 \times \overline{\mathrm{I}} \times \mathrm{P}_{5} \mathrm{eV}$ with $\mathrm{R}=1.99 \mathrm{cal} /$ mole-ब $\mathrm{K}$.

temperature calculated to minimize the absolute value of $p_{1}$. As discussed above, this method of fitting specific heat data should not be used in cases where the data are at temperatures higher than the Debye temperature. Therefore, this is not a valid fitting procedure for the high-temperature specific heat data of tungsten. Ir.leed, the average 
error, $\bar{\epsilon}_{\text {RMS' }}$ is larger for this fit than for any of the other fits except the last one, and the Debye temperature is much too large. The third fit was included to illustrate that the procedure does give poor resulte and to show how little the energy and entropy of formation of vacancies as calculated by these least-squares fitting methods depends on the Debye temperature.

As mentioned above, the fourth and fifth fits are based on Eq. (69) which uges the Nernst-Lindemamn relation (Eq. (53)) for the dilation term. Since the specific heat data rise Exponentially with temperature as the melting point of tungsten is approached, the Nernst-Lindemann relation gives an approximation to the dilation term which increases very rapidly at high temperatures compared to the power-series approrimation used in the first three fits. The fact that the average error, $\bar{\epsilon}_{\text {RMS }}$ is smaller for these fits than for any of the others suggests that for tungsten the Nernst-Lindemann relation gives a better approximation of the dilation term than a power series expansion which is terminated at the quadratic term.

The sixth and seventh fit are based on Eqs. (76) and (78), respectively, as described above. The sixth fit gave values for the energy and entropy of formation of vacancies which are rery similar to the values obtained from the first and eecond fits. This is to be expected aince the specific heat data were taken at temperatures well above the Debye temperature. The seventh fit had the largest average error. $\bar{\epsilon}$ AMS' Kowever, oince it is a four-parameter fit rather than a five-parameter fit, it is not posalble to compare directly the average error of the seventh fit with the average errors of the other fits. Even 80 , since there are more assumptions imvolved in the seventh fit, one would expect the reaults of this fit to be of questionabie value. Therefore, the values of the energy and entropy of formation of vacancies obtained from the last fit will be discarded from further analyais.

Figure $12(a)$ is a plot of the second fit from Table 9 and Fig. 12(b) is a plot of the last fit from Table 9. The differance between the two fits is plotted in Fig. 12(c). Although this difference is small, it probably is alizhtly larger than the experimental error in the data at low temperatures.

The calculated values of the Debye temperature are ghown in Table 10 along with the values given by Gachneidner ${ }^{68}$ for tungsten. $\theta_{M}$ sad $\theta_{M}^{N}$ are in surprisingly good agreement with the other values considering the weak dopendence of the fits on the Debye temperature. As lusted above, $\theta_{0}$ was not expected to be in agreement with the other values.

In Table 11, the values for the energy and entropy of formation of vacancies and the mole percent of vacancies at the melting point $\left(T_{m p}=3680 \%\right.$ ) are given along with the values obtained by other experimenters. The entires in Table 11 were calculated by averaging the five values obtained from Table 9 after discarding the third and geventh entries. An estimate for the error was taken to be the maximum spread in the five values. 
Table 10. Values for the Debye temperature of tungsten, calculated and taken from Ref. (68).

\begin{tabular}{lllllllllll}
\hline$\theta_{M}$ & $\theta_{M}^{N}$ & $\theta_{0}$ & $\theta_{0}^{S}$ & $\theta_{298}^{S}$ & $\theta^{M}$ & $\theta_{0}^{E}$ & $\theta_{298}^{E}$ & $\theta_{m}^{R}$ & $\theta_{m}^{D}$ & $\theta_{298}^{I}$ \\
\hline 371 & 354 & 803 & 388 & 312 & 291 & 384 & 370 & 359 & 310 & $\ldots$
\end{tabular}

Note: All temperatures are given in degrees Kelvin.

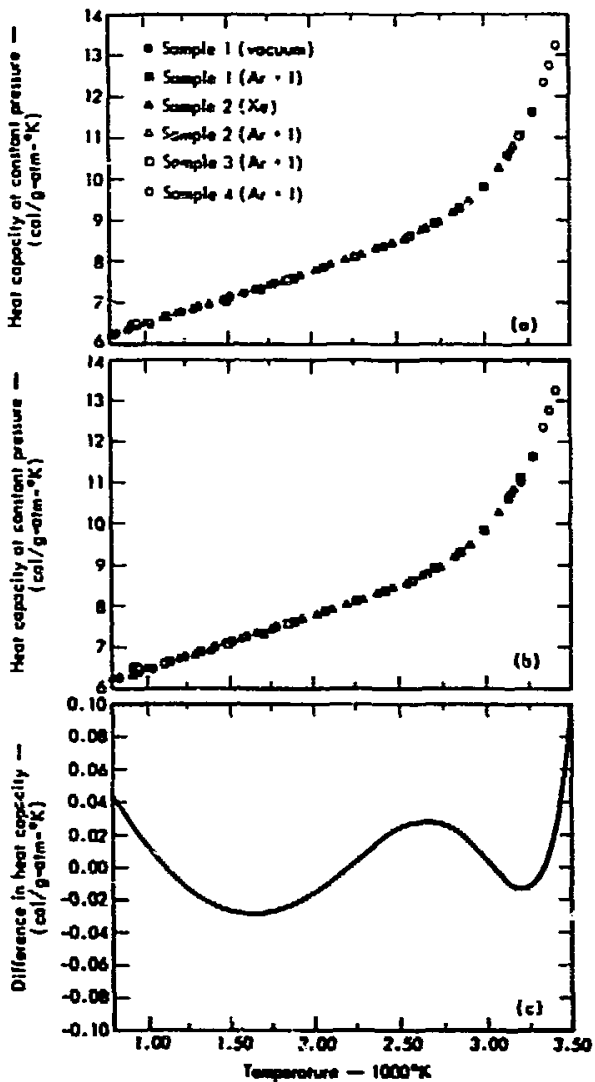

Fig. 12. Heat cepacity of tungoten at constant preasure (a) using the recond fit from Table 9 , (b) using the last fit from Table 8 . (c) Difference between the curves (a) and (b).
Table 11. Comparison of values of $\Delta E_{Y}^{0}$ $\Delta s p / R$, and canp formd in this work and in earlier work.

\begin{tabular}{|c|c|c|c|c|}
\hline Metiod & $A E_{y}^{0}(e V)$ & $a 5_{v}^{0} / R$ & $c_{\operatorname{mp}}(t h)$ & Refereace \\
\hline$=$ & $3.90 \pm 0.30$ & $8.4 \div 1.3$ & $2.1 \pm 0.7$ & Table s \\
\hline$a$ & 3.14 & 6.5 & 3.4 & (19) \\
\hline b & $3.30 \pm 0.1$ & 1.4 & 0.011 & (77) \\
\hline $\mathbf{b}$ & $3.6 \neq 0.2$ & - & - & (78) \\
\hline
\end{tabular}

Spectile heat at hiph temperatures.

bouechise in aupernald ligaid belium it.

Gur values obtained from the leastsquares fitting method are hicher than the other values given in Table 11 lexcept for the value of $\mathrm{cmp}_{\mathrm{mp}}$ which lies between the other two values). Fowever, the other wiues are probably not very rellable. The date from Ref. (19) Buffers from two deficiencies: the specific heat data are of questionahle accuracy, and the linear extrapolation procedure used in fitting the specific heat data (the equivalent of the seventh method used abovel is based on unsupported assumptions. The quenching experiments of Schults 77 and Groshover et al., 78 are very sensitive to small quantities of absorbed oxygen, nitrozon, $\sigma^{-}$carbon in interatitin solid colution. It is posaible that their dinta reflect the solubility of interstitial impurity atoms.

The quistionible accuracy of Kraftmacher and Strellov's data is illustrated in Fig. 13 where data is plotted from various experiments in which the spectfic 


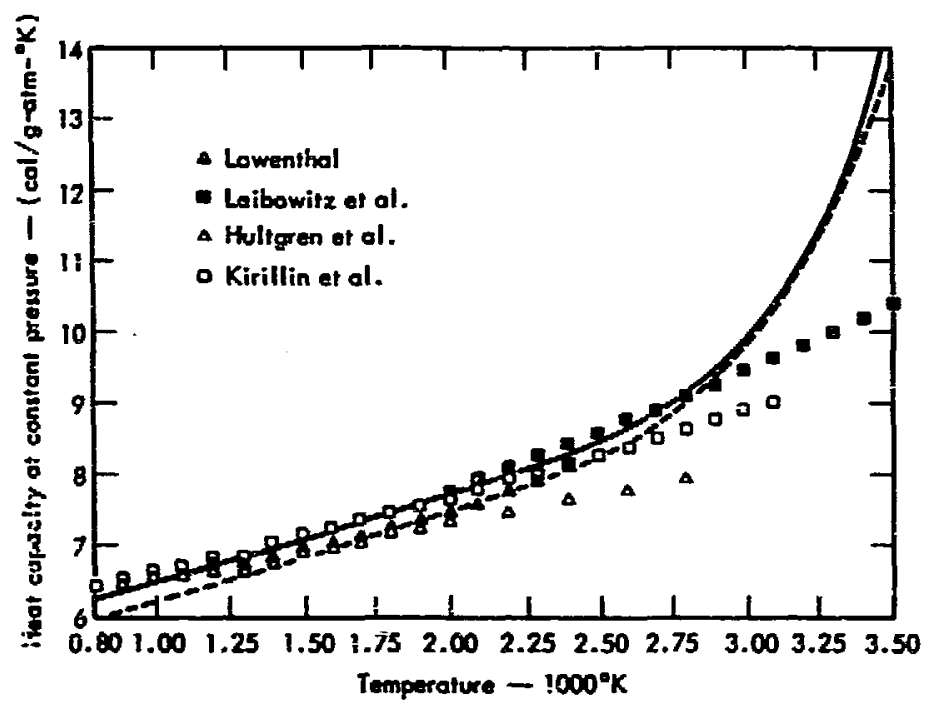

Fig. 13. Heat capacity of rungsten at constant presaure. Solid curve-this work, daskis + curve - Krathmacher and Strelkov.

heat of tungsten was measured. The dashed curve is the data of Kraftmacher and Strelkov. The solid curve corrasponds to the second fit given in Table 8 , that is, the curve from Fiz. 12(b). Data (com Lowenthai, ${ }^{17}$ Leibowits et al., ${ }^{79}$ Hultgren et al,, ${ }^{80}$ and Kirillin et al. ${ }^{3}$ are slou plotted. The data from Fig. 12(b) are in excellent agreenent with the data of Kirillin et al. up to $2000 \mathrm{~K}$. From $2000 \mathrm{~K}$ to $280 \mathrm{cT}$, the data from Fig. 12(b) are in excelleat agreement with the recent calorimetric data of Leibowitz et al. Over this same temperature range (800K to $2800 \%$ ), the data of Kraftmacher and Strelkor are about $4 \%$ low, comparing more favorably with data of Lowenthal and Hultgren et al. At temperatures above $2800 \%$, the contribution of vacancies to the apeciflc heat becomes important and the apecific heat atarts to rise exponentially. This effect is not present in the calorimetric data. This may be due to the fact that the vacancy contribution to the enthalpy is omall compared to the vacancy contribution to the apecific heat. In any event, both sets of data from the ac temperature method increase exponentially above $2800 \mathrm{~K}$ with the data from Fig. 12(b) continuing to be higher than Kraftmacher and Strelkor's data. It appears that there is a systematic error in Kraftmacher and Strelloov's data which resulted in a low value for the specific heat over ae entire temperature range. 
The data in Tabie 9 can be used to gain some understanding of the anharmonic specific heal of tungsten. The second fit which is based upon Eq. (66) can be used to find the specific heat due to the dilation term, $c_{D}$. plus the anharmonic lattice specific heat, $c_{A}$. That is,

$$
c_{D}+c_{A}=\left(d_{0}+a_{0}\right)+\left(d_{1}+a_{1}\right) T+\left(d_{2}+d_{2}\right) T^{2}
$$

from Eqs. (54) and (60). Therefore, uging Eq. (67)

$$
{ }^{c} D_{D}+c_{A}=p_{1}+\left(p_{2}-\gamma\right) T+p_{3} T^{2}
$$

The electronic specific heat constant, $\gamma$, is given by Grchneidner ${ }^{68}\left(\gamma=2.9210^{-4} \mathrm{cal} /\right.$ mole $X \mathrm{deg}^{2}$ ). Using this value and the vaiues for $p_{1}$ through $p_{3}$ given in the second row of Table 9, Eq. (79) becomes

$$
c_{D}+c_{A}=-0.402+0.552 T+0.129 T^{2}
$$

This estimate of the excess specific heat due to the dilation term anc the anharm zniclattice term is the solid curve ahown in Fig. 14. The Nernst-Lindemann approximation of the apecific heat due to the dilation term is the dashed curve shown in Fig. 14. The

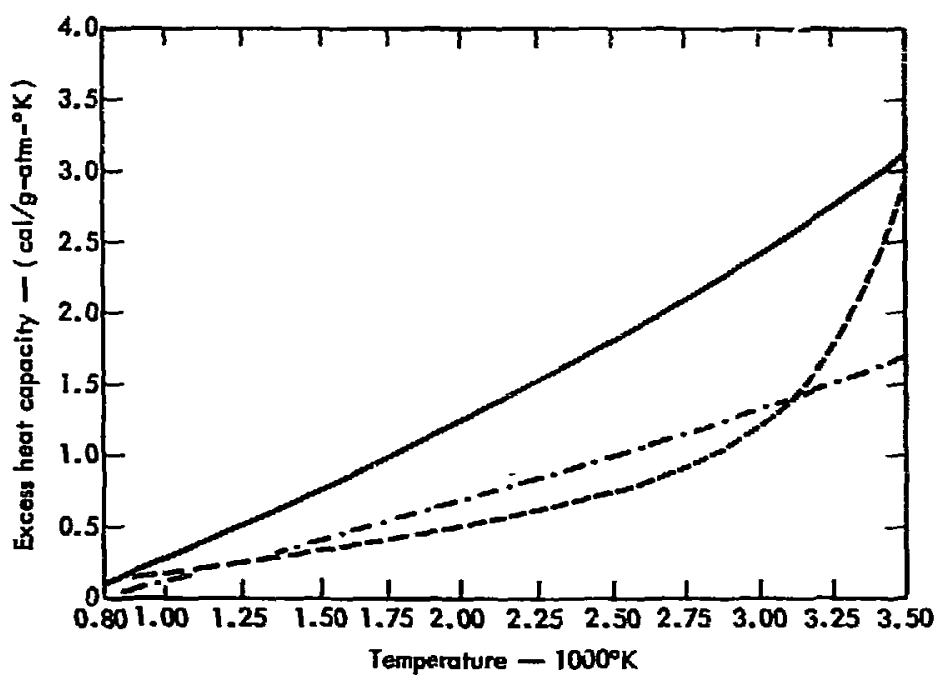

Fig. 14. Anharmonic heat capacity of tungsten. Solid curve: excess heat capacity, Eq. (80); dashed curve: Nerst-Lindemann term; dot-and-dash curve: excess heat capacity, Eq. (82). 
difference between these two curves would be an estimate of the anharmonic-lattice sperific heat. However, a more consistent method for estimating the anharmonic term can be obtained based on Eq. (69).

Using Eqs. (60) and (70).

$$
c_{A}=p_{1}^{\prime}+\left(p_{2}^{\prime}-\gamma\right) r+p_{3}^{t} T^{2}
$$

Then, using the values for $p_{1}^{\prime}$ through $F_{3}^{\prime}$ given ir, the fifth row of Table 9 and the value of the electronic specific heat constant given above,

$$
c_{A}=-0.493+0.56 .9 T+0.0153 T^{2}
$$

This estimate of the excess specific feat due to the anharmonic lattice is the dot-anddash curve plotted in Fig. 14. Equation (64) implies that $c_{A}$ is negative below about $850^{\circ} \mathrm{K}$. While this is possible, it must be remembered that all of the above expansions are valid only in the temperature range in which the data wtre taken ( $800^{\circ} \mathrm{K}$ to $3418^{\circ} \mathrm{K}$ ). Moreover, Eq. (68) is only as good as the Nernst-Lindemann approximation which itself is of unknown accuracy. Therefort, Eq. (8g) can only be regarded as a rough estimate of the anharmonic-lattice specific heat.

It it is assumed that self-Jiffusion in tungsten occurs by a racancy mechaniam. the migration energy for vacancies, $E_{M}$, may be estimater from the enercy of activation for self-dirtusion, $E_{S D}$, and the energy of formation $\Delta E_{V}^{0}$. That is,

$$
\mathbf{E}_{\mathbf{M}}=\mathbf{E}_{\mathbf{S D}}-\Delta \mathbf{E}_{\mathbf{V}}^{0}
$$

The energy of activation for self-diffusion has been measured by Andelin et al. ${ }^{81}$ and by Danneberg. ${ }^{82}$ Andelin et $\mathrm{al}$, obtained a value $\left(E_{\mathrm{SD}}-6.64 \pm 0.26 \mathrm{eV}\right.$, considerably lurger than the value given by Danneberg $\left(E_{\mathrm{SD}}=5.25 \pm 0.2 \mathrm{eV}\right)$. The value given by Dannebeig is thought to be incoryect. ${ }^{81}$ The calculated value of the migration energy for vacancies is given in Table 12. The first row value is calculated from the formation energy calculated fram the least-squares iits. The ssond was calculated using Schultz's ${ }^{77}$ value for the formation energy of vacencies. The third row contains the data given by Gripshover et at. ${ }^{78}$

The value for the migration energy reported by Schultz $^{77}\left(E_{\mathbf{M}}=1.93 \pm 0.3 \mathrm{eV}\right)$ was said to be consistent with the observations of the recovery of cold-worked tungsten. The corrected value for the migration energy based on the sctivation energy found by Andelin $=t$ al, $\left(E_{M}=3.34 \pm 0.36 \mathrm{eV}\right)$ is too large. The values obtalned from the leastsquares fit $\left(E_{M}=2.74 \pm 0.56\right)$ and the quenching experiment of Gripshover et al. ${ }^{78}$ $\left(E_{M}=2.5 \neq 0.5\right)$ ase more reasonable. These values are not much larger than the theorecieal estimate of Johnson $\left(E_{M}=2.0 \mathrm{eV}\right)^{83}$

$$
-14-
$$


Table 12. Migration energy calculated by several methods.

\begin{tabular}{lccc}
\hline $\begin{array}{c}\text { Formation } \\
\text { energy } \\
\Delta \mathrm{E}\end{array}$ & $\begin{array}{c}\text { Activation } \\
\text { energy } \\
\mathrm{E}_{\mathrm{SD}}\end{array}$ & $\begin{array}{c}\text { Migration } \\
\text { energs } \\
\mathbf{E}_{\mathbf{M}}\end{array}$ & Reference \\
\hline $3.90 \pm 0.30$ & $6.64 \pm 0.26$ & $2.74 \pm 0.56$ & This work \\
$3.30 \pm 0.1$ & $6.64 \pm 0.26$ & $3.34 \pm 0.36$ & $(77)$ \\
$3.6 \pm 0.2$ & $6.1 \pm 0.3$ & $2.5 \pm 0.5$ & $(78)$ \\
\hline
\end{tabular}

Note: All energies are given in $\mathrm{eV}$.

\section{Summary and Conclusions}

An accurate method for measuring the high-temperature specific heat of electrical conductors has been presented. This method was based on the fact that an electrical conductor which is heated by the combination of an ac and dc electric current has an impedance at the Irequency of the ac current that is approximately equivalent to the impedance of a resistance ghunted by a small capacitance.

An ac bridge using a phase-gensitive null detector was described which was capable of accurately measurine the impedance of a sample of an electrical conductar for various frequencies of the ac current and different values of the temperature of the sample. After balancing the bridge for geveral different frequencies of the ac current at a constant sample temperature, the bridge-balance equations were used to calculate the heat capacity of the sample at that temperature. This was accomplished through the use of a compater code which determined the values of the unknowns in the bridgebalance equations so that these equations fit the experimental data as accurately as possible in the least-squares aense.

The accuracy of this method was limited only by the accuracy of the measurement of the temperature. In particular, the accuracy of the specific heat data depended on the accuracy of the measurement of the derivative of the resistance of the aample vith respect to the temperature, evaluated at the temperature of the sample, (dR/dT/ T. $^{*}$ That is, the accuracy of the specific hest measurement depended on the accuracy of the measurement of the temperature coefficient of resiatance,

$$
\alpha=\left(1 / R_{0}\right)(\mathrm{dR} / \mathrm{dT})_{\mathbf{T}}
$$

where $R_{0}$ is the resiatance of the sample at zero degrees centigrade.

The temperature coefricient of resistance of tungeten was calculated from literature values of the resistance as a hunction of temperature. Using these valuea, the specific heat of tungsten from $800 \%$ to $3414 \%$ was found to be given by 


$$
\begin{aligned}
c_{p}(T)=5.43+9.50 \times 10^{-4} & \times \mathrm{T}+1.05 \times 10^{-7} \times \mathrm{T}^{2} \\
& +\left(2.92 \times 10^{13} / \mathrm{T}^{2}\right) \times \exp \left(-4.63 \times 10^{4} / \mathrm{T}\right) \mathrm{cal} / \mathrm{mole}-{ }^{\circ} \mathrm{K}
\end{aligned}
$$

with an estimated accuracy of plus or minus $1 \%$ at the low-temperature end to plus or minus $3 \%$ at the high-temperature end. These results were compared with literature values of the specific heat of tungsten and were found to be in good agreement with the most reliable values in the low - to intermediate-temperature range. At high temperature, the values were slightly larger than any of the literature values and considerably larger than the calorimetrie data.

A method of analyzing specific heat data to determine the contribution of lattice risinc-vacancies was presented. The result of this analysis was shown to give reliable values for the energy of formation of vacancies and reasonable values for the entropy and concentration of vacancies. Under certain conditions, the method was also shown to give a reasonable value for the Debye tamperature and an estimate for the anilarmonic-lattice specific heat. In particular, for tungaten the following results were found:

(1) The energy of formation of vacancies, $\Delta \mathbf{E}_{\mathbf{V}}=3.90 \pm 0.30 \mathrm{eV}$,

(2) The entropy of formation of vacancies, $\Delta S_{V} / R=8.4 \pm 1.3$,

(3) The concentration of vacancies at the melting point, $c_{m p}=2.1 \pm 0.7$ mole percent,

(4) The migration energy for vacancies, $\mathbf{E}_{M}=2.74 \pm 0.56 \mathrm{eV}$, and

(5) The anharmonic-lattice specific heat $\left(800^{\circ} \mathrm{K}<\mathrm{T}<3400^{\circ} \mathrm{K}\right), \mathrm{c}_{\mathrm{A}}=-0.48$ $+0.57 \times 10^{-3} \times \mathrm{T}+0.015 \times 10^{-6} \times \mathrm{T}^{2} \mathrm{cal} / \mathrm{mole}-{ }^{\circ} \mathrm{K}$.

The two primary objectives of this work, the development of an accurate method for measuring the bigh-temperature specific heat of metals and an improved technique for obtaining the energy of formation and concentration of vacancies from accurate hightemperature specific heat data, have been met. However, there are several possibilities for additional research:

(1) modification of the experimental equipment to facilitate the simultaneous measurement of the specific heat and the temperature coefficient of resistance;

(2) the extension of the ac temperature technique to electrical insulators (through the use of a thin metallic coating over the surface of the insulator);

(3) study of time-dependent specific heat effects by varying the frequency of the $a=$ current over a wider range than is normally done in measuring time-independem specific heats.

An accurate and fast method of measuring specific heats at high temperatures has been demonstrated. It is hoped that accurate high-temperature specific heat data for many metals and alloys will soon be available. 


\section{Acknowledgments}

The author wishes to express his appreciation to Prof. Richard J. Borg for the encouragement and advice given throughout the course of this work, to Prof. Benjamin Naylor, Dr. Michael Guinan, Dr. Lawrence Himmel, Mr. David Lai, Mr. Aki Kuramoto, Dr. Edmund Hsieh, and Mr. Robert Parker for their invaluable assistance, to the personnel of the Precision Electrical Measurements Laboratory at the Lawrence Radiation Laboratory for electronics support, and to the author's wife for her great patience and understanding. The research was performed under the auspices of the United States Atomic Energy Commission at the Lawrence Radiation Laboratory. Livermore, California, in the Inorganic Materials Division of the Chemistry Department. 


\section{Appendix A:}

\section{Solution of Eq. (11)}

The steady state solution of the differential equation

$$
\left.d \Delta T / d t+\left(M / \bar{C}_{p}\right) \Delta T=\left(2 i_{0} \overline{\bar{R}} / \bar{C}_{p}\right) \sin \omega t\right)-\left(i^{2} \bar{R} / 2 \bar{C}_{p}\right)(\cos \omega t)
$$

can be found using the method of Laplace transforms. Let

$$
\left.\xi=\omega t, \mu=M / \bar{C}_{p^{\prime}} a=\left(2 i_{0} i \bar{R}\right) / \bar{C}_{p^{\prime}}, f=\left(i^{2} \bar{R}\right) / 2 \bar{C}_{p^{\prime}}\right)
$$

Then Eq. (A 1) becomes

$$
\alpha \Delta T / d \zeta=-(\omega / \omega) \Delta T+(\alpha / \omega) \sin \zeta-(\beta / \omega) \cos 2 \zeta
$$

Taking the Laplace transform of Eq. (A2), we find

$$
8 \Delta_{T}-\Delta T(+0)=-(\mu / \omega) \Delta T+(\alpha j \omega)\left(1 / s^{2}+1\right)-(\beta / \omega)\left(s / s^{2}+4\right)
$$

where $\Delta T$ ia the Laplace transform of $\Delta T$. The $\Delta T(+0)$ term correaponds to a transient term in the general solution and may be neglected in the steady state solution. Therefore

$$
\Delta r=(\alpha / \omega)\left[1 /(s+\mu / \omega)\left(s^{2}+1\right)\right]-(\beta / \omega)\left[B /(B+\mu / \omega)\left(B^{2}+4 h\right.\right.
$$

but

$$
\begin{aligned}
{\left[(s+\mu / \omega)\left(a^{2}+1\right)\right]^{-1}=} & {\left.\left[w^{2}\right)\left(\mu^{2}+\omega^{2}\right)(s+\mu / \omega)\right]^{-1} } \\
& +\left(-\left(\omega^{2} s\right) / u^{2}+\omega^{2}\right) \\
& \\
& \left.\left.f(\omega) / u^{2}+\omega^{2}\right)\right]\left[s^{2}+1\right]^{-1}
\end{aligned}
$$

and

$$
\begin{aligned}
& a\left[(s+\mu / \omega)\left(s^{2}+4\right)\right\}^{-1}=-(\omega)\left[\left(\mu^{2}+\omega^{2}\right)(s+\mu / \omega)\right]^{-1} \\
& \left.+((\mu) a) /\left(u^{2}+4\right)^{2}\right) \\
& \left.\left.+\left(4 w^{2}\right) / u^{2}+4 w^{2}\right)\right]\left(s^{2}+4\right)^{-1} \text {. } \\
& -48-
\end{aligned}
$$


Now neglecting the transient terms (the ones which have the factor $(s+\mu / \omega)^{-1}$ ), we have

$$
\begin{aligned}
\Delta T= & {\left[(\alpha) /\left(\mu^{2}+\omega^{2}\right)\right][(\mu-\omega g) /(B+1)] } \\
& -\left[(\beta) /\left(\mu^{2}+4 \omega^{2}\right)\right]\left[(\mu \theta+4 \omega) /\left(s^{2}+4\right)\right] .
\end{aligned}
$$

Therefore takirg the inverse Laplace transform, the solution to Eq. (A2) is

$$
\begin{aligned}
\Delta \mathrm{T}= & {\left.\left[(\alpha) / \mu^{2}+\omega^{2}\right)\right][-\omega \cos \zeta+\mu \sin \zeta] } \\
& -\left[(\beta) /\left(\mu^{2}+4 \omega^{2}\right)\right][\mu \cos 2 \zeta+2 \omega \sin 2 \zeta] .
\end{aligned}
$$

Let $\tan \phi=(\omega / \mu)$ and $\tan \theta=(\mu / 2 \omega)$, then Eq. (A3) becomes

$$
\begin{aligned}
\Delta T= & {\left.\left[(\omega \omega) / \mu^{2}+\omega^{2}\right)\right][\sin (\zeta-\phi) / \sin \phi] } \\
& \left.-\left[(2 \beta \omega) /\left(\mu^{2}+4 \omega^{2}\right)\right](\sin (2 \zeta+\theta) / \cos \theta)\right] .
\end{aligned}
$$

Now

$$
1+\left(\mu^{2} / 4 \omega^{2}\right)=(\cos \theta)^{-2} \text { and } 1+\left(\mu^{2} / \omega^{2}\right)=(\sin \phi)^{-2} \text {, }
$$

so that

$$
\Delta T=(a / \omega)(\sin \phi) \sin (\zeta-\phi)-(\beta / 2 \omega)(\cos \theta)_{\sin }(25+\theta) .
$$

Let

$$
\Delta T_{1}=(a / \omega)(\sin \phi)=\left[\left(2 i_{0} i \bar{R}\right) /\left(\bar{C}_{p}\right)\right] \sin \phi
$$

and

$$
\Delta T_{2}=(\beta / 2 \omega)(\cos \theta)=\left[\left(i^{2} \bar{R}\right) /\left(4 \omega \bar{C}_{p}\right)\right] \cos \theta,
$$

then

$$
\Delta T=\Delta T_{1} B \ln (\omega t-\phi)-\Delta T_{2} \sin (2 \omega t+\theta),
$$

which is Eq. (12). 


\section{Appendix B: \\ Assumptions Used to Derive Eq. (17)}

The effects of heat conduction were neglected in Eq. (1). These effects have been analyzed by Holland and Smith ${ }^{25}$ using the frequency dependent diffusion length,

$$
\lambda=\sqrt[i]{(\kappa / \omega)},
$$

where $\alpha$ is the thermal diffusivity (units: $\mathrm{cm}^{2} / \mathrm{sec}$ ).

They have shown that the effect of heat conduction in the axial direction along the sample is the generation of a damped temperature wave traveling away from the end supports. The wave is sufficiently damped at distances greater than a few diffusicn lengths from the end supports so as to have a negligible effect upon the ac temperature. Therefore, Eq. (1) may be used for samples which are very long compared to the diffusion length.

Holland and Smith ${ }^{25}$ have also shown that the erifect of heat conduction in the radial direction from the center of the sample is the generation of a temperature wave at the gurface which decays as it travels inio the material, shifting its phase relative to the ac temperature given by Eq. (12). The wave has a negligible effect for samples with a radius less than the diffusion length.

Since the diffusion length depends upon the frequency, the errors introduced in using Eq. (1) are frequency-dependent. Therefore, if the specific heat is determined Irom experiments which are analyzed with equations derived from Eq. (1), the specific heat measured will be frequency-dependent if the effects due to heat conduction are not negligible. Conversely, if the measured specific heat is independent of frequency, the use oi Eq. (1) is justified.

The diffusion length for a material may be estimated from Eq. (B1). For example, the thermal diffusivity of tungsten is approximately one (i. e., $0.5<k<1.5$ ) 80 the diffusion length ranges from $0.04 \mathrm{~cm}$ to $0.13 \mathrm{~cm}$ for $\omega=100 \mathrm{~Hz}$ to $10 \mathrm{Ez}$. Therefore, heat conduction effects may be neglected for samples with a diameter (or thickness in the case of a foil) of less than three mils and a length greater than five inches. If samples are made with a larger diameter or a shorter length, the frequency dependence of the measured specific heat should be examined.

The approximate Eqs. (2)-(6) are quite accurate if the amplitude of the ac temperature is less than $10^{\circ} \mathrm{C}$. These equations will be very accurate at high frequencies where the ac temperature is less than $1^{\circ} \mathrm{C}$.

The effects of assuming Eg. (8) to be a valid approximation and neglecting the last two terms on the left-hand side of Eq. (9) can be shown by substituting Eq. (12) into the neglected terms from Eq. (9). That is, letting 


$$
\operatorname{Term}_{1}=2 i_{0} i(d R / d T)_{T} \Delta T(g i n \omega t)
$$

and

$$
\operatorname{Term}_{2}=-\left(i^{2} / 2\right)(d R / d T)_{T} \Delta T(\cos 2 \omega t)
$$

we have

$$
\begin{aligned}
\operatorname{Term}_{1}+\operatorname{Term}_{2}= & i(d R / d T)_{T_{0}}\left[i_{0} \Delta T_{1}(\cos \phi)+(i / 4) \Delta T_{2}(\sin \theta)\right. \\
& +\left(i / 4 \Delta T_{1} \sin (\omega t+\phi)-i_{0} \Delta T_{2} \cos (\omega t+\theta)\right. \\
& -i_{0} \Delta T_{1} \cos (2 \omega t-\phi) \\
& -(i / 4) \Delta T_{1} \sin (3 \omega t-\phi)+i_{0} \Delta T_{2} \cos (3 \omega t+\theta) \\
& \left.+(i / 4) \Delta T_{2} \sin (4 \omega t+\theta)\right]
\end{aligned}
$$

The first two terms in this equation which do not depend upon the time were neglected in Eq. (8). A more accurate equation for the conservation of average power can now be written:

$$
\overline{\mathbf{R}}\left(i_{0}^{2}+\mathrm{i}^{2} / 2\right)+\mathrm{i}(\mathrm{dR} / \mathrm{dT})_{\mathrm{T}}\left[\mathrm{i}_{0} \Delta \mathrm{T}_{1}(\cos \phi)+(\mathrm{i} / 4) \Delta \mathrm{T}_{2}(\sin \theta)\right]=\mathrm{L}
$$

The last terms in Eq. (B2) show that we have neglected high-frequency components in the ac temperature by neglecting Term and Term $_{2}$ in Eq. (9). For applications, the component of the ac temperature at the frequency $\omega$ is most useful. Therefore, a closer examination of the terms in $\omega$ from Eq. (B2) is in order. Let

$$
\left.E(\omega)=i(d R / A T)_{\bar{T}}[C i / 4) \Delta T_{1} \sin (\omega t+\phi)-i_{0} \Delta T_{2} \cos (\omega t+\theta)\right]
$$

Now using Eqs. (13)-(16! with gome trigonometry, we find

$$
\begin{aligned}
E(\omega) & \left.=\left[\left(i_{0} i^{3} \bar{R}\right) /\left(2 \omega \bar{C}_{p}\right)\right][d R / d T)_{\bar{T}}\right] \\
& \times\left\{\left[1 \div\left(M / \omega \bar{C}_{p}\right)^{2}\right]^{-1}\left[\left(M / \omega \bar{C}_{p}\right) \sin (\omega t)+\cos (\omega t)\right]\right. \\
& \left.+\left[1+\left(M / 2 \omega \bar{C}_{p}\right)^{2}\right]^{-1}\left[\left(M / 4 \omega \bar{C}_{p}\right) \sin (\omega t)-\cos (\omega t)\right]\right\}
\end{aligned}
$$


Now at sufficiently high frequencies

$$
\left[1+\left(M / \omega \bar{C}_{p}\right)^{2}\right]^{-1}=\left[1+\left(M / 2 \omega \bar{C}_{p}\right)^{2}\right]^{-1}=1
$$

so that

$$
E(\omega)=\left[\left(5 i_{0} i^{3} M \bar{R}\right) /\left(8 \omega^{2} \bar{C}_{p}^{2}\right)\right]\left[(d R / d T)_{\bar{T}}\right][\sin (\omega t)]
$$

Therefore, $E(\omega)$ is proportional to $\omega^{-2}$ where as the terms included in Eq. (9) are proportional to $\omega^{0}$ and $\omega^{-1}$, and Eq. $(10)$ is an accurate approximation at sufficiently high frequencies. 


\section{Appendix C:}

\section{Supplementary Data}

Sample No. 1a $\left(\mathrm{Ar}+\mathrm{I}_{2}\right)$

\begin{tabular}{|c|c|c|c|c|c|}
\hline $\begin{array}{c}\overline{\mathrm{T}} \\
\left({ }^{\circ} \mathrm{K}\right)\end{array}$ & 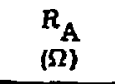 & $\begin{array}{l}\omega / 2 \pi \\
(\mathrm{Hz})\end{array}$ & $\begin{array}{c}R_{A} C_{A} \\
(\Omega-\mu F)\end{array}$ & $\begin{array}{r}i_{0} \\
\text { (A) }\end{array}$ & $\stackrel{i}{i}$ \\
\hline \multirow[t]{9}{*}{726} & 75.00 & 20.000 & 13.251 & 1.268 & 0.091 \\
\hline & & 25.000 & 9.269 & 1.268 & 0.090 \\
\hline & & 35.002 & 5.781 & 1.269 & 0.090 \\
\hline & & 45.000 & 4.334 & 1.268 & 0.090 \\
\hline & & 54.990 & 3.591 & 1.268 & 0.090 \\
\hline & & 65.003 & 3.164 & 1.269 & 0.090 \\
\hline & & 74.996 & 2.901 & 1.269 & 0.090 \\
\hline & & 84.998 & 2.721 & 1.269 & 0.090 \\
\hline & & 95.021 & 2.591 & 1.269 & 0.090 \\
\hline \multirow[t]{9}{*}{934} & 100.00 & 20.001 & 18.008 & 1.489 & 0.090 \\
\hline & & 24.995 & 12.298 & 1.489 & 0.090 \\
\hline & & 35.003 & 7.308 & 1.488 & 0.090 \\
\hline & & 45.002 & 5.208 & 2.489 & 0.090 \\
\hline & & 54.993 & 4.138 & 1.488 & 0.090 \\
\hline & & 64.998 & 3.638 & 1.489 & 0.090 \\
\hline & & 75.013 & 3.268 & 1.488 & 0.090 \\
\hline & & 84.898 & 2.968 & 1.489 & 0.090 \\
\hline & & 95.021 & 2.785 & 1.485 & 5.080 \\
\hline \multirow[t]{9}{*}{935} & 100.00 & 20.000 & 18.008 & 1.488 & 0.090 \\
\hline & & 25.001 & 12.298 & 1.488 & 0.090 \\
\hline & & 35.001 & 7.308 & 1.487 & 0.090 \\
\hline & & 45.002 & 5.258 & 1.487 & 0.090 \\
\hline & & 55.012 & 4.197 & 1.487 & 0.090 \\
\hline & & 64.990 & 3.618 & 1.488 & 0.090 \\
\hline & & 75.013 & 3.232 & 1.489 & 0.090 \\
\hline & & 85.012 & 2.975 & 1.488 & 0.090 \\
\hline & & 95.012 & 2.793 & 1.487 & 0.090 \\
\hline \multirow[t]{6}{*}{1134} & 125.00 & 20.000 & 24.010 & 1.739 & 0.100 \\
\hline & & 24.998 & 16.160 & 1.740 & 0.100 \\
\hline & & 35.001 & 9.310 & 1.738 & 0.100 \\
\hline & & 45.002 & 6.473 & 1.739 & 0.100 \\
\hline & & 55.006 & 5.010 & 1.738 & 0.100 \\
\hline & & 64.994 & 1.198 & 1.738 & 0.100 \\
\hline
\end{tabular}


Sample No. 1 a $\left(A r+I_{2}\right)($ Continued)

\begin{tabular}{|c|c|c|c|c|c|}
\hline$\underset{\left({ }^{2} \mathrm{~K}\right)}{\bar{T}}$ & $\begin{array}{l}\mathbf{R}_{A} \\
(\Omega)\end{array}$ & $\begin{array}{l}\omega / 2 \pi \\
(H z)\end{array}$ & $\underset{(\Omega-\mu F)}{\mathbf{A}_{\mathbf{A}} \mathrm{C}_{\mathbf{A}}}$ & $\begin{array}{c}i_{0} \\
\text { (A) }\end{array}$ & $\begin{array}{c}i \\
\text { (rms A) }\end{array}$ \\
\hline & & 75.008 & 3.664 & 1.739 & 0.100 \\
\hline & & 85.005 & 3.313 & 1.738 & 0.100 \\
\hline & & 95.012 & 3.063 & 1.738 & 0.100 \\
\hline \multirow[t]{9}{*}{1325} & 150.00 & 20.000 & 31.977 & 2.033 & 0.100 \\
\hline & & 24.999 & 21.240 & 2.032 & 0.100 \\
\hline & & 35.003 & 11.879 & 2.032 & 0.100 \\
\hline & & 45.002 & 8.025 & 2.032 & 0.100 \\
\hline & & 54.956 & 6.053 & 2.032 & 0.100 \\
\hline & & 65.003 & 4.926 & 2.032 & 0.100 \\
\hline & & 75.002 & 4.220 & 2.033 & 0.100 \\
\hline & & 84.983 & 3.740 & 2.032 & 0.100 \\
\hline & & 95.003 & 3.402 & 2.031 & 0.100 \\
\hline \multirow[t]{9}{*}{1513} & 175.00 & 19.999 & 42.277 & 2.367 & 0.110 \\
\hline & & 25.000 & 27.874 & 2.367 & 0.110 \\
\hline & & 35.003 & 15.248 & 2.368 & 0.110 \\
\hline & & 45.000 & 10.068 & 2.368 & 0.110 \\
\hline & & 54.999 & 7.410 & 2.368 & 0.110 \\
\hline & & 64.994 & 5.896 & 2.367 & 0.110 \\
\hline & & 75.008 & 4.935 & 2.366 & 0.110 \\
\hline & & 85.005 & 4.295 & 2.365 & 0.110 \\
\hline & & 94.994 & 3.824 & $\mathbf{z . 3 6 5}$ & 0.110 \\
\hline \multirow[t]{9}{*}{1699} & 200.00 & 20.002 & 55.416 & 2.740 & 0.140 \\
\hline & & 25.004 & 36.416 & 2.739 & 0.140 \\
\hline & & 35.005 & 19.498 & 2.740 & 0.140 \\
\hline & & 45.009 & 12.606 & 2.739 & 0.140 \\
\hline & & 54.999 & 8.116 & 2.759 & 0.140 \\
\hline & & 65.007 & 7.098 & 2.739 & 0.140 \\
\hline & & 75.008 & 5.838 & 2.738 & 0.140 \\
\hline & & 85.005 & 4.982 & 2.736 & 0.140 \\
\hline & & 95.021 & 4.386 & 2.734 & 0.140 \\
\hline \multirow[t]{8}{*}{1885} & 225.00 & 20.002 & 71.566 & 3.145 & 0.150 \\
\hline & & 24.999 & 46.595 & 3.145 & 0.150 \\
\hline & & 35.001 & 24.853 & $3 . i 4 i$ & 0.150 \\
\hline & & 44.998 & 15.788 & 3.145 & 0.150 \\
\hline & & 54.993 & 11.246 & 3.145 & 0.150 \\
\hline & & 64.986 & 8.613 & $3 . i 45$ & 0.150 \\
\hline & & 75.002 & 6.966 & 3.145 & 0.150 \\
\hline & & 84.998 & 5.852 & 3.145 & 0.150 \\
\hline
\end{tabular}


Sample No. 1 a $\left(\mathrm{Ar}+\mathrm{I}_{2}\right)($ Continued $)$

\begin{tabular}{|c|c|c|c|c|c|}
\hline $\begin{array}{c}\overline{\mathrm{T}} \\
(\mathrm{\sigma} \mathrm{K})\end{array}$ & $\begin{array}{l}R_{A} \\
(\Omega)\end{array}$ & $\begin{array}{l}\omega / 2 \pi \\
(\mathrm{Hz})\end{array}$ & $\underset{(\Omega-\mu \mathrm{F})}{\mathrm{R}_{\mathrm{A}} \mathrm{C}_{\mathrm{A}}}$ & $\begin{array}{c}i_{0} \\
(A)\end{array}$ & $\stackrel{i}{(\operatorname{mms} A)}$ \\
\hline & & 95.012 & 5.083 & 3.145 & 0.150 \\
\hline \multirow[t]{9}{*}{2068} & 250.00 & 20.000 & 90.770 & 3.577 & 0.150 \\
\hline & & 25.000 & 58.853 & 3.578 & 0.150 \\
\hline & & 34.998 & 31.080 & 3.578 & 0.150 \\
\hline & & 45.005 & 19.583 & 3.578 & 0.150 \\
\hline & & 54.993 & 13.788 & 3.577 & 0.150 \\
\hline & & 64.994 & 10.420 & 3.578 & 0.150 \\
\hline & & 74.991 & 8.320 & 3.577 & 0.150 \\
\hline & & 85.005 & 6.208 & 3.577 & 0.150 \\
\hline & & 95.003 & 5.913 & 3.575 & 0.150 \\
\hline \multirow[t]{9}{*}{2063} & 250.00 & 20.001 & 88.470 & 3.526 & 0.500 \\
\hline & & 25.002 & 57.370 & 3.526 & 0.500 \\
\hline & & 35.002 & 30.320 & 3.526 & 0.500 \\
\hline & & 45.002 & 19.133 & 3.526 & 0.500 \\
\hline & & 54.996 & 13.503 & 3.526 & 0.500 \\
\hline & & 64.990 & 10.213 & 3.527 & 0.500 \\
\hline & & 75.002 & 8.165 & 3.525 & 0.500 \\
\hline & & 84.998 & 6.800 & 3.526 & 0.500 \\
\hline & & 94.985 & 5.835 & 3.525 & 0.500 \\
\hline \multirow[t]{7}{*}{2063} & 250.00 & 24.999 & 54.520 & 3.420 & 1.000 \\
\hline & & 35.001 & 28.870 & 3.421 & 1.000 \\
\hline & & 45.002 & 18.250 & 3.420 & 1.000 \\
\hline & & 55.002 & 12.900 & 3.419 & 1.000 \\
\hline & & 64.986 & 9.808 & 3.420 & 1.000 \\
\hline & & 75.002 & 7.853 & 3.420 & 1.000 \\
\hline & & 84.998 & 6.568 & 3.420 & 0.999 \\
\hline & & 95.012 & 5.643 & 3.419 & 1.000 \\
\hline \multirow[t]{9}{*}{21} & 275.00 & 20.000 & 113.040 & 4.028 & 0.139 \\
\hline & & 24.999 & 73.205 & 4.028 & 0.200 \\
\hline & & 34.999 & 38.401 & 4.029 & 0.200 \\
\hline & & 45.002 & 23.997 & 4.025 & 0.200 \\
\hline & & 54.999 & 16.737 & 4.030 & 0.200 \\
\hline & & 64.998 & 12.515 & 4.030 & 0.200 \\
\hline & & 75.002 & 9.884 & 4.029 & 0.200 \\
\hline & & k. .20 & 8.121 & 4.028 & 0.200 \\
\hline & & 94.985 & 6.886 & 4.027 & 0.200 \\
\hline \multirow[t]{2}{*}{2419} & 300.00 & 20.000 & 136.100 & 4.461 & 0.220 \\
\hline & & 25.000 & 88.014 & 4.463 & 0.220 \\
\hline
\end{tabular}


Sample No. 1a (Ar $\left.+I_{2}\right)$ (Contimed)

\begin{tabular}{|c|c|c|c|c|c|}
\hline $\begin{array}{c}\bar{T} \\
\left({ }^{\circ} \mathrm{K}\right)\end{array}$ & $\begin{array}{l}R_{A} \\
(\Omega)\end{array}$ & $\begin{array}{l}\omega / 2 \pi \\
(\mathrm{Hz})\end{array}$ & $\begin{array}{c}\mathbb{R}_{A} C_{A} \\
(\Omega-\mu F)\end{array}$ & $\begin{array}{l}\mathrm{i}_{0} \\
\text { (A) }\end{array}$ & $\begin{array}{c}i \\
\text { (rms A) }\end{array}$ \\
\hline & & 35.002 & 45.984 & 4.464 & 0.221 \\
\hline & & 44.998 & 28.578 & 4.464 & 0.220 \\
\hline & & 54.992 & 15.794 & 4.464 & 0.220 \\
\hline & & 65.007 & 14.706 & 4.465 & 0.220 \\
\hline & & 75.002 & 11.532 & 4.465 & $0.2: 0$ \\
\hline & & 85.012 & 9.405 & 4.465 & 0.220 \\
\hline & & 95.021 & 7.911 & 4.465 & 0.220 \\
\hline \multirow[t]{9}{*}{2562} & 320.00 & 19.999 & 156.830 & 4.838 & 0.240 \\
\hline & & 24.999 & 101.350 & 4.849 & 0.240 \\
\hline & & 35.001 & 52.790 & 4.848 & 0.240 \\
\hline & & 45.002 & 32.739 & 4.843 & 0.240 \\
\hline & & 54.999 & 22.528 & 4.843 & 0.240 \\
\hline & & 64.998 & 16.698 & 4.843 & 0.240 \\
\hline & & 74.991 & 12.992 & 4.844 & 0.240 \\
\hline & & 84.991 & 10.538 & 4.843 & 0.240 \\
\hline & & 95.030 & 8.810 & 4.843 & 0.240 \\
\hline \multirow[t]{9}{*}{2847} & 360.00 & 20.000 & 198.680 & 5.619 & 0.280 \\
\hline & & 25.001 & 128.310 & 5.624 & 0.280 \\
\hline & & 34.996 & 66.665 & 5.627 & 0.280 \\
\hline & & 45.002 & 41.105 & 5.629 & 0.280 \\
\hline & & 55.002 & 28.127 & $5.6 \mathrm{2}^{\mathrm{J}} \mathrm{J}$ & 0.280 \\
\hline & & 65.003 & 20.678 & 5.630 & 0.280 \\
\hline & & 75.008 & 15.980 & 5.630 & 0.280 \\
\hline & & 84.969 & 12.863 & 5.631 & 0.280 \\
\hline & & 95.012 & 10.652 & 5.630 & 0.280 \\
\hline \multirow[t]{9}{*}{2990} & 380.00 & 20.000 & 218.350 & 6.032 & 0.300 \\
\hline & & 25.000 & 141.010 & 6.037 & 0.300 \\
\hline & & 34.999 & 73.101 & 6.040 & $0.3 c 0$ \\
\hline & & 45,007 & 44.988 & 6.042 & 0.300 \\
\hline & & 54.999 & 30.750 & 6.044 & 0.300 \\
\hline & & 64.998 & 22.557 & 6.045 & 0.300 \\
\hline & & 75.008 & 17.366 & 6.045 & 0.300 \\
\hline & & 85.005 & 13.931 & 6.046 & 0.300 \\
\hline & & 95.012 & 11.518 & 6.044 & 0.300 \\
\hline \multirow[t]{4}{*}{3134} & 400.00 & 20.001 & 235.720 & 6.465 & 0.320 \\
\hline & & 25,000 & 152.190 & 6.471 & 0.320 \\
\hline & & 35.002 & 78.760 & 6.477 & 0.320 \\
\hline & & 45.000 & 48.464 & 6.479 & 0,320 \\
\hline
\end{tabular}


Sample No. $1 \mathrm{a}\left(\mathrm{Ar}+\mathrm{I}_{2}\right)($ Continued)

\begin{tabular}{|c|c|c|c|c|c|}
\hline$\underset{(\circ \mathrm{K})}{\bar{T}}$ & $\begin{array}{l}R_{A} \\
(\Omega)\end{array}$ & $\begin{array}{l}\varphi / 2 \pi \\
(\mathrm{Hz})\end{array}$ & $\underset{\left(\Omega-\mu F^{\prime}\right)}{R_{A} C_{A}}$ & $\begin{array}{c}\mathbf{i}_{0} \\
(\mathrm{f})\end{array}$ & $\stackrel{i}{\text { (rms A })}$ \\
\hline & & 54.993 & 33.040 & 6.482 & 0.321 \\
\hline & & 64.986 & 24.200 & 6.483 & 0.320 \\
\hline & & 75.019 & 18.584 & $6.48 ?$ & E.320 \\
\hline & & 85.020 & 14.868 & 6.481 & 0.320 \\
\hline & & 95.012 & 12.264 & 6.481 & 0.320 \\
\hline \multirow[t]{9}{*}{3134} & 800.00 & 20.000 & 235.670 & 6.469 & 0.321 \\
\hline & & 25.000 & 151.930 & 6.475 & 0.320 \\
\hline & & 34.878 & 79.016 & 6.480 & 0.320 \\
\hline & & 45.000 & 48.160 & 6.483 & 0.320 \\
\hline & & 54.999 & 32.696 & 6.482 & 0.320 \\
\hline & & 64.998 & 23.864 & 6.484 & 0.320 \\
\hline & & 75.002 & 18.296 & 6.485 & 0.320 \\
\hline & & 85.005 & 14.616 & 6.486 & 0.320 \\
\hline & & 95.021 & 12.008 & 6.485 & 0.320 \\
\hline \multirow[t]{9}{*}{3206} & 820.00 & 19.992 & 243.770 & 6.701 & 0.300 \\
\hline & & 25.005 & 156.891 & 6.707 & 0.300 \\
\hline & & 35.005 & 80.942 & 6.712 & 0.300 \\
\hline & & 45.007 & 49.626 & 6.714 & 0.300 \\
\hline & & 54.981 & 33.710 & 6.716 & 0.300 \\
\hline & & 65.007 & 24.543 & 6.714 & 0.300 \\
\hline & & 75.019 & 18.819 & 6.717 & 0.300 \\
\hline & & 85.027 & 14.998 & 6.714 & 0.300 \\
\hline & & 95.012 & 12.308 & 6.714 & 0.300 \\
\hline \multirow[t]{9}{*}{3279} & 840.00 & 19.996 & 249.421 & 6.935 & 0.330 \\
\hline & & 25.001 & 160.835 & 6.941 & 0.330 \\
\hline & & 35.012 & 82.807 & 6.950 & 0.330 \\
\hline & & 44.994 & 50.887 & 6.954 & 0.330 \\
\hline & & 54.972 & 34.524 & 6.958 & 0.330 \\
\hline & & 64.994 & 25.108 & 6.959 & 0.331 \\
\hline & & 74.996 & 19.253 & 6.960 & 0.330 \\
\hline & & 84.969 & 15.355 & 6.960 & 0.330 \\
\hline & & 94.967 & 12.542 & 6.956 & 0.330 \\
\hline
\end{tabular}

Sample Nc. 1b (Vacuum)

831

88.00

19.999
24.999
35.002
45.002

6.220

4.761

3.483

2.952

.750

0.101

.750

0.100

.750

0.101

.750

0.100 
S:.mple No. 1b (Vacuum)(Continued)

\begin{tabular}{|c|c|c|c|c|c|}
\hline$\underset{(\widetilde{K})}{\vec{T}}$ & $\begin{array}{l}R_{A} \\
(\Omega)\end{array}$ & $\begin{array}{l}\omega / 2 \pi \\
(\mathrm{H} z)\end{array}$ & $\begin{array}{c}R_{A} C_{A} \\
(\Omega-\mu F)\end{array}$ & $\begin{array}{c}i_{0} \\
(A)\end{array}$ & $\begin{array}{c}\text { i } \\
\text { (rms A) }\end{array}$ \\
\hline & & 55.002 & 2.683 & .750 & 0.100 \\
\hline & & 65.007 & 2.530 & .750 & 0.100 \\
\hline & & 75.008 & 2.430 & .750 & 0.100 \\
\hline & & 85.005 & 2.360 & .750 & 0.100 \\
\hline & & 95.021 & 2.313 & .750 & 0.100 \\
\hline \multirow{9}{*}{1032} & 113.00 & 19.998 & 9.942 & $1.03 ?$ & 0.100 \\
\hline & & 24.999 & 7.134 & 1.032 & 0.100 \\
\hline & & 35.001 & 4.687 & i.031 & 0.100 \\
\hline & & 45.000 & 3.682 & 1.032 & 0.100 \\
\hline & & 54.999 & 3.162 & 1.031 & 0.100 \\
\hline & & 64.994 & 2.868 & 1.032 & 0.100 \\
\hline & & 74.991 & 2.626 & 1.032 & 0.100 \\
\hline & & 85.005 & 2.550 & 1.032 & 6.100 \\
\hline & & 95.012 & 2.459 & 1.031 & 0.100 \\
\hline \multirow[t]{9}{*}{1226} & 138.00 & 19.999 & 15.536 & 1.350 & 0.100 \\
\hline & & 24.998 & 10.710 & 1.350 & 0.100 \\
\hline & & 34.999 & 6.511 & 1.350 & 0.100 \\
\hline & & 44.998 & 4.780 & 1.351 & 0.100 \\
\hline & & 54.996 & 3.900 & 1.351 & 0.100 \\
\hline & & 65.02B & 3.396 & 1.351 & 0.100 \\
\hline & & 75.002 & 3.075 & 1.351 & 0.100 \\
\hline & & 84.998 & 2.857 & 1.351 & 0.100 \\
\hline & & 95.003 & 2.710 & 1.351 & $0.10 n$ \\
\hline \multirow[t]{9}{*}{1413} & 163.00 & 20.000 & 23.192 & 1.698 & 0.110 \\
\hline & & 25.001 & 15.611 & 1.698 & 0.110 \\
\hline & & 34.996 & 9.011 & 1.699 & 0.110 \\
\hline & & 45.000 & 6.276 & 1.699 & 0.110 \\
\hline & & 54.999 & 4.901 & 1.698 & 0.110 \\
\hline & & 64.994 & 4.103 & 1.699 & 0.110 \\
\hline & & 74.996 & 3.599 & 1.699 & 0.110 \\
\hline & & 84.991 & 3.271 & 1.699 & 0.110 \\
\hline & & 95.003 & 3.035 & 1.700 & 0.110 \\
\hline \multirow[t]{6}{*}{1597} & 188.00 & 20.000 & 33.366 & 2.080 & 0.130 \\
\hline & & 24.998 & 22.135 & 2.080 & 0.130 \\
\hline & & 34.996 & 12.348 & 2.081 & 0.130 \\
\hline & & 45.000 & 8.278 & $-\mathbf{2 . 0 8 1}$ & 0.130 \\
\hline & & 54.984 & 6.238 & 2.082 & 0.130 \\
\hline & & 64.994 & 5.052 & 2.082 & 0.130 \\
\hline
\end{tabular}


Sample No. 1b (Vacuum)(Contimed)

\begin{tabular}{|c|c|c|c|c|c|}
\hline$\underset{\left({ }^{\circ} \mathrm{K}\right)}{\bar{T})}$ & $\begin{array}{l}\mathbf{R}_{A} \\
(\Omega)\end{array}$ & $\begin{array}{l}w / 2 x \\
(f x)\end{array}$ & $\begin{array}{c}R_{A} C_{A} \\
(\Omega-\mu F)\end{array}$ & $\begin{array}{r}\mathbf{i}_{0} \\
\text { (A) }\end{array}$ & $\frac{i}{(\operatorname{ras} A)}$ \\
\hline & \multirow{12}{*}{213.00} & 75.002 & 4.311 & 2.082 & 0.130 \\
\hline & & 84.998 & 3.816 & 2.081 & 0.130 \\
\hline & & 95.012 & 3.470 & 2.082 & 0.130 \\
\hline \multirow[t]{9}{*}{1779} & & 20.001 & 46.004 & 2.480 & 0.140 \\
\hline & & 25.000 & 30.242 & 2.482 & 0.140 \\
\hline & & 35.005 & 16.461 & 2.432 & 0.140 \\
\hline & & 45.000 & 10.786 & 2.483 & 0.140 \\
\hline & & 55.002 & 7.898 & 2.484 & 0.140 \\
\hline & & 65.020 & 6.230 & 2.485 & 0.140 \\
\hline & & 74.996 & 5.189 & 2.485 & 0.140 \\
\hline & & 84.983 & 4.490 & 2.486 & 0.140 \\
\hline & & 94.994 & 4.011 & 2.488 & 0.140 \\
\hline
\end{tabular}

Sample No. $2 a\left(A r+I_{2}\right)$

$\begin{array}{crrrr}922 & 19.999 & 20.018 & 1.598 & 0.100 \\ & 24.997 & 13.618 & 1.597 & 0.100 \\ & 35.002 & 7.988 & 1.597 & 0.100 \\ & 45.005 & 5.668 & 1.597 & 0.100 \\ & 55.009 & 4.488 & 1.598 & 0.100 \\ & 64.986 & 3.808 & 1.597 & 0.100 \\ & 75.008 & 3.380 & 1.598 & 0.100 \\ & 94.998 & 3.095 & 1.599 & 0.100 \\ & 95.002 & 2.893 & 1.601 & 3.130 \\ & 20.003 & 243.600 & 6.698 & 0.319 \\ & 25.000 & 157.180 & 6.707 & 0.320 \\ & 35.009 & 81.082 & 6.711 & 0.320 \\ & 45.009 & 49.766 & 6.714 & 0.319 \\ & 54.996 & 33.800 & 6.715 & 0.320 \\ & 64.990 & 24.649 & 6.715 & 0.320 \\ & 75.008 & 18.876 & 6.714 & 0.320 \\ & 84.991 & 15.063 & 6.715 & 0.320 \\ & 94.094 & 12.386 & 6.719 & 0.320 \\ & 95.084 & 12.349 & 6.715 & 0.320\end{array}$


Sample No. 2b (Xenon)

\begin{tabular}{|c|c|c|c|c|c|}
\hline$\underset{(0 k)}{\bar{T}}$ & $\begin{array}{l}R_{A} \\
(\Omega)\end{array}$ & $\begin{array}{l}\omega / 2 \pi \\
(H z)\end{array}$ & $\underset{\left(\Omega-\mu \mathbf{F}^{*}\right.}{\mathbf{R}_{\mathrm{A}} \mathbf{C}_{\mathrm{A}}}$ & $\begin{array}{l}i_{0} \\
\text { (A) }\end{array}$ & $\begin{array}{c}i \\
\text { (rms A) }\end{array}$ \\
\hline \multirow[t]{9}{*}{815} & 87.50 & 20.000 & 8.250 & .934 & 0.112 \\
\hline & & 25.001 & 6.071 & .931 & 0.112 \\
\hline & & 35.001 & 4.146 & .935 & 0.112 \\
\hline & & 45.002 & 3.358 & .927 & 0.112 \\
\hline & & 55.002 & 2.947 & .928 & 0.112 \\
\hline & & 65.028 & 2.720 & .938 & 0.112 \\
\hline & & 75.008 & 2.571 & .928 & 0.112 \\
\hline & & 84.976 & 2.472 & .929 & 0.112 \\
\hline & & 95.003 & 2.396 & .928 & 0.112 \\
\hline \multirow[t]{9}{*}{917} & 100.00 & 19.999 & 10.078 & 1.053 & 0.120 \\
\hline & & 25.000 & 7.218 & 1.053 & 0.120 \\
\hline & & 35.003 & 4.733 & 1.053 & 0.120 \\
\hline & & 44.992 & 3.708 & 1.053 & 0.120 \\
\hline & & 55.002 & 3.178 & 1.053 & 0.120 \\
\hline & & 65.028 & 2.874 & 1.053 & 0.120 \\
\hline & & 75.002 & 2.684 & 1.053 & 0.130 \\
\hline & & 85.027 & 2.556 & 1.053 & 0,120 \\
\hline & & 95.003 & 2.464 & 1.054 & 0.120 \\
\hline \multirow[t]{9}{*}{1016} & 112.50 & 20.000 & 12.373 & 1.185 & 0.120 \\
\hline & & 25.004 & 8.67' & 1.188 & 0.120 \\
\hline & & 34.998 & 5.477 & 1.189 & 0.120 \\
\hline & & 44.998 & 4.163 & 1.189 & 0.120 \\
\hline & & 55.002 & 3.485 & 1.189 & 0.130 \\
\hline & & 65.003 & 3.102 & 1.189 & 0.120 \\
\hline & & 74.996 & 2.853 & 1.189 & 0.220 \\
\hline & & 84.969 & 2.687 & 1.189 & 0.120 \\
\hline & & 94.984 & 2.566 & 1.189 & 0.120 \\
\hline \multirow[t]{9}{*}{1112} & 125.00 & 20.002 & 15.073 & 1.336 & 0.120 \\
\hline & & 25,003 & $10.4 \pm 0$ & 1.336 & 0.120 \\
\hline & & 34.998 & 6.364 & 1.336 & 0.120 \\
\hline & & 45.007 & 4.691 & 1.336 & 0.120 \\
\hline & & 55.006 & 3.848 & 1.336 & 0.120 \\
\hline & & 55.011 & 3.356 & 1.336 & 0.120 \\
\hline & & 74.996 & 3,046 & 1.336 & 0.120 \\
\hline & & 85.012 & 2.839 & 1.336 & 0.120 \\
\hline & & 94.994 & 2.691 & 1.335 & 0.120 \\
\hline \multirow[t]{2}{*}{1207} & 137.50 & 19.999 & 18.285 & 1.492 & 0.120 \\
\hline & & 25.001 & 12.460 & 1.491 & 0.120 \\
\hline
\end{tabular}


Sample No. 2b (Xenon.. _untirued)

\begin{tabular}{|c|c|c|c|c|c|}
\hline $\begin{array}{c}\bar{T} \\
\left({ }^{\circ} \mathrm{K}\right)\end{array}$ & $\begin{array}{l}R_{A} \\
(\Omega)\end{array}$ & $\begin{array}{l}\omega / 2 \pi \\
(\mathrm{Hz})\end{array}$ & $\begin{array}{r}R_{A} C_{A} \\
(\Omega-\mu F) \\
\end{array}$ & $\begin{array}{r}i_{0} \\
(A) \\
\end{array}$ & $\begin{array}{c}\mathrm{i} \\
\text { (rms A) }\end{array}$ \\
\hline & & 34.997 & 7.415 & 1.491 & 0.120 \\
\hline & & 44.994 & 5.323 & 1.492 & 0.120 \\
\hline & & 55.002 & 4.265 & 1.942 & 0.120 \\
\hline & & 64.990 & 3.663 & 1.492 & $0.12 G$ \\
\hline & & 75.002 & 3.273 & 1.492 & 0.120 \\
\hline & & 35.005 & $\therefore-14$ & 1.492 & 0.120 \\
\hline & & 94.991 & 2.830 & 1.492 & 0.120 \\
\hline \multirow[t]{9}{*}{1299} & 150.00 & 19.397 & 21.935 & 1.654 & 0.150 \\
\hline & & 25.043 & 14.817 & 1.655 & 0.150 \\
\hline & & 35.002 & 8.622 & 1.655 & 0.150 \\
\hline & & 45.002 & 6.0313 & 1.654 & 0.150 \\
\hline & & 55.006 & 4.740 & 1.654 & 0.150 \\
\hline & & 65.011 & 3.993 & 1.655 & 0.150 \\
\hline & & 74.996 & 3.522 & 1.656 & 0.150 \\
\hline & & 85.005 & 3.206 & 1.657 & 0.150 \\
\hline & & 94.985 & 2.990 & 1.654 & 0.150 \\
\hline \multirow[t]{6}{*}{1390} & 162.50 & 20.001 & 26.241 & 1.827 & 0.150 \\
\hline & & 25.002 & 17.576 & 1.827 & 0.150 \\
\hline & & 35.001 & 10.004 & 1.826 & 0.150 \\
\hline & & 54.999 & 5.302 & 1.826 & 0.150 \\
\hline & & 75.008 & 3.822 & 1.825 & 0.150 \\
\hline & & 95.030 & 2.174 & 1.823 & 0.150 \\
\hline \multirow[t]{6}{*}{1482} & 175.00 & 20.000 & 31.136 & 2.010 & 0.160 \\
\hline & & 25.003 & 20.703 & 2.010 & 0.160 \\
\hline & & 35.005 & 11.615 & 2.010 & 0.160 \\
\hline & & 54,996 & 5.948 & 2.009 & 0.160 \\
\hline & & 75.002 & 4.165 & 2.069 & 0.160 \\
\hline & & 95.012 & 3.385 & 2.0 .10 & 0.160 \\
\hline \multirow[t]{6}{*}{1574} & 187.50 & 20.000 & 36.737 & -2.201 & 0.160 \\
\hline & & 24.999 & 24.278 & 2.200 & 0.160 \\
\hline & & 34.997 & 13.431 & 2.200 & 0.160 \\
\hline & & $54.99 ?$ & 6.679 & 2.200 & 0.160 \\
\hline & & 75.002 & 4.549 & 2.200 & 0.160 \\
\hline & & 95.003 & $\mathbf{3 . 6 1 5}$ & 2.201 & 0.160 \\
\hline \multirow[t]{4}{*}{1664} & 200.00 & 20.001 & 42.916 & 2.398 & 0.160 \\
\hline & & 25.001 & 28.256 & 2.398 & 0.159 \\
\hline & & 34.997 & 15.448 & 2.398 & 0.160 \\
\hline & & 55.006 & 7.478 & 2.399 & 0.160 \\
\hline
\end{tabular}


Sample No. 2b (Xenon)(Continued)

\begin{tabular}{|c|c|c|c|c|c|}
\hline \multirow[t]{2}{*}{$\underset{(\circ \mathrm{T})}{\overrightarrow{\mathrm{T}}}$} & $\begin{array}{l}R_{A} \\
\text { (R) }\end{array}$ & $\begin{array}{l}\omega / 2 \pi \\
(\mathrm{Hz})\end{array}$ & $\begin{array}{c}R_{A} C_{A} \\
(\Omega-\mu F)\end{array}$ & $\begin{array}{l}i_{0} \\
\text { (A) }\end{array}$ & $\begin{array}{c}i \\
(12+5 \text { A })\end{array}$ \\
\hline & & 75.003 & 4.974 & 2.399 & $0 . \vdots 60$ \\
\hline & & 95.003 & 3.874 & 2.398 & 0.160 \\
\hline \multirow[t]{6}{*}{1754} & 212.50 & 20.000 & 49.865 & 2.602 & 0.170 \\
\hline & & 24.996 & 32.755 & 2.603 & $0 . \$ 70$ \\
\hline & & 34.999 & 17.714 & 2.602 & 0.170 \\
\hline & & 54.996 & 8.398 & D.603 & 0.170 \\
\hline & & 74.996 & 5.461 & 2.602 & 0.170 \\
\hline & & 94.994 & 4.169 & 2.601 & 0.170 \\
\hline \multirow[t]{6}{*}{1843} & 225.00 & 19.999 & 57.611 & 2.814 & 0.170 \\
\hline & & 25.000 & 37.701 & 2.814 & 0.170 \\
\hline & & 35.001 & 20.223 & 2.813 & 0.170 \\
\hline & & 55.006 & 9.405 & 2.814 & 0.170 \\
\hline & & 74.991 & 5.996 & 2.814 & 0.170 \\
\hline & & 95.012 & 4.507 & 2.814 & 0.170 \\
\hline \multirow[t]{6}{*}{1933} & 237.50 & 20.001 & 66.077 & 3.030 & 0.180 \\
\hline & & 25.000 & 43.078 & 3.029 & 0.180 \\
\hline & & 35.002 & 23.000 & 3.030 & 0.180 \\
\hline & & 55.006 & 10.524 & 3.030 & 0.180 \\
\hline & & 74.991 & 6.591 & 3.030 & 0.180 \\
\hline & & 94.994 & 4.864 & 3.031 & 0.180 \\
\hline \multirow[t]{6}{*}{2022} & 250.00 & 20.001 & 75.370 & 3.251 & 0.180 \\
\hline & & 25.000 & 49.095 & 3.252 & 0.180 \\
\hline & & 35.001 & 26.088 & $3.25 \mathrm{~s}$ & 0.180 \\
\hline & & 54.999 & 11.738 & 3.251 & 0.180 \\
\hline & & 75.002 & 7.243 & 3.252 & 0.180 \\
\hline & & 95.012 & 5.260 & 3.252 & 0.180 \\
\hline \multirow[t]{6}{*}{2111} & 262.50 & 20.003 & 85.465 & 3.477 & 0.190 \\
\hline & & 25.002 & 55.469 & 3.477 & 0.190 \\
\hline & & 35.004 & 29.363 & 3.478 & 0.190 \\
\hline & & 55.006 & 13.075 & 3.478 & 0.190 \\
\hline & & 74.996 & 7.951 & 3.478 & 0.190 \\
\hline & & 95.921 & 5.681 & 3.178 & 0.190 \\
\hline \multirow[t]{6}{*}{2199} & 275.00 & 20.000 & 96.289 & 3.707 & 0.190 \\
\hline & & 24.998 & 62.431 & 3.709 & 0.190 \\
\hline & & 35.004 & 32.896 & 3.708 & 0.190 \\
\hline & & 54.999 & 14.512 & 3.707 & 0.190 \\
\hline & & 74.996 & 8.712 & 3.708 & 0.190 \\
\hline & & 95.012 & 6.163 & 3.705 & 0.190 \\
\hline
\end{tabular}


Sampie No. 2b (Xenc.)(Continued)

\begin{tabular}{|c|c|c|c|c|c|}
\hline $\begin{array}{c}\bar{T} \\
\left({ }^{\circ} K\right)\end{array}$ & $\begin{array}{l}R_{A} \\
(\Omega)\end{array}$ & $\begin{array}{l}\omega / 2 \pi \\
(\mathrm{Hz})\end{array}$ & $\begin{array}{r}R_{A} C_{A} \\
(\Omega-\mu F)\end{array}$ & $\begin{array}{c}i_{9} \\
\text { (A) }\end{array}$ & $\stackrel{\text { i }}{(\operatorname{rms} A)}$ \\
\hline \multirow[t]{6}{*}{2287} & 287.50 & 20.001 & 107.750 & 3.940 & 0.200 \\
\hline & & 25,601 & 69.756 & 3.942 & 0.200 \\
\hline & & 34.998 & 36.653 & 3.942 & 0.200 \\
\hline & & 55.002 & 16.040 & 3.942 & 0.200 \\
\hline & & 75.002 & 9.519 & 3.942 & 0.200 \\
\hline & & 95.021 & 6.664 & 3.942 & 0.200 \\
\hline \multirow[t]{6}{*}{2375} & 300.00 & 20.001 & 119.870 & 4.177 & C.200 \\
\hline & & 24.999 & 77.424 & 4.176 & 0.200 \\
\hline & & 34.999 & 40.581 & 4.178 & 0.200 \\
\hline & & 55.002 & 17.631 & 4.179 & 0.200 \\
\hline & . & 75,002 & 10.356 & 4.178 & 0.200 \\
\hline & & 95.003 & 7.182 & 4.178 & 0.200 \\
\hline \multirow[t]{6}{*}{2462} & 312.50 & 20.000 & 132.370 & 4.417 & 0.210 \\
\hline & & 25.000 & 85.588 & 4.416 & 0.210 \\
\hline & & 35.002 & 44.713 & 4.418 & 0.210 \\
\hline & & 54.999 & 19.303 & 4.420 & 0.211 \\
\hline & & 75.002 & 11.250 & 4.419 & 0.210 \\
\hline & & 95.012 & 7.731 & 4.420 & 0.210 \\
\hline \multirow[t]{6}{*}{2550} & 325.00 & 20.000 & 145.500 & 4.660 & 0.220 \\
\hline & & 25.001 & 93.935 & 4.660 & 0.220 \\
\hline & & 35.001 & 49.017 & 4.662 & 0.220 \\
\hline & & 55.006 & 21.021 & 4.663 & 0.221 \\
\hline & & 74.991 & 12.171 & 4.661 & 0.220 \\
\hline & & 95.012 & 8.301 & 4.661 & 0.220 \\
\hline \multirow[t]{6}{*}{2638} & 337.50 & 20.000 & 158.650 & 4.904 & 0.240 \\
\hline & & 24.999 & 102.460 & 4.906 & 0.240 \\
\hline & & 35.002 & 53.318 & 4.957 & 0.240 \\
\hline & & 55.006 & 22.788 & 4.308 & 0.240 \\
\hline & & 75.008 & 13.115 & 4.909 & 0.240 \\
\hline & & 95.003 & 8.870 & 4.908 & 0.240 \\
\hline \multirow[t]{8}{*}{2654} & 340.00 & 20.001 & 161.190 & 4.951 & 0.260 \\
\hline & & 25.003 & 104.200 & 4.955 & 0.259 \\
\hline & & 35.002 & 54.257 & 4.957 & 0.260 \\
\hline & & 45.000 & 33.551 & 4.957 & 0.260 \\
\hline & & 54.999 & 23.137 & 4.959 & 0.260 \\
\hline & & 65.007 & 17.105 & 4.958 & 0.260 \\
\hline & & 74.996 & 13.304 & 4.958 & 0.260 \\
\hline & & 84.998 & 10.768 & 4.956 & 0.260 \\
\hline
\end{tabular}


Sample No. 2b (Xenon)(Continued)

\begin{tabular}{|c|c|c|c|c|c|}
\hline $\begin{array}{c}\overline{\mathrm{T}} \\
\left(\mathrm{\sigma}^{\mathrm{K}} \mathrm{K}\right)\end{array}$ & $\begin{array}{l}R_{A} \\
(\Omega)\end{array}$ & $\begin{array}{l}\omega / 2 \pi \\
(\mathrm{Hz})\end{array}$ & $\begin{array}{c}R_{A} C_{A} \\
(\Omega-\mu F)\end{array}$ & $\begin{array}{c}i_{0} \\
(A)\end{array}$ & $\begin{array}{c}\mathrm{i} \\
\text { (rms A) }\end{array}$ \\
\hline & & 95.012 & 6.879 & 4.953 & 0.259 \\
\hline \multirow[t]{6}{*}{2725} & 350.00 & 20.000 & 172.120 & 5.153 & 0.259 \\
\hline & & 25.000 & 111.120 & 5.154 & 0.260 \\
\hline & & 35.002 & 57.813 & 5.157 & 0.260 \\
\hline & & 55.006 & 24.539 & 5.157 & 0.260 \\
\hline & & 75.008 & 14.042 & 5.154 & 0.260 \\
\hline & & 95.003 & 9.454 & 5.152 & 0.260 \\
\hline \multirow[t]{6}{*}{2813} & 362.50 & 20.002 & $185.12 \mathrm{C}$ & 5.405 & 0.270 \\
\hline & & 25.002 & 119.620 & 5.409 & 0.270 \\
\hline & & 35.003 & 62.143 & 5.411 & 0.270 \\
\hline & & 55.009 & 26.296 & 5.412 & 0.270 \\
\hline & & 75.013 & 15.000 & 5.412 & 0.270 \\
\hline & & 95.030 & 10.045 & 5.409 & 0.270 \\
\hline \multirow[t]{6}{*}{2900} & 375.00 & 20.003 & 198.380 & 5.669 & 0.280 \\
\hline & & 25.003 & 128.040 & 5.671 & 0.280 \\
\hline & & 34.999 & 66.488 & 5.675 & 0.280 \\
\hline & & 55.006 & 28.058 & 5.675 & 0.280 \\
\hline & & 75.013 & 15.926 & 5.675 & 0.280 \\
\hline & & 95.003 & 10.624 & 5.671 & 0.380 \\
\hline \multirow[t]{6}{*}{2987} & 387.50 & 20.002 & 210.600 & 5.931 & 0.289 \\
\hline & & 25.002 & 136.140 & 5.935 & 0.290 \\
\hline & & 34.999 & 70.575 & 5.939 & 0.290 \\
\hline & & 55.002 & 29.702 & 5.940 & 0.290 \\
\hline & & 75.008 & 16.821 & 5.940 & 0.290 \\
\hline & & 95.021 & 11.160 & 5.933 & 0.290 \\
\hline \multirow[t]{9}{*}{3076} & $800: 00$ & 20.000 & 223.820 & 6.225 & 0.300 \\
\hline & & 25.003 & 144.220 & 6.229 & 0.300 \\
\hline & & 34.999 & 74.488 & 6.234 & 0.300 \\
\hline & & 44.998 & 45.792 & 6.235 & 0.300 \\
\hline & & 55.006 & 31.08B & 6.232 & 0.300 \\
\hline & & 65.003 & 22.704 & 6.232 & 0.300 \\
\hline & & 75.008 & 17.416 & 6.229 & 0.300 \\
\hline & & 84.991 & 13.920 & 6.224 & 0.300 \\
\hline & & 95,012 & 11.440 & 6.219 & 0.300 \\
\hline \multirow[t]{4}{*}{3146} & 820.00 & 19.999 & 234.340 & 6.472 & 0.320 \\
\hline & & 24.999 & 150.950 & 6.479 & 0.320 \\
\hline & & 34.999 & 77.892 & 6.484 & 0.320 \\
\hline & & 45.005 & 47.831 & 6.488 & 0.320 \\
\hline
\end{tabular}


Sample No. 2b (Xenon)(Conticued)

\begin{tabular}{|c|c|c|c|c|c|}
\hline $\begin{array}{c}\overline{\mathrm{T}} \\
\left({ }^{C} \mathrm{~K}\right)\end{array}$ & $\begin{array}{l}R_{A} \\
(\Omega)\end{array}$ & $\begin{array}{l}\omega / 2 \pi \\
(\mathrm{Hz})\end{array}$ & $\begin{array}{c}R_{A} C_{A} \\
(\Omega-\mu F)\end{array}$ & $\begin{array}{l}\mathrm{i}_{0} \\
\text { (A) }\end{array}$ & $\begin{array}{c}\mathrm{i} \\
(\mathrm{rms} A)\end{array}$ \\
\hline & & 55.006 & 33.472 & 6.483 & 0.320 \\
\hline & & 65.003 & 23.682 & 6.483 & 0.320 \\
\hline & & 75.002 & 18.147 & 6.479 & 0.326 \\
\hline & & 84.983 & 14.481 & 6.475 & 0.326 \\
\hline & & 95.021 & 11.865 & 6.463 & 0.320 \\
\hline
\end{tabular}

Sample No. $3\left(\mathrm{Ar}+\mathrm{I}_{2}\right)$

\begin{tabular}{|c|c|c|c|c|c|}
\hline \multirow[t]{9}{*}{1117} & 125.00 & 95.003 & 3.135 & 1.822 & 0.200 \\
\hline & & 84.983 & 3.410 & $\therefore .821$ & 0.200 \\
\hline & & 75.002 & 3.785 & 1.922 & 0.200 \\
\hline & & 64.998 & 4.348 & 1.823 & 0.200 \\
\hline & & 54.999 & 5.248 & 1.824 & 0.200 \\
\hline & & 45.000 & 6.773 & 1.823 & 0.200 \\
\hline & & 35.001 & 9.785 & 1.823 & 0.200 \\
\hline & & 25.000 & 1?.1.5 & 1.822 & 0.199 \\
\hline & & 19.999 & $25.5 \pm 5$ & 1.823 & 0.200 \\
\hline \multirow[t]{9}{*}{14.90} & 175.00 & 94.985 & 3.917 & 2.430 & 0.200 \\
\hline & & 85.012 & 4.372 & 2.430 & 0.200 \\
\hline & & $75.00 \bar{z}$ & 8.037 & 2.430 & 0.200 \\
\hline & & 65.003 & 6.034 & 2.430 & 0.200 \\
\hline & & 55.006 & 7.574 & 2.431 & 0.200 \\
\hline & & 44.994 & 10.322 & 2.433 & $t .200$ \\
\hline & & 35.003 & 15.677 & 2.433 & 0.200 \\
\hline & & 25.000 & 28.749 & 2.433 & 0.200 \\
\hline & & 20.000 & 43.449 & 2.433 & 0.200 \\
\hline \multirow[t]{9}{*}{1854} & 225.00 & 94.994 & 5.130 & 3.195 & 0.200 \\
\hline & & 85.005 & 5.911 & 3.195 & 0.200 \\
\hline & & 74.991 & 7.027 & 3.196 & 0.200 \\
\hline & & $\$ 4.998$ & 8.667 & 3.196 & $0.20^{\circ}$ \\
\hline & & 54.990 & 11.327 & 3.195 & 0.200 \\
\hline & & 44.996 & 15.903 & 3.196 & 0.200 \\
\hline & & 35.003 & 24.971 & 3.196 & 0.200 \\
\hline & & 24.999 & 46.841 & 3.197 & 0.200 \\
\hline & & 20.000 & 71.996 & 3.197 & 0.200 \\
\hline
\end{tabular}


Sample No. $4\left(\mathrm{Ar}+\mathrm{I}_{2}\right)$

\begin{tabular}{|c|c|c|c|c|c|}
\hline $\begin{array}{c}\bar{T} \\
\left({ }^{\circ} \mathrm{K}\right)\end{array}$ & $\begin{array}{l}\mathrm{R}_{A} \\
(\Omega)\end{array}$ & $\begin{array}{l}\omega / 2 \pi \\
(\mathrm{Hz})\end{array}$ & $\begin{array}{c}{ }_{A} C_{A} \\
(\Omega-\mu F)\end{array}$ & $\begin{array}{r}\mathfrak{i}_{0} \\
\text { (A) }\end{array}$ & $\begin{array}{c}\mathrm{i} \\
(\mathrm{rms} \mathrm{A})\end{array}$ \\
\hline \multirow[t]{9}{*}{953} & 100.00 & Eû.002 & 19.908 & 1.576 & 0.099 \\
\hline & & 25.001 & 13.518 & 1.575 & 0.100 \\
\hline & & 35.003 & 7.948 & 1.576 & 0.100 \\
\hline & & 45.005 & 5.658 & 1.576 & 0.100 \\
\hline & & 55.006 & 4.485 & 1.575 & 0.100 \\
\hline & & 65.011 & 3.813 & 1.575 & 0.100 \\
\hline & & 75.008 & 3.394 & 1.575 & 0.100 \\
\hline & & 84.998 & 3.105 & 1.575 & 0.100 \\
\hline & & 95.021 & 2.892 & 1.571 & 0.100 \\
\hline \multirow[t]{9}{*}{953} & 100.00 & 20,028 & 19.408 & 1.552 & 0.301 \\
\hline & & 25,002 & 13.228 & 1.552 & 0.300 \\
\hline & & 34.994 & 7.808 & 1.552 & 0.300 \\
\hline & & 45.000 & 5.588 & 1.552 & 0.300 \\
\hline & & 55.002 & 4.438 & 1.552 & 0.300 \\
\hline & & 64.998 & 3.783 & 1.551 & 0.300 \\
\hline & & 75.002 & 3.368 & 1.551 & 0.300 \\
\hline & & 84.991 & 3.098 & 1.552 & 0.300 \\
\hline & & 95.030 & 2.897 & 1.552 & 0.300 \\
\hline \multirow[t]{9}{*}{3200} & 800.00 & 20.003 & 239.180 & 6.652 & 0.501 \\
\hline & & 25.002 & 153.610 & 6.660 & 0.500 \\
\hline & & 35.005 & 79.316 & 6.666 & 0.500 \\
\hline & & 45.000 & 48.724 & 6.668 & 0.500 \\
\hline & & 54.999 & 33.112 & 6.671 & 0.500 \\
\hline & & 65.011 & 24.168 & 6.673 & 0.500 \\
\hline & & 75.698 & 18.552 & 6.674 & 0.500 \\
\hline & & 85.020 & 14.820 & 6.676 & 0.500 \\
\hline & & 95.057 & 12.168 & 6.677 & 0.500 \\
\hline \multirow[t]{9}{*}{3202} & 800.00 & 19.999 & 239.130 & 6.665 & 0.250 \\
\hline & & 24.998 & 154.170 & 6.672 & 0.250 \\
\hline & & 35.002 & 79.568 & 6.676 & 0.250 \\
\hline & & 45.002 & 48.864 & 5.680 & 0.250 \\
\hline & & 54,996 & 33.182 & 6.681 & 0.250 \\
\hline & & 64.998 & 24.236 & 6.684 & 0.250 \\
\hline & & 75.002 & 18.600 & 5.685 & 0.250 \\
\hline & & 85.012 & 14.848 & 6.685 & 0.250 \\
\hline & & 95.102 & 12.204 & 6.685 & 0.250 \\
\hline \multirow[t]{2}{*}{3346} & 840.00 & 19.999 & 249.040 & 7.148 & 0.251 \\
\hline & & 24.999 & 160.450 & 7.157 & 0.250 \\
\hline
\end{tabular}


Sample No. $4\left(A_{I}+I_{2}\right)$ (Continued)

\begin{tabular}{|c|c|c|c|c|c|}
\hline$\underset{T}{T}$ & $\begin{array}{l}\mathrm{R}_{\mathrm{A}} \\
(\Omega)\end{array}$ & $\begin{array}{l}\omega / 2 g \\
(G z)\end{array}$ & $\underset{\left(\Omega-\mu F^{2}\right)}{R_{A} C_{A}}$ & $\begin{array}{c}\mathbf{i}_{\mathbf{0}} \\
\text { (A) }\end{array}$ & $\stackrel{i}{\text { (rms A) }}$ \\
\hline & & 34.993 & 82.849 & 7.167 & 0.250 \\
\hline & & 54.399 & 34.490 & 7.173 & 0.250 \\
\hline & & $7 千 .996$ & 19.270 & 7.176 & 0.250 \\
\hline & & 94.954 & 12.604 & 7.177 & 0.250 \\
\hline \multirow[t]{6}{*}{3383} & 850.00 & 19.999 & 250.180 & 7.278 & 0.250 \\
\hline & & 25.063 & 161.190 & 7.287 & 0.251 \\
\hline & & 34.996 & 83.173 & 7.294 & 0.250 \\
\hline & & $54 \_996$ & 34.638 & 7.302 & 0.250 \\
\hline & & 74.996 & 19.363 & 7.305 & 0.250 \\
\hline & & 95.021 & 12.648 & 7.304 & 0.250 \\
\hline \multirow[t]{6}{*}{3418} & 860.00 & 20.001 & 250.410 & 7.405 & 0.250 \\
\hline & & 24.998 & 161.470 & 7.417 & 0.250 \\
\hline & & 34.997 & 83.325 & 7.428 & 0.250 \\
\hline & & 54.999 & 34.675 & 7.4 .34 & 0.250 \\
\hline & & 74.991 & 19.367 & 7.435 & 0.250 \\
\hline & & 95.003 & 12.659 & 7.435 & 0.250 \\
\hline
\end{tabular}




\section{References}

1. I. E. Camphell and E. M. Sherwood, High-Temperature Materials and Technology (John Wiley and Sons, N. Y. 1969), p. 910.

2. V. A. Kirillin, A. E. Sheindlin, V. Ya Chekhovskoy, and V. A. Petrov, "Enthalpy and Heat Capacity of Molybdenum at Extremely High Temferatures," in Proc. Founth Symposium on Thermophysical Properties, J. R. Moszynski, Ed. (ASME, N. Y., 1958), p. 54.

3. V. A. Kirillin, A. E. Sheir iin, and V. Ya Chekhovskoy, "Enthalpy and Heat Capacity of Some Solid Materials at Extremely High Temperatures," in High Temperature Technology (Butterworths, London, 1964), p. 471.

4. A. G. Worthing, PhrB. Rev. 12, 199 (1918).

5. T. E. Pochapsky, Rev. Sci. Instr. 25, 238 (1954).

6. T. G. Kol'ie, Rev, Sci. Instr. 38, 1452 (1967).

7. B. Kurrelmeyer, W. H. Mais, and E. Green, Rev. Sci. Ingtr. 14, 349 (1943).

8. R. Parker, Trans, TMS-AIME 233,1545 (1965).

9. R. E. Tayior and R. A. Finch, J. Less-Common Metals 6, 288 (1964).

10. O. M. Corbino, Phys. Zeits. 11, 413 (1910).

11. O. M. Corbino, Phys. Zeite 13, 375 (1912).

12. K. K. Smith and P. W, Bigler, Phyg, Rev. 19, 268 (1922).

13. L. I, Bockstahler, Phys, Rev. 25, 677 (1925).

14. C. Zwikker, Z. Phygik 52, 168 (1928).

15. C. Herring and M. H. Nichols, Rev. Mod. Phys, 21, 185 (1949).

16. D. B. Langmuir and L. Malter, Phys, Rev. 55, 1138 (1939).

17. G. C. Lowerthal, Aust. J. Phys. 16, 47 (1962).

18. Ya. A. Kraftmacher, J. Appl. Mech. Tech. Phys. 5 , 176 (1962).

19. Ya. A. Kraftmacher and P. G. Strelkov, Sov. Phys. -Solid State 4, 1662 (1962).

20. Ya. A. Krafmacher, Sov. Phys. -Solid State 6,396 (1964).

21. Ya. A. Kraftmacher, Sov. Phys, -Solid State 5,696 (1963).

22. O. M. Kanel and Ya. A. Kraftmacher, Sov. Phys. -Solid Stare 8,232 (1966).

23. Ya. A. Kraftmacher and E. B. Lanina, Sov. Fhys, -Solid St ate 7, 92 (1965).

24. L. R. Holland, J. Appl. Phys. 34, 2350 (1963).

25. I. R. Holland and R. C. Smith, J.Appl. Phyg. 37, 4529 (1966).

26. R. C. Smith and L. R. Holland, J. Appl. Phyg. 37, $485 e$ (1966).

27. L. P. Filippou and R. P. Yurchak, Teplofizika Vysokikh Temperatur 3, 901 (1965).

28. P. Sullivan and G. Seidel, Ann. Acad. Sci. Fenn. 210, 58 (1966).

29. P. Sullivan and G. Seidel, Fhys. Lett. 25A, 229 (1967).

30. P. Eandier, D. E. Mepother, and M. Rayl, Phyl. Rev, Lett 19, 356 (1967).

31. T. E. Pochapsky, Acta. Met. 1, 747 (1953).

32. C. R. Brooks and R. E. Bingham, J. Phys. Chem. Solids 29, 1553 (1968). 
33. C. R. Brooks, W. E. Norem, D. E. Hendrix, J. W. Wright, and . .

W. G. Northcutt, J. Phys. Chem. Solids 29, 565 (1968).

34. Ya. A. Kraftmacher and P. G. Strelkov, Sov. Phys. -Solid State 8,460 (1966).

35. V. A. Kirillin, A. E. Sheindlin, V. Ya. Chekhovskoi, and 1. A. Zhukova, T.V.T. 3 , 395 (1965).

36. L. G. Carpenter and C. J. Stenari, Fil. Mag. 27, 551 (1939).

37. I. G. Carpenter, T. F. Harle, and C. J. Steward, Nature 141, 1015 (1938).

38. Ya. A. Kraftmacher, Zh. Prikl, Mekh. Tekh. Fiz. 2, 158 (1963).

39. D. Wallace, Phys. Rev. 120,84 (1960).

40. Ya. A. Kraftmacher and P. G. Strelhov, Sov. Phys. -Solid State B, 83B (1966).

41. L. G. Carpenter, J. Chem. Phys. 21, 2244 (1953).

42. J. R. Terrall, Lawrence Radiation Laboratory, Livermore, Rept. UCRL50250 (1967).

43. B. Hague, Alternating Current Bridga Methods (Sir Isaac Pitman and Sons Ltd., London, 5tt Ed. 1923), p. 525.

44. S. Dushman, Vacuum Technique (John Wiley and Sons, N. Y., 1949), p. 679.

45. E. G. Zubler and F. M. Mosby, ㅍ. Eng LIV 734 (1959).

46. R. J. Thorn and G, H. Winslow, "Radiation of Thermal Energy from Real Bodies," in Temperature, Its Measurement and Control in Science and Industrys Vol III-1, F. G. Brickwedde, Ed. (Reinhold Pub. Co., N.Y., 1962), p. 439.

47. Temperature, Its Measurement and Control in Science and Industry, Vol, 1 (Reinhold Pub. Co., N. Y., 1858), p. 1318.

48. I. Langmuir, Phys. Rev. 7, 306 (1916).

49. R. E. von Holdt, Lawrence Radiation Laboratory, Livermore, C. I. C. Rep. R3-001 (1969).

50. B. S. Bokshtein et al., Sor. Phys, - Solid State 11, 194 (1969).

51. B. S. Bokshtein et al., Sov. Phys.-Dokl, 13, 123: (1969).

52. R. C. Smith, J. Appl. Phys. 37,4860 (1966).

53. H. U. Astrom, Arkiv For Fysik 14,263 (1958).

54. C. R. Brooks, I. Phys. Chem. Solids 29, 1377 (1968).

55. A. I. Kaznoff, "Thermal Properties of Indium," Ph. D. thesis, University of California, Berkeley, Cal., 1961.

56. A. H. Wilson, The Theory of Metals (Cambridge University Press, Cambridge, 1954), p. 144.

57. J. M. Ziman, Principles of the Theory of Solids (Cambriuge University Press, Cambridge, 1964), p. 44.

58. F. Sahnke, F. Ende, and F. Losch, Tables of Higher Functions, F. Losch, Rev. (McGraw-Hill, N. Y., 1960), p. 293.

59. J. M. Keller and D. C. Wallase, Phys, Rev. 126, 1275 (1962).

60. A. J. Foreman, Proc. Phys. Soc. (London) 79, 1124 (1962).

61. P. Loyd, Aust. J. Phys. 17, 269 (1964). 
62. D. C. Wallace, Phys. Lett. 26A, 256 (1968).

63. K. N. Pathak and Y. P. Varshni, Phys. Lett. 28A, 539 (1969).

64. A. G. Damask and G. J. Dienes, Point Defects in Metals (Gordon and Breach, N. Y., 1963), P. 6.

65. G. Borelius, Arkiv. Fysik 15, 65 (1958).

56. G. Borelius, "The Changes in Energy Content, Volume, and Resistivity with Temperature in Simple Solids and Liquids," in Solid State Physics, Vol. 15, F. Seitz and D. Turnbull, Ede. (Academic Press, N. Y., 1963), p. 1.

67. F. B. Hildebrand, Introduction to Numerical Analysis (McGraw-Hill, N.Y., 1956), p. 264 .

68. K. A. Gschneidner, Jr., "Physical Properies of Metallic and Semimetallic Elements," in Solid State Phygics, Vol. 16, F. Seitz and D. Turnbull, Eds. (Academic Press, N. Y., 1964), p. 2 ?5.

59. R. O. Simmons and R. W. Balluffi, Phys. Rev, 117, 52 (1960).

70. R. O. Simmona and R. W. Ballưfi, Playg, Rev. 129, 1533 (1963).

71. R. Feder and $A$. S. Nowici, Phus, Rev. 109, 1959 (1958).

72. S. Nenno and J. W. Kauffman, Phil. Mag. \& 1382 (1959).

73. G. Blanchi, et al., C.,R._Acad. Sc.,Paris 263, 1404 (1966).

74. P. Jongeburger, Phys, Rey, 106, 66 (1957).

75. L. Dobrzyngkt, I, Phys, Chem. Solida s0, 2395 (1969).

76. J. Holder and A. V. Granato, Phys, Reg. 182, 729 (1969).

77. H. Schultz, "Quenching of Vacancies in Tungsten," in Lattice Defects in Quenched Metals, R. M. J. Colterill, et al., Sds, (Academic Press, N. Y.= 1965) p. 761.

78. R. J. Gripshover, M. Khoshnevisan, and J. S. Zelts, Bulletin Am. Phys, Soc. 15, 357 (1970).

79. L. Leibowitz, M. G. Chasanov, and L. W. Mishler, Trans. Met. Soc, AIME 245 , 981 (1969).

80. R. Aultgren, R. L. Orr, P. D. Anderson, K. K. Kelley, Selected Valves of Thermodynamic Properties of Metals and Allozg (John Wiley and Sons, N. Y. . 1963), p. 309.

81. R. L. Andelin, J. D. Knight, and M. Kahn, Trans ATME 233, 19 (1965).

82. W. Danneberg, Metal 15, 97 ? (1961).

83. R. A. Johnson, "Diffusion in Body-Centered Cubic Metals," in American Society for Metals (Metals Park, Ohio, 1565), p. 357. 